NUREG/CR-3288

SAND83- 1064

R7

Printed September 1983

\title{
Intermediate-Scale Tests of Sodium Interactions With Calcite and Dolomite Aggregate Concretes
}

Erik Randich, Russell U. Acton

\section{DO NOT MICROFILM
THIS PAGE}

Prepared by

Sandia National Laboratories

Albuquerque, New Mexico 87185 and Livermore, California 94550

for the United States Department of Energy

under Contract DE-AC04-76DP00789

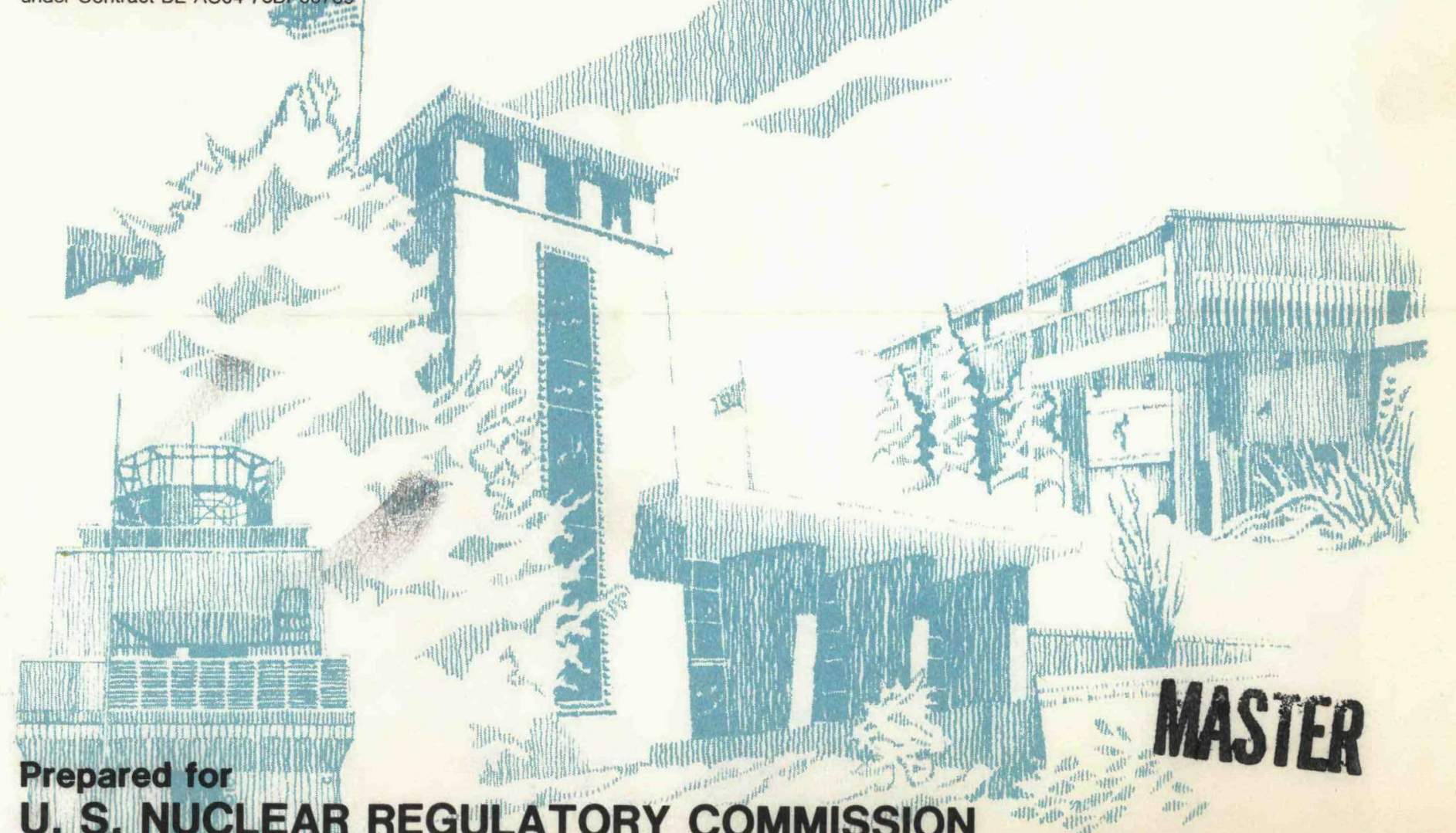

U. S. NUCLEAR REGULATORY COMMISSION 


\section{DISCLAIMER}

This report was prepared as an account of work sponsored by an agency of the United States Government. Neither the United States Government nor any agency Thereof, nor any of their employees, makes any warranty, express or implied, or assumes any legal liability or responsibility for the accuracy, completeness, or usefulness of any information, apparatus, product, or process disclosed, or represents that its use would not infringe privately owned rights. Reference herein to any specific commercial product, process, or service by trade name, trademark, manufacturer, or otherwise does not necessarily constitute or imply its endorsement, recommendation, or favoring by the United States Government or any agency thereof. The views and opinions of authors expressed herein do not necessarily state or reflect those of the United States Government or any agency thereof. 


\section{DISCLAIMER}

Portions of this document may be illegible in electronic image products. Images are produced from the best available original document. 


\section{DO NOT MICROFILM THIS PAGE}

\section{NOTICE}

This report was prepared as an account of work sponsored by an agency of the United States Government. Neither the United States Government nor any agency thereof, or any of their employees, makes any warranty, expressed or implied, or assumes any legal liability or responsibility for any third party's use, or the results of such use, of any information, apparatus product or process disclosed in this report, or represents that its use by such third party would not infringe privately owned rights.

Available from

GPO Sales Program

Division of Technical Information and Document Control

U.S. Nuclear Regulatory Commission

Washington, D.C. 20555

and

National Technical Information Service

Springfield, Virginia 22161 
NUREG/CR-3288

SAND 83-1064

R7

Intermediate-Scale Tests of Sodium Interactions

With Calcite and Dolomite Aggregate Concretes

E. Randich

R. U. Acton

September 1983

Sandia National Laboratories

Albuquerque, New Mexico 87185

operated by

Sandia Corporation

for the

U. S. Department of Energy

\title{
NOTIEE
}

PORTIONS OF THIS REPQTT APE ILIEADAE.

It has been reproduced fren the best

available copy to permit the broadest. possible availability.

\author{
Prepared for \\ Division of Reactor Safety Research \\ office of Nuclear Regulatory Research \\ U. S. Nuclear Regulatory Commission \\ Washington, DC 20555 \\ Under Memorandum of Understanding DOE 40-550-75 \\ NRC FIN No. A-1054
}

\section{DISCLAIMER}

This report was prepared as an account of work sponsored by an agency of the United States Government. Neither the United States Government nor any agency thereof, nor any of their employees, makes any warranty, express or implied, or assumes any legal liability or responsibility for the accuracy, completeness, or usefulness of any information, apparatus, product, or process disclosed, or represents that its use would not infringe privately owned rights. Reference herein to any specific commercial product, process, or service by trade name, trademark, manufacturer, or otherwise does not necessarily constitute or imply its endorsement, recommendation, or favoring by the United States Government or any agency thereof. The views and opinions of authors expressed herein do not necessarily state or reflect those of the United States Government or any agency thereof. 


\section{ABSTRACT}

Two intermediate-scale tests were performed to compare the behavior of calcite and dolomite aggregate concretes when attacked by molten sodium. The tests were performed as part of an interlaboratory comparison between Sandia National Laboratories and Hanford Engineering Development Laboratories. Results of the tests at Sandia National Laboratories are reported here. The results show that both concretes exhibit similar exothermic reactions with molten sodium. The large difference in reaction vigor suggested by thermodynamic considerations of $\mathrm{CO}_{2}$ release from calcite and dolomite was not realized. Penetration rates of $1.4-1.7 \mathrm{~mm} / \mathrm{min}$ were observed for short periods of time with reaction zone temperatures in excess of $800^{\circ} \mathrm{C}$ during the energetic attack. The penetration was not uniform over the entire sodium-concrete contact area. Rapid attack may be localized due to inhomogeneities in the concrete. The chemical reaction zone is less than one $\mathrm{cm}$ thick for the calcite concrete but is about seven $\mathrm{cm}$ thick for the dolomite concrete. This difference is apparently caused by the lower thermal decomposition temperature of dolomite. The major chemical reactions of importance are $\mathrm{Na}+\mathrm{H}_{2} \mathrm{O}+1$ imestone $\longrightarrow \mathrm{Na}_{2} \mathrm{CO}_{3}+\mathrm{CaO}+\mathrm{MgO}+\mathrm{H}_{2}$ and $\mathrm{Na}+\mathrm{H}_{2} \mathrm{O} \longrightarrow \mathrm{NaOH}+1 / 2 \mathrm{H}_{2} \cdot$ 


\section{TABLE OF CONTENTS}

$\underline{\text { Page }}$

Introduction

1

Thermodynamic Considerations 4

Calcite 6

Dolomite $\quad 8$

Experimental Procedures 13

Test Articles 13

$\begin{array}{ll}\text { Test Method } & 19\end{array}$

Chemical Analysis of Reaction Debris 27

$\begin{array}{ll}\text { Results } & 28\end{array}$

$\begin{array}{ll}\text { Calcite Test } & 28\end{array}$

$\begin{array}{ll}\text { Dolomite Test } & 47\end{array}$

Discussion $\quad 73$

$\begin{array}{ll}\text { Conclusions } & 83\end{array}$

$\begin{array}{ll}\text { Acknowledgements } & 85\end{array}$

$\begin{array}{lr}\text { Appendix } & 89\end{array}$ 


\section{TABLES}

1 Equilibrium Partial Pressures of $\mathrm{CO}_{2}$ over Calcite

2 Equilibrium Partial Pressures of $\mathrm{CO}_{2}$ Over Dolomite

3 Calcite Concrete Mix Specifications 14

4 Dolomite Concrete Mix Specifications 15

5 Concrete Materials Data 16

6 Concrete Strength Data 17

7 Chemical Analyses of Calcite and Dolomite Test Debris

8 X-ray Diffraction Pattern of Calcite Test Debris

9 X-Ray Diffraction Pattern of Dolomite Test Debris

10 Summary of Calcite and Dolomite Test Results

A-1 Calibrated Multiplying Factor for the Brookfield LV-3 spindle

A-2 Calcite Test Reaction Debris Viscosity 


\section{ILLUSTRATIONS}

Figure

Page

1 Schematic of Test Article Showing Thermocouple and Heater Placement.

2 Photograph of Test Article Showing a) Heater Placement and Welded Steel Top Flange and b) Article with Insulation in Place.

3 Test Article Placement in Test Enclosure.

4 Aerosol Sampler Used in Dolomite Test.

5 Pool Temperatuares During Heatup Portion of the Tests and the Target TMBDB Heatup Curve.

6 Calcite Test, Pool and Vapor Space Thermocouple Data for Test Time.

7 Calcite Test, Concrete Thermocouple Data for Test Time.

8 Calcite Test, Pool and Vapor space Thermocouple Data for Test Time and 8 Hours of Cooldown Period

9 Calcite Test, Concrete Thermocouple Data for Test Time and 8 Hours of Cooldown Period.

10 Calcite Test, Concrete Thermocouple Data for Centerline and Mid-radius Thermocouples Located at 1.3 and $2.5 \mathrm{~cm}$ Beneath Original Interface.

11 Calcite Test, Hydrogen Gas Generation.

12 Schematic Cross Section of Calcite Test Article.

13 Cross-Sectioned Calcite Test Article (First Half) with Unreacted Sodium and Lower Portion of Concrete Removed. 


\section{ILLUSTRATIONS Continued}

Figure

Page

14 Sodium/Concrete Reaction Zone in Calcite Test (Second Half). (Note Unevenness of Interface Between the Reaction Debris and Unreacted Concrete.)

15 Closeup Photograph of Debris/Concrete Interface. (Note clear Demarcation Between Completely Reacted Debris and Unreacted Calcite Concrete.)

16 Aerosol Plug in Vent Line of Calcite in Test Article.

17 Scanning Electron Micrographs of Aerosol from Calcite Test, a) $35 \mathrm{X}$, b) $4000 \mathrm{x}$.

18 Dolomite Test, Pool and Vapor space Thermocouple Data.

19 Dolomite Test, Concrete Thermocouple Data.

20 Dolomite Test, Thermocouple Data for

Centerline and Mid-radius Thermocouples Located at 1.3 and $2.5 \mathrm{~cm}$ Beneath Original Interface.

21 Dolomite Test, Internal Pressure.

22 Schematic Cross section of Dolomite Test Article.

23 Cross-Sectioned Dolomite Test Article, Excess Unreacted Sodium, and Bottom Portion of Concrete Test Article Have Been Removed.

24 Higher Magnification View of Reaction Zone in Dolomite Test, a)-c) Sequential Photographs Taken Left to Right on Figure 23.

25 Closeup Photograph of Black Debris Layer in Dolomite Test. 


\section{ILLUSTRATIONS Continued}

\section{Figure}

$\underline{\text { Page }}$

26 Modified Vent system for Dolomite Test. Lettered Sections Correspond to Photographs in Figure 27.

27 Aerosol Deposited in Main Vent Line (a-d) and Secondary Vent Line (e)
a) Section $A A$, b) Section BB,
c) Section $C C$, d) Section $D D$,
e) Section EE, as noted in Figure 26.

28 Scanning Electron Micrographs of Aerosol Sample Taken from Sampler 2 (see Figure 4) in Dolomite Test, a) $35 x$, b) $4000 x$.

A-1 Schematic Diagram of High Temperature Viscosity Apparatus.

A-2 Viscosity of Calcite Test Debris. 


\section{INTRODUCTION}

A major safety concern for liquid metal fast breeder reactors is an accident wherein molten sodium contacts structural materials in the reactor building. One of the more important considerations in such an event is the contact between molten sodium and the concretes used in the construction of the reactor cavity. The chemical reactions which occur when molten sodium attacks concrete can generate heat, hydrogen, and cause erosion of the concrete. The heat and hydrogen produced can cause elevated temperatures and pressures and a deflagration hazard in the containment structure. The erosion of concrete caused by chemical reactions presents the possibility that material from the reactor cavity such as sodium or core debris may escape containment. Because of such possibilities, a considerable amount of effort has been expended in studying and modeling sodium-concrete interactions.1-10 These studies have included both experimental and theoretical considerations of the interactions which occur between sodium and a variety of concretes. The concretes studied generally differed only in the type of aggregate used. The major types of aggregates used have been: basalt (a complex silicate rock), calcite $\left(\mathrm{CaCO}_{3}\right)$, and magnetite $\left(\mathrm{Fe}_{3} \mathrm{O}_{4}\right)$. A fourth type of concrete (known as limestone-common sand concrete) which uses a calcite coarse aggregate and a riverbed sand (silica) fine aggregate has also received some attention. 9 The results have demonstrated that there are major differences among the chemical interaction mechanisms and response of the different types of concrete to attack by molten sodium. The chemical reactions which occur between the various types of concrete and sodium depend upon the reacting species. The reaction 
between sodium and a basalt (silicate aggregate) concrete is of a different chemical nature than that which occurs with a limestone (mineral carbonate aggregate) concrete. For example, the major products of the reaction between sodium and basalt concrete are sodium silicates. These reactions are relatively well understood and characterized.10,11 of more recent interest, however, has been the reaction between sodium and limestone concretes which use either a calcite $\left(\mathrm{CaCO}_{3}\right)$ or dolomite $\left(\mathrm{CaMg}\left(\mathrm{CO}_{3}\right)_{2}\right)$ aggregate. The possible chemical reactions in this case are more numerous and quite different from those which occur for the reaction with basalt concrete. The chemical mechanism of attack of the limestone concrete is not yet fully understood.

In addition to the differences in the chemical reactions, there have been variations noted in experimental results for the same or similar types of concrete reacting with sodium under fairly similar test conditions. Significant variations have been noted in the amount and rate of erosion, the vigor of the interaction, and the nature of the debris layer (which may play a role in inhibiting the interaction) $3,5,8$

The differences in interpretation of the experimental results from the various laboratories have caused some confusion in the scientific community. In such a circumstance, it is generally desirable to run an interlaboratory comparison in which different laboratories run identical tests. The results of the tests can then be compared directly and without confusion to clearly define the response of certain types of concrete to attack by molten sodium under identical conditions. In the United States, the two major laboratories involved in studying sodium-concrete interactions are Hanford 
Engineering Development Laboratories (HEDL) in Hanford, Washington, and Sandia National Laboratories (SNLA) in Albuquerque, New Mexico. These laboratories saw the need for, and agreed to participate in, a set of interlaboratory comparison tests. The concretes chosen for the test used Portland Type II cement and limestone aggregate. The Clinch River Breeder Reactor project (CRBRP) in Oak Ridge, Tennessee, is planning to use a limestone aggregate in the concrete for the reactor cavity floor. The limestone will either be calcite or dolomite. For this reason, two prototypic CRBRP concretes using calcite and dolomite aggregate were chosen for the tests. The test configuration and experimental procedures were prepared jointly by the laboratories prior to the tests. Each laboratory performed a test with calcite concrete and a test with dolomite concrete under as nearly identical conditions as possible. This design allowed a comparison of results for identical tests done at different laboratories as well as a comparison of different tests done at the same laboratory. This test design would, hopefully, resolve some of the confusion in interpretation of the results obtained at different laboratories and also would be a direct (although limited) comparison of the two types of concretes under consideration for use in CRBR.

It is the purpose of this report to present the results of the two tests which used molten sodium in contact with calcite concrete and dolomite concrete that were performed at SNLA. For a comparison of these test results with the sister tests run at HEDL, the reader is referred to the companion report prepared at HEDL summarizing the results of their tests. 12 


\section{THERMODYNAMIC CONSIDERATIONS}

Limestones are popular aggregates for structural concretes. Calcite $\left(\mathrm{CaCO}_{3}\right)$ and dolomite $\left(\mathrm{Camg}\left(\mathrm{CO}_{3}\right)_{2}\right)$ are the most important members of this mineral family. Molten sodium reactions with concrete made using calcite aggregate have been investigated extensively $3,5,7,9,10$ but similar studies of the reaction between molten sodium and concretes using a dolomite aggregate have not been done. The logical first step in evaluating the potential differences between the sodium reaction with either type of limestone concrete is a thermodynamic, or equilibrium, analysis of the important chemical reactions involved. Although the real sodiumconcrete system may not be at equilibrium, such an analysis is useful in determining whether there are potential areas of concern with regard to energy or heat release.

The possible chemical reactions between sodium and limestone concrete are numerous and the relative importance of the many reactions is not known. For simplicity, the following discussion concentrates on the reaction of sodium with the aggregate material and neglects sodium reactions with the water and cement phases of the concrete. We consider this a reasonable approach since the concretes involved contain greater than $75 \%$ aggregate and both have the same cement phases and similar water contents. Even though the presence of water may change the reactions involved because of the formation of $\mathrm{NaOH}$, it would affect both concretes in a similar fashion. The relative release of $\mathrm{CO}_{2}$ from the respective carbonate aggregates is a more important consideration in evaluating potential differences between the concretes. Therefore, several simplifying assumptions are made to limit the following discussion to the effects of $\mathrm{CO}_{2}$ 
release. These assumptions do not decrease the usefulness of such an approach in comparing calcite and dolomite for other generic sets of reactions where water is involved, as would actually be the case for concretes which use these materials as aggregates.

A consideration of the possible reactions between molten sodium and limestone indicate that a major reaction of concern from a heat generation standpoint is the sodium reduction of $\mathrm{CO}_{2}$ from the carbonates in the limestone to form carbon. 8 The precise reaction mechanism is not yet firmly established. However, thermochemical analyses suggest that the following reactions are thermodynamically allowed

$$
\begin{aligned}
\mathrm{CO}_{2}+4 \mathrm{Na} & \longrightarrow 2 \mathrm{Na}_{2} \mathrm{O}+\mathrm{C} \\
\mathrm{CO}_{2}+4 / 3 \mathrm{Na} & \longrightarrow 2 / 3 \mathrm{Na}_{2} \mathrm{CO}_{3}+1 / 3 \mathrm{C}
\end{aligned}
$$

Both of the above reactions are quite exothermic. The enthalpies of reaction in the 700 to $1100 \mathrm{~K}$ range are respectively about 105 and $83 \mathrm{kcal} / \mathrm{mole}$ of $\mathrm{CO}_{2}$ consumed. This represents a significant heat source in a reactor accident. The result of such heat production would cause further dehydration of the concrete as well as heating and possibly boiling of the sodium pool. Therefore, any difference in the facility of the different aggregates to produce $\mathrm{CO}_{2}$ for the reaction with sodium would be of concern in a safety analysis. A comparison of the thermal decomposition of calcite and dolomite to yield $\mathrm{CO}_{2}$ is presented below. 


\section{Calcite}

Upon heating, calcite decomposes to yield calcium oxide and carbon dioxide according to the reaction:

$$
\mathrm{CaCO}_{3} \longrightarrow \mathrm{CaO}+\mathrm{CO}_{2}
$$

This reaction will proceed to the right until the equilibrium partial pressure of $\mathrm{CO}_{2}$ is reached. The equilibrium partial pressure of $\mathrm{CO}_{2}$ for this reaction is determined by:

$$
\Delta G_{f}\left(\mathrm{CO}_{2}\right)+\Delta G_{f}(\mathrm{CaO})-\Delta G_{f}\left(\mathrm{CaCO}_{3}\right)=-\mathrm{RT} \ln \mathrm{P}_{\mathrm{CO}_{2}}
$$

where

$$
\begin{aligned}
\Delta G_{f}(A)= & \text { free-energy of formation of species } A \\
& \text { at temperature } T \\
R= & \text { universal gas constant } \\
\mathrm{T}= & \text { absolute temperature } \\
\mathrm{P}_{\mathrm{CO}_{2}=} & \text { equilibrium partial pressure of } \mathrm{CO}_{2}
\end{aligned}
$$

Table 1 lists equilibrium partial pressures of $\mathrm{CO}_{2}$ over calcite calculated using equation (4) and data from the U.S.G.S. data set, 13 the data tabulated by Barin and Knacke, 14 and the data tabulated by stern and Weise. 15 Since higher $\mathrm{CO}_{2}$ partial pressures provide more $\mathrm{CO}_{2}$ to react exothermically with the sodium, it is clear that as temperature increases the sodium-calcite reaction should become more vigorous. At low temperatures near a typical breeder reactor operating temperature $\left(550^{\circ} \mathrm{C}\right)$, the $\mathrm{CO}_{2}$ 


\section{$\underline{T A B L E} 1$}

Equilibrium Partial Pressures of $\mathrm{CO}_{2}$ Over Calcite $\left(\mathrm{CaCO}_{3} \longrightarrow \mathrm{CaO}+\mathrm{CO}_{2}\right)^{2}$

\begin{tabular}{|c|c|c|c|c|}
\hline $\begin{array}{c}\text { Temperature } \\
(\mathrm{K})\end{array}$ & $\begin{array}{l}\mathrm{P}_{\mathrm{CO}_{2}}{ }^{\star} \\
(\operatorname{atm} .)\end{array}$ & $\begin{array}{l}\mathrm{P}_{\mathrm{CO}_{2}}{ }^{* \star} \\
(\text { atm. })\end{array}$ & $\begin{array}{l}\mathrm{P}_{\mathrm{CO}_{2}}^{+} \\
\quad(\text { atm. })\end{array}$ & $\begin{array}{c}\text { Temperature } \\
\qquad\left({ }^{\circ} \mathrm{C}\right)\end{array}$ \\
\hline 700 & $8.044 \times 10^{-6}$ & $1.480 \times 10^{-5}$ & $9.01 \times 10^{-6}$ & 427 \\
\hline 800 & $3.380 \times 10^{-4}$ & $6.213 \times 10^{-4}$ & $3.71 \times 10^{-4}$ & 527 \\
\hline 900 & $6.044 \times 10^{-3}$ & $1.078 \times 10^{-2}$ & $6.55 \times 10^{-3}$ & 627 \\
\hline 1000 & $5.950 \times 10^{-2}$ & 0.1084 & $6.36 \times 10^{-2}$ & 727 \\
\hline 1100 & 0.379 & 0.688 & 0.401 & 827 \\
\hline 1200 & 1.00 & 3.148 & 1.84 & 927 \\
\hline
\end{tabular}

* Calculated from the U.S.G.S. free-energy data ${ }^{12}$

** Calculated from the data tabulated by Barin and Knacke 13

+ From compilation by stern and weise 14 
partial pressure is quite low, about $10^{-5}$ atmospheres. Near the boiling point of sodium $\left(883^{\circ} \mathrm{C}\right)$ however, the equilibrium partial pressure of $\mathrm{CO}_{2}$ rises to a large fraction of an atmosphere. At sodium-concrete reaction temperatures near the breeder reactor operating temperatures, the reaction should be relatively mild but as the temperature approaches the boiling point of sodium the reaction will become much more vigorous.

\section{Dolomite}

The thermal decomposition of dolomite is not as simple as the thermal decomposition of calcite. The total decomposition reaction:

$$
\mathrm{CaMg}\left(\mathrm{CO}_{3}\right)_{2} \longrightarrow \mathrm{CaO}+\mathrm{MgO}+2 \mathrm{CO}_{2}
$$

is probably not important except at higher temperatures than the temperature range of interest here. Reaction (5) yields $\mathrm{CO}_{2}$ partial pressures higher than the equilibrium $\mathrm{CO}_{2}$ partial pressure calculated for the thermal decomposition of calcite [reaction (3)]. Therefore if reaction (5) occurred, calcium oxide would react with the $\mathrm{CO}_{2}$ to form calcium carbonate. In the temperature range of interest, the important reaction to consider is:

$$
\mathrm{CaMg}\left(\mathrm{CO}_{3}\right)_{2} \longrightarrow \mathrm{MgO}+\mathrm{CaCO}_{3}+\mathrm{CO}_{2}
$$

Subsequent decomposition of the calcite occurs only at higher temperatures. The stepwise nature of the thermal decomposition of dolomite has been demonstrated by differential 
thermal analysis. 16 The first decomposition reaction begins it temperatures of approximately $600^{\circ} \mathrm{C}$. The second decomposition reaction, which has been shown to be related to calcite decomposition, begins at temperatures of approximately $700^{\circ} \mathrm{C}$. Since DTA type analyses are not equilibrium analyses, these results can be used only as a general comparison as to the relative temperatures at which the two reactions occur.

Equilibrium partial pressures of $\mathrm{CO}_{2}$ over dolomite can be calculated using an expression similar to that used for calcite:

$\Delta G_{f}\left(\mathrm{CO}_{2}\right)+\Delta G_{f}\left(\mathrm{CaCO}_{3}\right)+\Delta G_{f}(\mathrm{MgO})-\Delta G_{f}\left(\mathrm{CaMg}\left(\mathrm{CO}_{3}\right)_{2}\right)=-$ RT In $\mathrm{P}_{\mathrm{CO}_{2}}$

Equilibrium $\mathrm{CO}_{2}$ partial pressures calculated using the U.S.G.S. data set 13 and the data tabulated by Barin and Knacke ${ }^{14}$ are listed in Table 2. The equilibrium $\mathrm{CO}_{2}$ partial pressures for dolomite are several orders of magnitude higher than the $\mathrm{CO}_{2}$ partial pressures calculated for calcite at the same temperatures. The calculated partial pressure of $\mathrm{CO}_{2}$ over dolomite at $427^{\circ} \mathrm{C}$ is in excess of one atmosphere and is higher than the $\mathrm{CO}_{2}$ partial pressure over calcite calculated for the boiling point of sodium. The thermodynamic calculations, therefore, indicate that $\mathrm{CO}_{2}$ will be released in a far greater quantity for dolomite than for calcite. This suggests that the reaction between molten sodium and the concrete aggregate [reactions (1) and (2) combined with either (3) or (6)] would potentially be much more vigorous for dolomite concrete than for calcite concrete. 


\section{TABLE 2}

Equilibrium Partial Pressures of $\mathrm{CO}_{2}$ Over Dolomite $\left(\mathrm{CaMg}\left(\mathrm{CO}_{3}\right)_{2} \rightarrow \mathrm{MgO}+\mathrm{CO}_{2}+{ }^{2} \mathrm{CaCO}_{3}\right)$

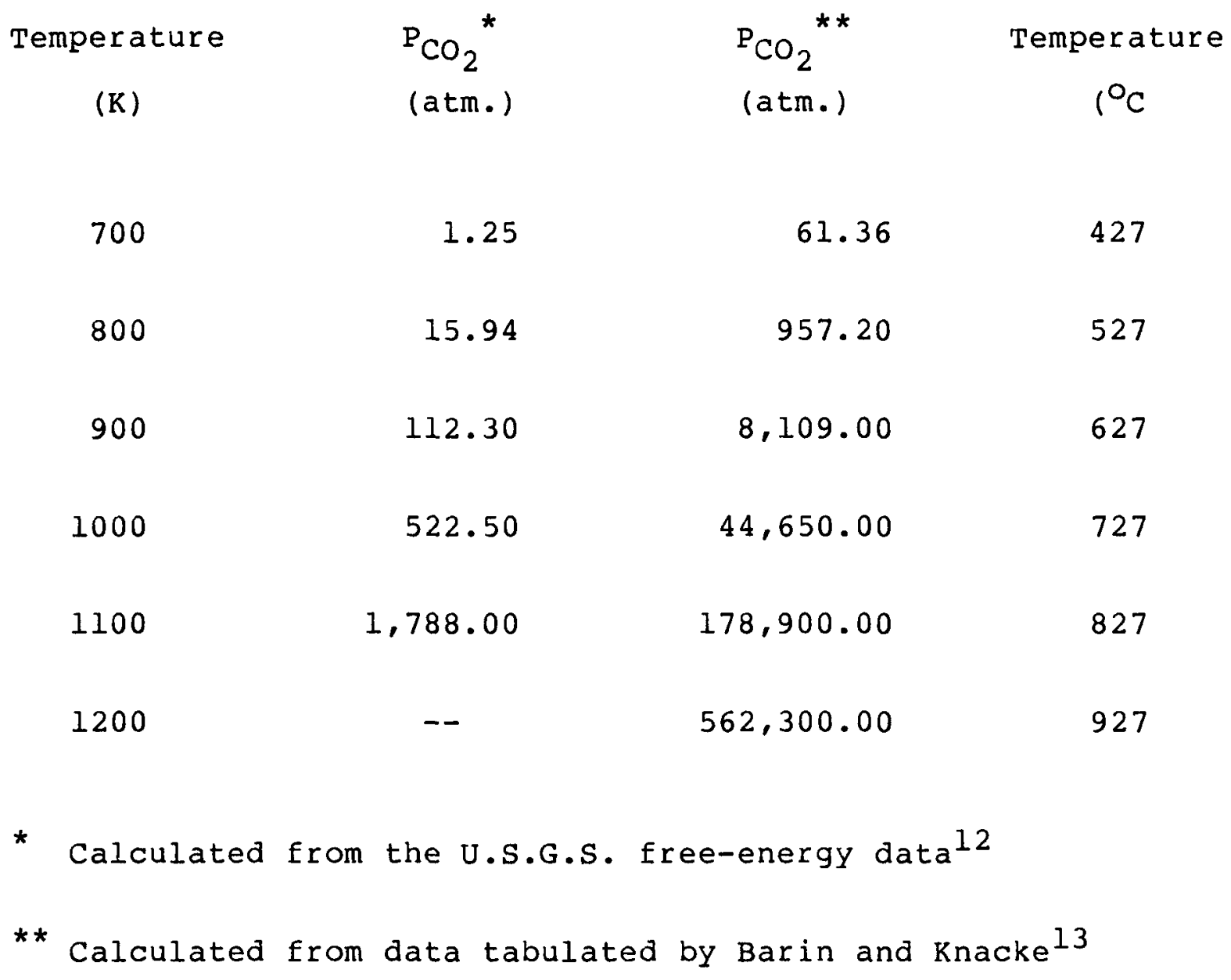


A notable feature of Table 2 is that the calculated partial pressures of $\mathrm{CO}_{2}$ using the different thermochemical data sets are quite different. The magnitude of this difference suggests that either one or both of the data sets or some portions thereof are possibly in error. Inspection of the thermochemical data suggests that the uncertainty in the free energy of formation of dolomite is almost totally responsible for these differences. Harker and Tuttle 7 report that dolomite decomposes into $\mathrm{CaCO}_{3}$ and $\mathrm{MgO}$ (periclase) at $900^{\circ} \mathrm{C}$ and 1840 atmospheres of $\mathrm{CO}_{2}$. Their results suggest that the equilibrium partial pressures calculated with U.S.G.S data set are more nearly correct than those calculated with the data from Barin and Knacke. It must also be noted that the calculation of equilibrium partial pressures involves small differences among large numbers. Consequently, uncertainties in the published thermochemical data are quite important. Generally, such uncertainties in free energy data within a particular data set are small. In addition, the free energy of $\mathrm{CO}_{2}$ is particularly well known. However, even small uncertainties can lead to rather large uncertainties in the calculations when partial pressures are low. For example, the uncertainty in the partial pressure of $\mathrm{CO}_{2}$ over calcite is about $\pm 100 \%$ at $427^{\circ} \mathrm{C}$ but this uncertainty is only $\pm 0.2 \%$ at $827^{\circ} \mathrm{C}$. Unfortunately, the discrepancies among partial pressures calculated with different data sets are larger than the uncertainties within the data sets can explain.

A thermodynamic analysis such as the one described above is only the first step in determining the nature and extent of the chemical reactions that can or do occur in a given chemical system. Kinetic effects and the effects of minor impurities or other materials present in the system must also 
be considered. Investigations by Hashimoto, et al, 18 have shown that the presence of the Mgo product inhibits the thermal decomposition of the $\mathrm{CaCO}_{3}$ product in the partial decomposition of dolomite reaction (5) for short periods of time at high temperatures. Paulik et al, 19 have demonstrated that the presence of water vapor inhibits the thermal decomposition of dolomite. The results of both of these studies would mean that the high equilibrium partial pressures of $\mathrm{CO}_{2}$ over dolomite may not be achieved in actual practice, especially in short times, e.g., on the order of minutes. The experiments of Harker and Tuttle 17 generally required tens of hours to reach equilibrium in the temperature range $600^{\circ}$ to $900^{\circ} \mathrm{C}$.

Simple thermodynamic considerations, therefore, suggest that there would be a significant difference in the vigor of the reaction of molten sodium with calcite and dolomite concretes. The cause is the large difference in the $\mathrm{CO}_{2}$ release during the thermal decomposition of the two minerals. The experimental evidence of the effects of other materials present in the system presents contrary arguments. The kinetic information, therefore, is confusing. If the decomposition reaction is indeed affected by the presence of Mgo or water, the differences between calcite and dolomite in their reactions with molten sodium would be mitigated. The experimental kinetic studies suggest that thermodynamic considerations alone are not enough to evaluate the differences that might be seen in the reaction of molten sodium with calcite and dolomite concretes. 


\section{EXPERIMENTAL PROCEDURES}

\section{Test Articles}

The test articles were fabricated at HEDL using Iimestone concrete which met current specifications for the structural concrete to be used in CRBRP. Tables 3,4 , and 5 list the mix specifications for the concretes and the materials sources for both concretes. Table 6 lists the concrete strength data. (The test articles were designed and fabricated at HEDL using English units of measurement. For purposes of clarification and accuracy, the English units will be used in this report for describing the test articles.)

The test articles were fabricated by placing (casting) a $2 \mathrm{ft}$. depth of concrete into a cylinarical steel shell as shown in Figure 1 . The test article container was a mild steel cylinder 54 inches long with a steel plate welded to the bottom end. The inside diameter of the steel cylinder was $131 / 8$ " which resulted in an exposed concrete surface of nominally $1 \mathrm{ft}^{2}$.

Fifteen thermocouples were embedded in the concrete at the time of placing. Thirteen of the thermocouples extended to the centerline of the test article and two thermocouples extended to mid-radius only (Figure 1). The thermocouples were 1/16" diameter 316 s.s. sheathed, type $\mathrm{K}$ (chromelalumel). They were held rigidly in place by $1 / 8$ " stainless steel tubing which extended along the majority of their length. The thermocouple tip and first inch of the thermocouple were exposed directly to the concrete. 


\section{TABLE 3}

\section{Calcite Concrete Mix Specifications}

\section{Materials}

Cement (Type II)

Pozzolan (Volcanic Ash)

Water

Fine Aggregate Coarse Aggregate

Air Entraining Agent

Water Reducer
Weights

(per Cubic Yard)

4231 bs.

141 lbs.

275 lbs.

$14041 \mathrm{bs} . *$

1716 lbs.*

$356 \mathrm{ml}$

$500 \mathrm{ml}$

\section{Mix Reguirements}

28 day strength

Slump

W/C Ratio

W/C + FA Ration

Air Content

Unit Weight
: 4600 psi Ave \pm 400 psi

: 1-3 inches

: $\quad 0.63$

$: \quad 0.47$

: $\quad 4-88$

$: \quad 147.0 \pm 31 \mathrm{~b} / \mathrm{ft}^{3}$

Combined Aggregate Gradation:

Sieve Size o Passing

$\begin{array}{lr}3 / 4 " & 100 \\ 3 / 8 " & 66.3 \\ \# 4 & 48.7 \\ \# 8 & 42.3 \\ \# 16 & 30.4 \\ \# 30 & 17.9 \\ \# 50 & 7.8 \\ \# 100 & 2.8\end{array}$

* Saturated - Surface Dry Weight 


\section{TABLE 4}

Dolomite Concrete Mix Specifications

Materials

Cement (Type II)

Flyash

Water

Fine Aggregate

Coarse Aggregate

Air Entraining Agent

Water Reducer
Weights

(per Cubic Yard)

423 1bs.

141 lbs.

2651 bs.

1425 lbs.*

1728 lbs.*

$296 \mathrm{ml}$

$503 \mathrm{ml}$

Mix Requirements

$\begin{array}{ll}28 \text { day strength }\left(f_{C}^{\prime}\right) & : 4600 \text { psi Ave } \pm 400 \text { psi } \\ \text { Slump } & : 1-3 \text { inches } \\ \text { W/C Ratio } & : 0.53 \\ \text { W/C }+ \text { FA Ration } & : 0.47 \\ \text { Air Content } & : 147.0 \pm 31 \mathrm{~b} / \mathrm{ft}^{3}\end{array}$

Combined Aggregate Gradation:

Sieve Size of Passing

$\begin{array}{lr}3 / 4 " & 100 \\ 3 / 8 " & 66.3 \\ \# 4 & 48.7 \\ \# 8 & 42.3 \\ \# 16 & 30.4 \\ \# 30 & 17.9 \\ \# 50 & 7.8 \\ \# 100 & 2.8\end{array}$

* Saturated - Surface Dry Weight 


\section{TABLE 5}

\section{Concrete Materials Data}

1. Coarse Aggregate: Meets ASTM C33, \#67 grading, crushed Iimestone, $3 / 4^{\prime \prime}$ to \#4, bulk saturated surface dry specific gravity: 2.80 , absorption: $0.80 \%$, Source: dolomite: CRBRP on-site quarry, calcite: Ralph Rogers quarry.

2. Fine Aggregate: Meets ASTM C33, crushed limestone, minus \#4, bulk saturated surface dry specific gravity: 2.80 , absorption: 1.208 , fineness modulus: 2.80 , Source: Same as coarse aggregate.

3. Cement: Type II meeting moderate heat of hydration and false set, ASTM Cl50, specific gravity: 3.18, Source: Ideal Cement Type II.

4. Flyash: Meets ASTM C618, Class F. Source: TVA, Kingston, Tennessee, Specific gravity (bulk, SSD): 2.40 .

5. Air Entraining Admixture: Meets ASTM C260, Source: Protex Industries, Denver, Colorado.

6. Water Reducer: Meets ASTM C494, Type A, Source: Protex Industries, Denver, Colorado.

7. Water: Not more than 2,000 ppm solids - not more than $250 \mathrm{ppm}$ chlorides, includes free water in aggregates. Potable. 
TABLE 6

Concrete Strength Data

$\begin{array}{lcc}\begin{array}{l}\text { Cure Time } \\ \text { (days) }\end{array} & \text { Calcite (psi) } & \text { Dolomite (psi) } \\ 7 & 3237 & 2577 \\ 28 & 4367 & 4043 \\ & & \\ \text { Day of Test } & 5898 & 5686\end{array}$




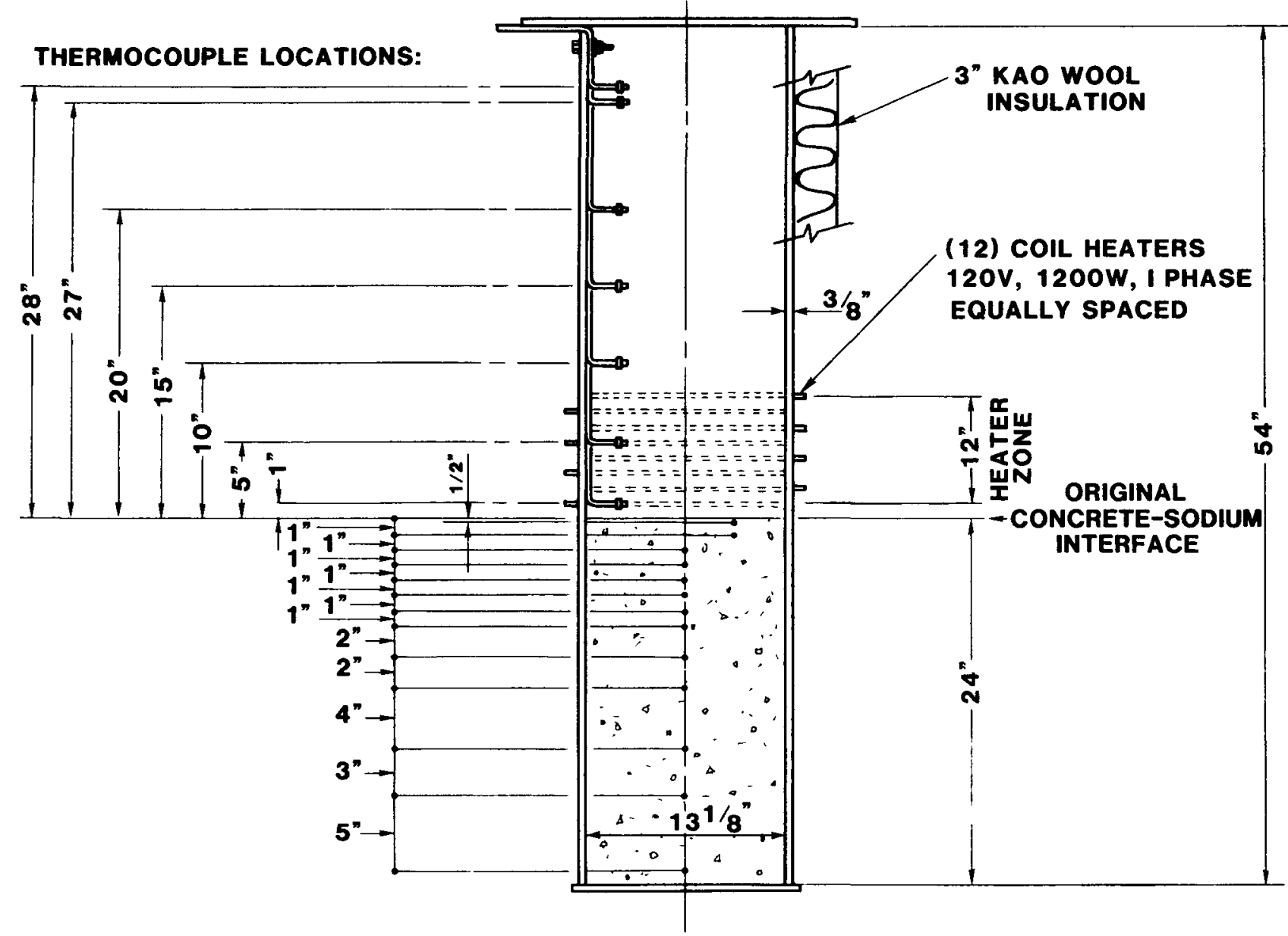

Figure 1. Schematic of Test Article Showing Thermocouple and Heater Placement. 
The top flange, remaining instrumentation, and external pool heaters were attached to the test articles after they were received at SNLA. Seven thermocouples were placed as shown in Figure 1 to monitor pool and vapor space temperatures. These thermocouples were protected by 1/4" diameter stainless steel tubing and Swagelock end caps. General Electric Calrod heaters were used as pool heaters. The heaters were placed circumferentially around the outside of the test article, vertically spaced approximately one inch apart in a region extending for 12 inches above the original concrete interface. A photograph of the test article before and after adding the Kaowool insulation is shown in Figure 2. A mild steel flange was welded to the top of the test article cylinder so that a mating steel "top hat" could be attached to the test article. The top hat contained access holes for all remaining instrumentation, the sodium transfer line, and the gas vent line.

Test Method

The Large Scale Test Facility at SNLA was used for the tests. This facility has been described in detail elsewhere. ${ }^{3}$ The facility was modified to handle the present HEDL designed test article configuration. A schematic of the test article enclosure is shown in Figure 3. The sodium was transferred to the test article via a $10 \mathrm{~cm}$ transfer line placed at the center line of the test article. Reaction gases were vented via either one or two $5 \mathrm{~cm}$ vent lines as shown in Figure 3. The vent line contained a baffle type filter and a water spray gas scrubbing system which cleaned the product gases before returning them to the atmosphere. A differentially pumped mass spectrometer was used to monitor gas composition during the test. A liquid nitrogen trapped 


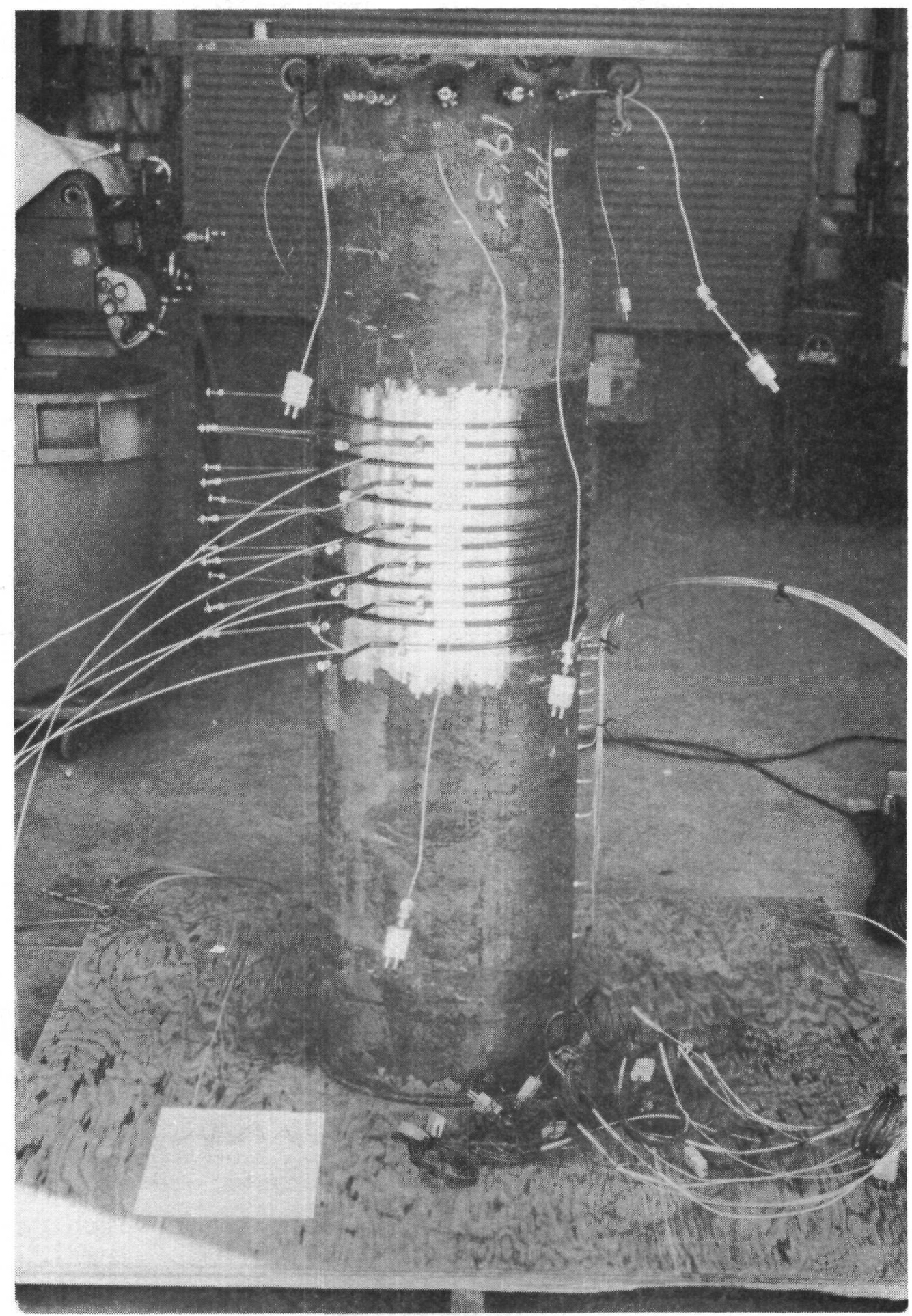

Figure 2. Photograph of Test Article Showing a) Heater Placement and Welded Steel Top Flange and b) Article with Insulation in Place. 


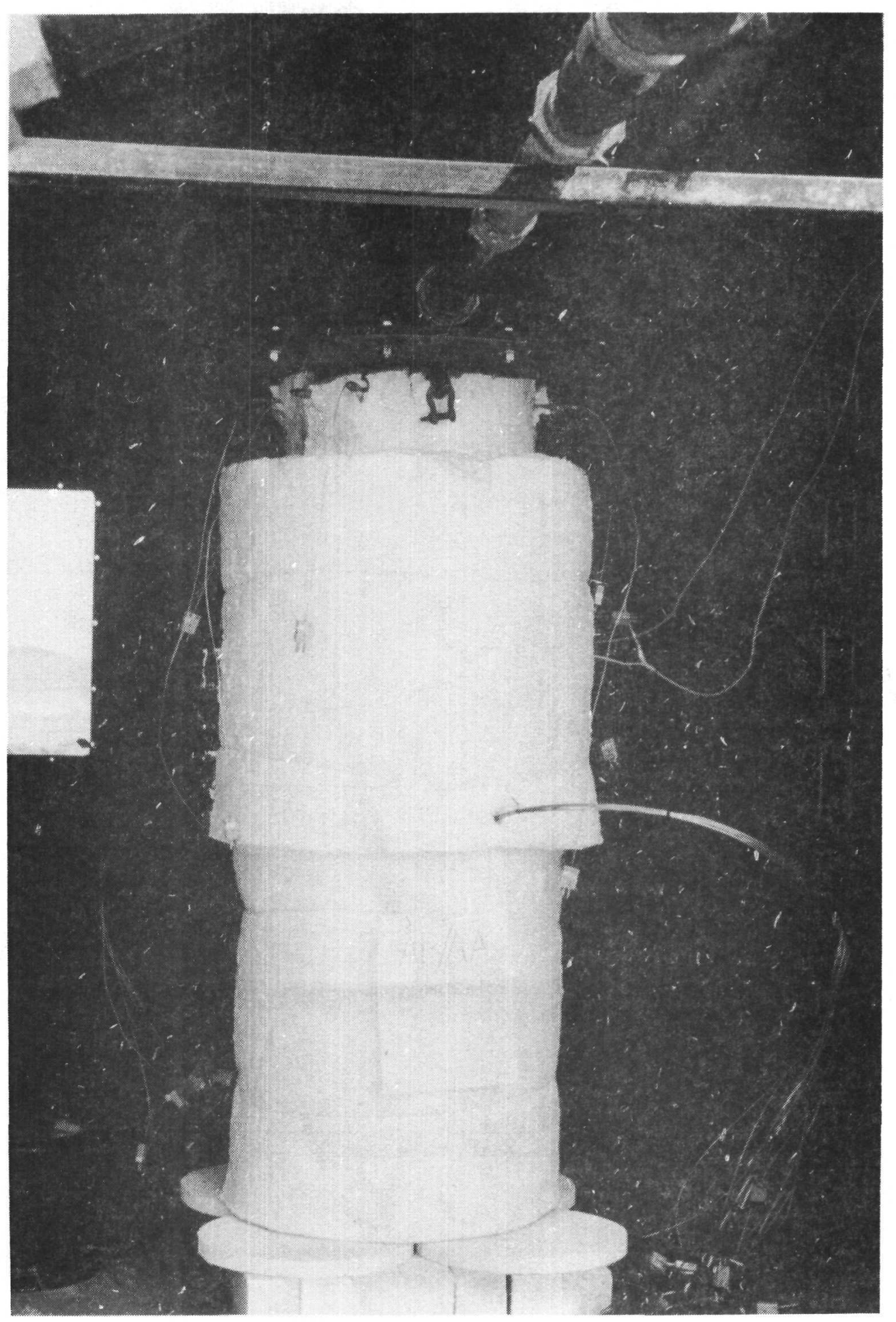

Figure 2b. 


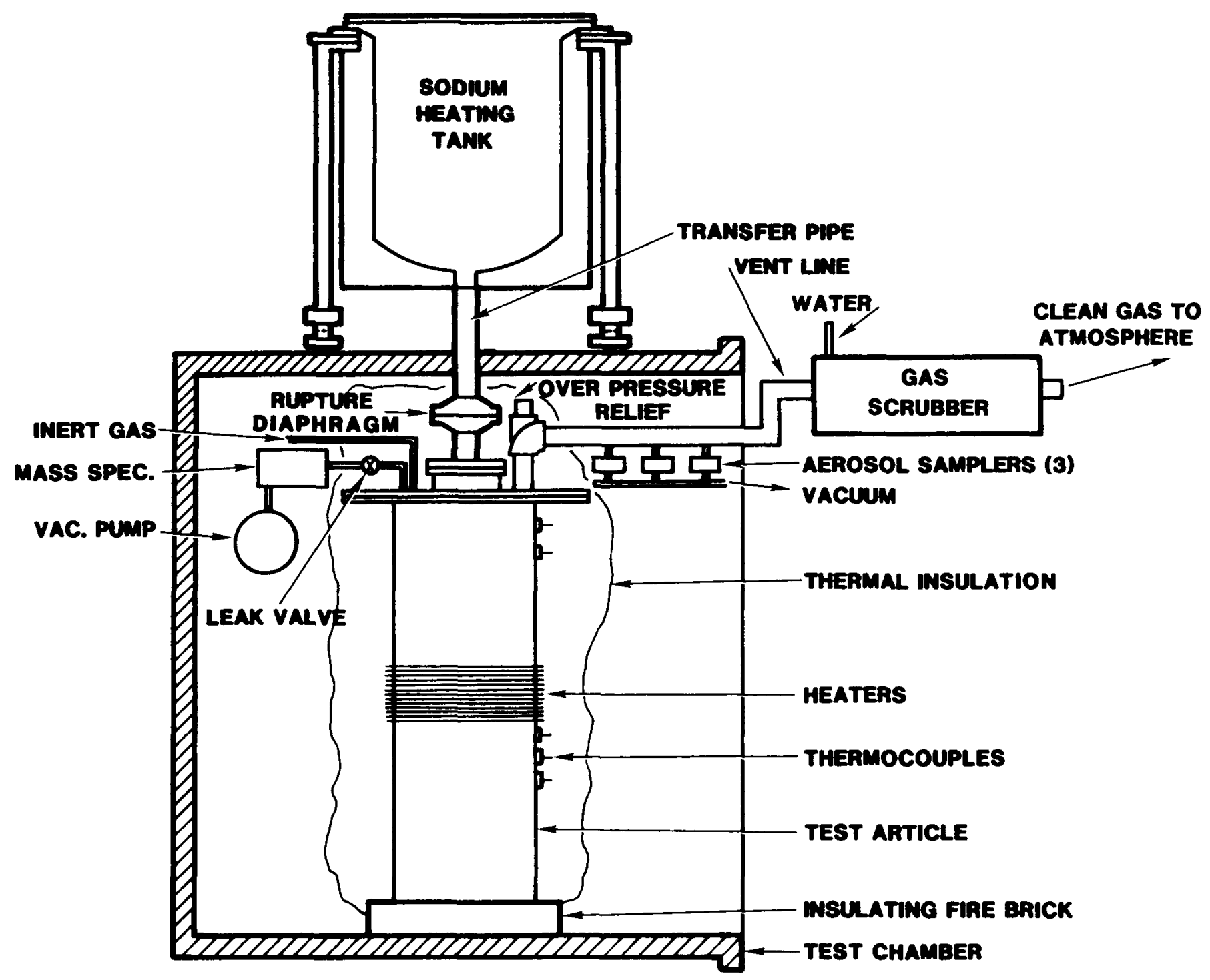

Figure 3. Test Article Placement in Test Enclosure. 
diffusion pump-mechanical pump system was used as the vacuum pump. A leak valve was mounted directly on top of the test article top hat as shown in Figure 3. Filter type aerosol samplers were used in the dolomite test. These samplers were located in the test article vent line approximately $60 \mathrm{~cm}$ from the test article as shown in Figure 4. The aerosol sampling system was designed to take filter samples at three different times during the test. When a sampler was not being used, the respective filter holder and lines were constantly purged with argon to prevent undesired deposit of aerosols.

The tests were configured as shown in Figures 1-3. Forty-five and one-half kilograms (100 lbs) of sodium were used in each test. An argon gas purge of the test article was begun five hours before the start of the test at a rate of $21 / \mathrm{min}$. The pool heaters were energized to preheat the steel container and the concrete surface 17 minutes before the sodium transfer. This was done to minimize the quenching of the molten sodium when it contacted the cold concrete. The concrete surface temperature was monitored and not allowed to go above $100^{\circ} \mathrm{C}$ during the preheat in order to prevent concrete water loss. The sodium preheat temperature was $750^{\circ} \mathrm{C}$ for the calcite test and $776^{\circ} \mathrm{C}$ for the dolomite test. The sodium was transferred into the test article in approximately 10 seconds. Once the sodium was transferred, the heaters were programmed to follow the TMBDB 20 (thermal margin beyond the design base) curve (Figure 5). This curve represents the calculated heating rate of the sodium pool in a core disruptive accident at CRBRP due to core debris decay heat. As agreed prior to the tests, an adjustment was made to the isothermal portion of the curve. HEDL performed their tests at a nominal temperature of $850^{\circ} \mathrm{C}$. The SNLA tests were 


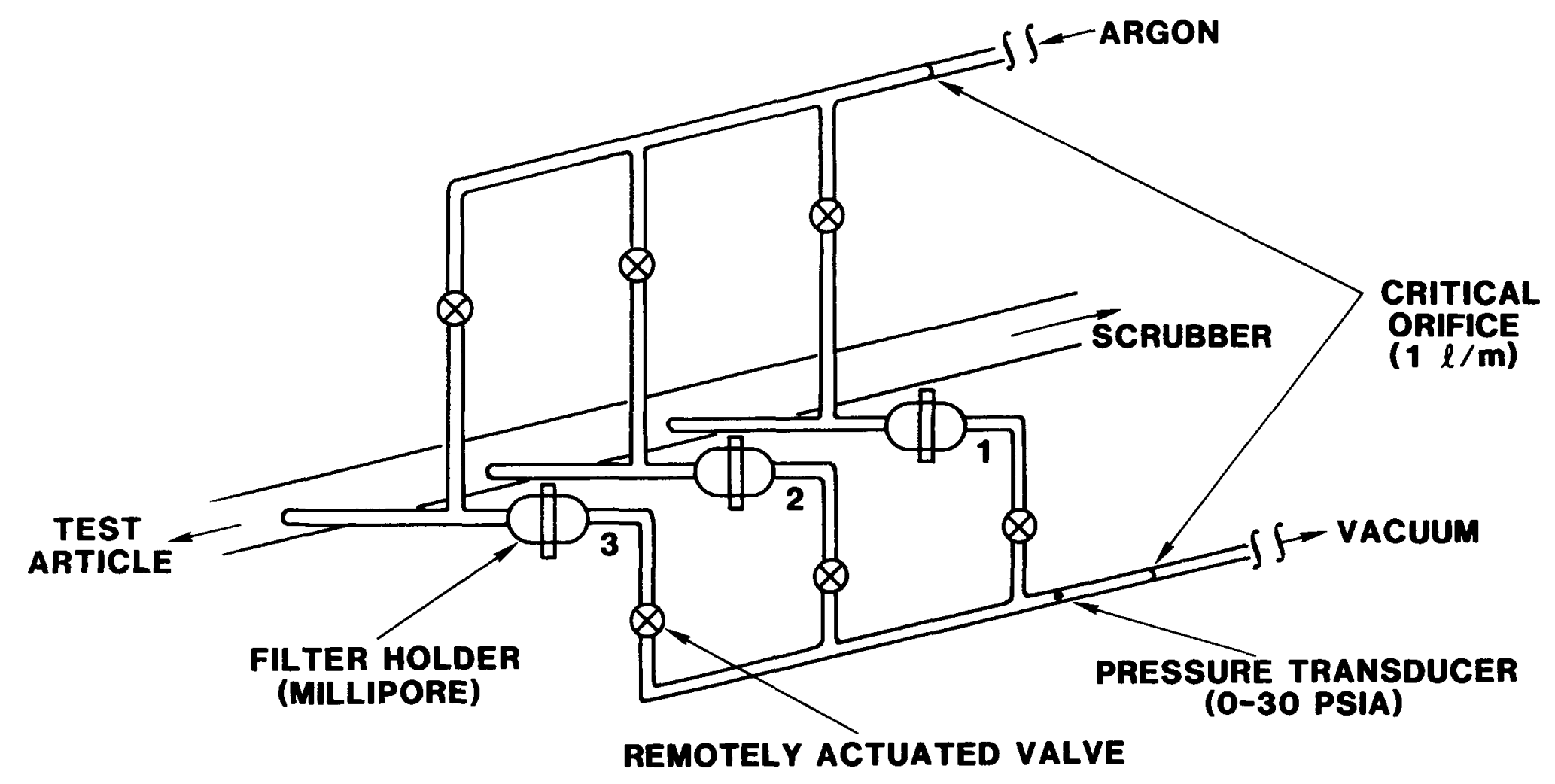

Figure 4. Aerosol Sampler Used in Dolomite Test. 


\section{TEST HEATUP CURVES}

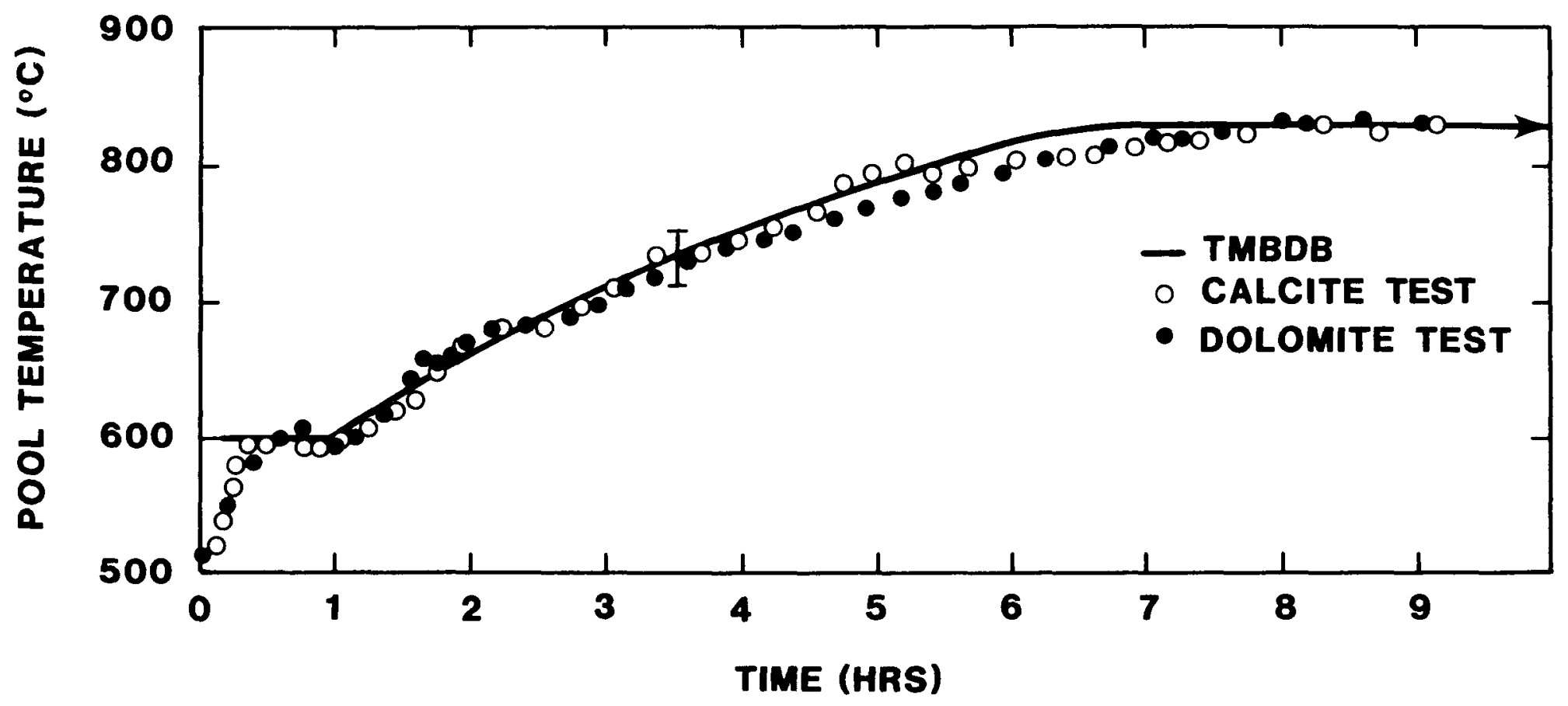

Figure 5. Pool Temperatuares During Heatup Portion of the Tests and the Target TMBDB Heatup Curve. 
run at $830^{\circ} \mathrm{C}$. This was done to equalize the amount of sodium lost by vaporization during the tests. Because of the difference in elevation between the two laboratories, atmospheric pressure at SNLA is 0.83 bars, whereas HEDL is close to sea level with a correspondingly higher atmospheric pressure. The lower test temperature at SNLA was chosen to make the vapor pressure of sodium the same relative percentage (74\%) of the local atmospheric pressure in the tests.

The total test time including the heatup portion of the TMBDB curve was 20 hours.

The calcite test proceeded smoothly until the test temperature of $830^{\circ} \mathrm{C}$ was reached, whereupon sodium leaks developed. At 9 hours and 43 minutes test time, the test was terminated because a fire had started under the insulation on top of the test article.

The dolomite test article configuration was modified slightly from the calcite test as shown in Figures 1-3. Additional precautions were taken with the mass spectrometer

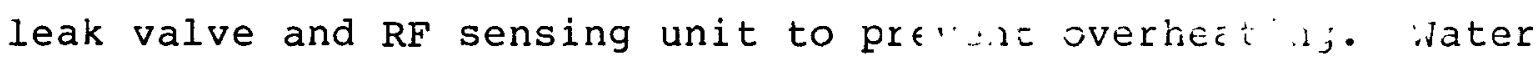
cooling coils and additional insulation were added in an effort to protect the the critical spectrometer parts from the high temperature, hostile environment. An additional vent line was also installed to prevent vent line plugging by aerosols. 


\section{Chemical Analysis of Reaction Debris}

The composition of the reaction debris was expected to be quite varied due to the large number of possible reactions in the two chemical systems. Of particular interest, however, were the relative amounts of carbonates, elemental carbon, calcium, and magnesium. Therefore an analytical scheme was derived to determine $\mathrm{CO}_{2}$, carbon, calcium, and magnesium contents for $10 \mathrm{gm}$ samples taken from the debris region when the tests were cross-sectioned. $\mathrm{CO}_{2}$ was determined gravimetrically after it was 1 iberated from the carbonates by a dilute $\mathrm{HCl}$ leach. After $\mathrm{HCl}$ leaching, the insolubles remaining were filtered from the solution, dried and weighed. The elemental carbon content of the dried insolubles was determined using a perkin Elmer model $240 \mathrm{~B}$ elemental analyzer. The filtrate was diluted to a specified volume and aliquots were used to determine the calcium and magnesium contents by selective EDTA titrations. The sum of the calcium and magnesium is determined by one type of EDTA titration and calcium alone is determined by another titration. Magnesium is then obtained by difference. Some uncertainty exists in the titration end point for calcium, however, because of the presence of aluminum, iron, and other elements. However, the error in the calcium and magnesium results is expected to be small ( \pm 18 ) 


\section{RESULTS}

\section{Calcite Test}

The pool heaters were used to preheat the test article for 17 minutes before the start of the test. The sodium charge, preheated to $750^{\circ} \mathrm{C}$, was transferred to the test article when the surface temperature of the concrete reached $90^{\circ} \mathrm{C}$. Figure 5 compares the actual target TMBDB 20 pool temperatures for the first 10 hours of the test. The error bar indicates the allowable deviation from the target curve. Even with the preheating procedure and high sodium temperature at transfer, some quenching of the sodium occurred and a minimum pool temperature of $510^{\circ} \mathrm{C}$ was realized a few minutes after the start of the test. The $600^{\circ} \mathrm{C}$ target temperature was regained within 20 minutes, however, and maintained for the first hour of the test. The actual temperatures in the test followed the heatup curve within the allowable limits. Heating to the test temperature of $830^{\circ} \mathrm{C}$ required seven hours. Beyond seven hours a constant temperature of $830^{\circ} \mathrm{C}$ was maintained for the test.

The initial portion of the calcite test proceeded smoothly. The test was terminated after less than 10 hours duration, however, because a sodium fire had developed on top of the test article at about nine hours. Sodium was found to be leaking out of the test article where the sodium transfer pipe entered the top hat. The leaking sodium and resulting sodium fires were apparently caused by pressurization of the test article due to plugging of the vent line. For safety reasons the test was terminated short of the desired 20 hour test length. 
Temperatures recorded in the sodium pool, vapor space, and concrete for the test time (10 hours) are shown in Figures 6 and 7. The same temperature profiles for the test time of 10 hours plus the following 8 hours of the cooldown period are shown in Figures 8 and 9 . All of the pool thermocouples indicated that the entire height of the sodium pool remained at a very uniform temperature. The initial sodium pool depth was $61 \mathrm{~cm}$. The pool thermocouple data (Figure 8 ) show that the sodium pool dropped below the thermocouple located at $51 \mathrm{~cm}$ at approximately 12 hours. This indicates that during the test the sodium level had dropped by somewhat less than $10 \mathrm{~cm}$ due to vaporization and interaction with the concrete.

The thermocouples in the concrete are used to monitor temperature response during the test. Temperature excursions above the current pool temperature on these thermocouples are interpreted to mean that an exothermic reaction front is passing their location at that time. The data show a uniform heating of the concrete for the first 2.6 hours. Then, an exothermic reaction between the sodium and calcite concrete began at 2.6 hours and lasted for a period of about 50 minutes. Peak reaction zone temperatures were $830^{\circ} \mathrm{C}$ when the pool temperature was $750^{\circ} \mathrm{C}$. By comparing pool temperatures and concrete temperatures it can be seen that the top three concrete thermocouples (located at $1.3,2.5$, and $5.0 \mathrm{~cm}$ ) experienced the passing of the reaction front in rapid succession but that the thermocouple located at $7.6 \mathrm{~cm}$ did not experience the front. Thus, during this period, the thermocouple data indicate the total penetration of the sodium into the concrete was between 5 and $7.6 \mathrm{~cm}$. 


\section{CALCITE TEST}

\section{POOL AND VAPOR SPACE TEMPERATURES}

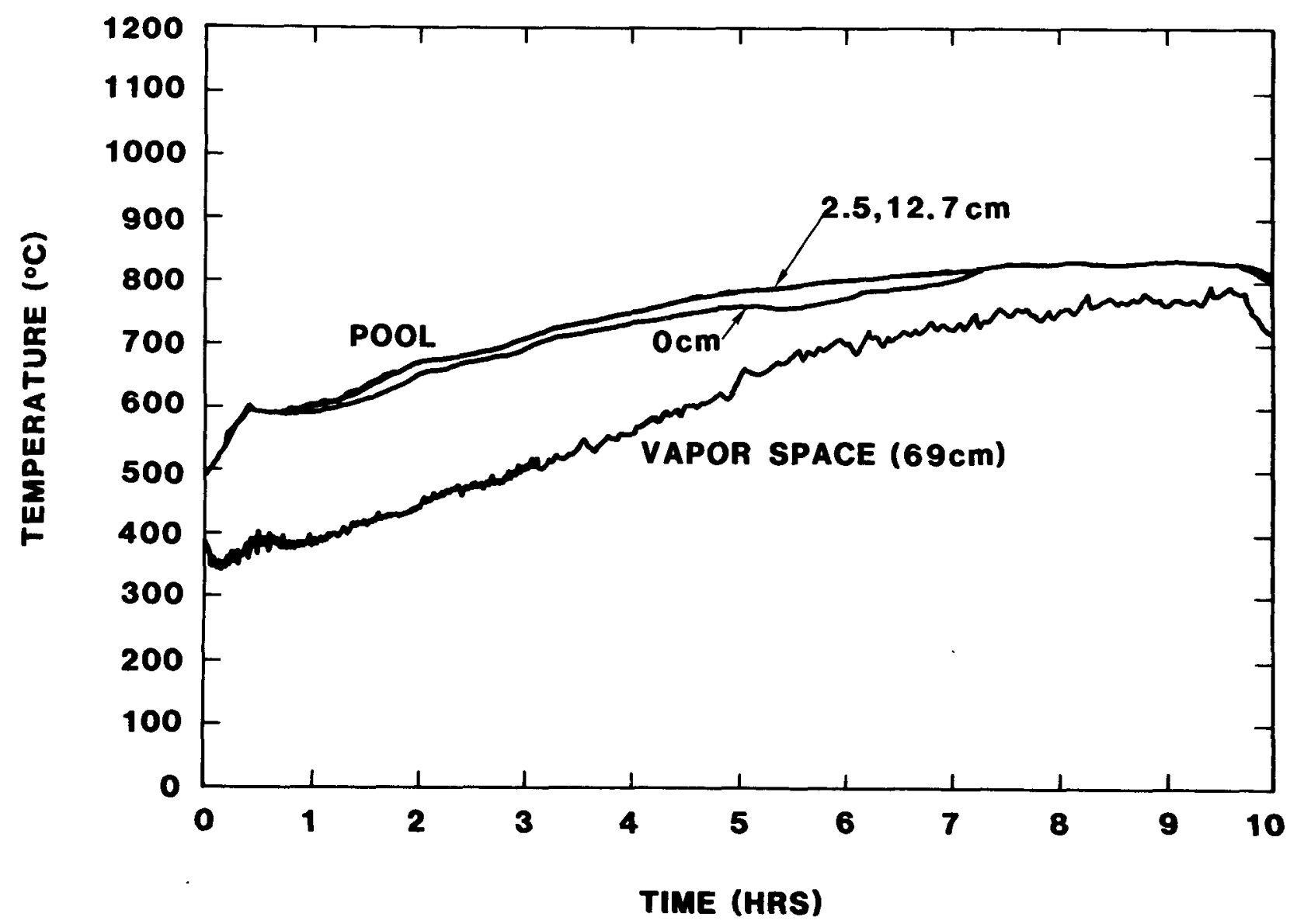

Figure 6. Calcite Test, Pool and Vapor Space Thermocouple Data for Test Time. 


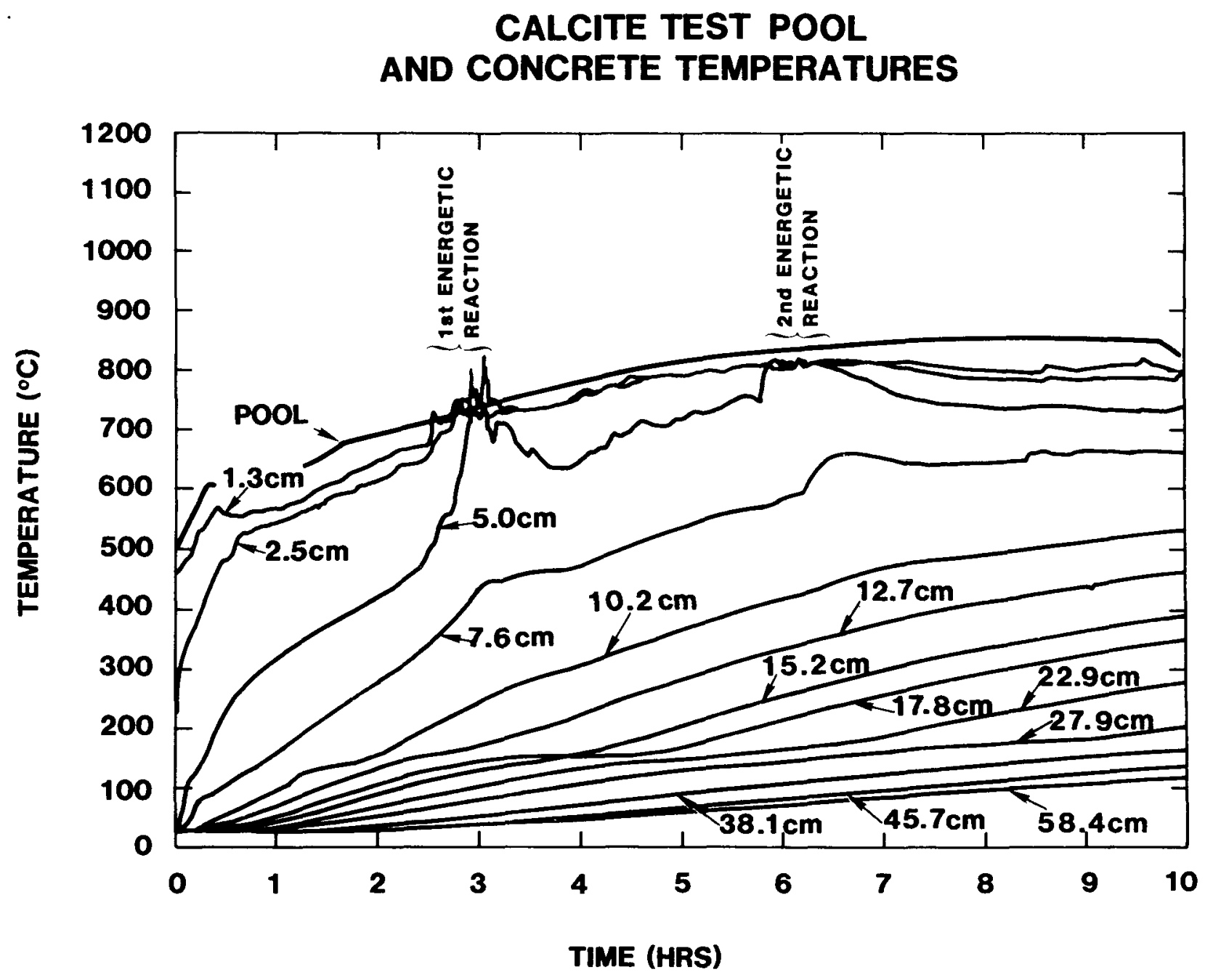

Figure 7. Calcite Test, Concrete Thermocouple Data for Test Time. 


\section{CALCITE TEST}

POOL AND VAPOR SPACE TEMPERATURES

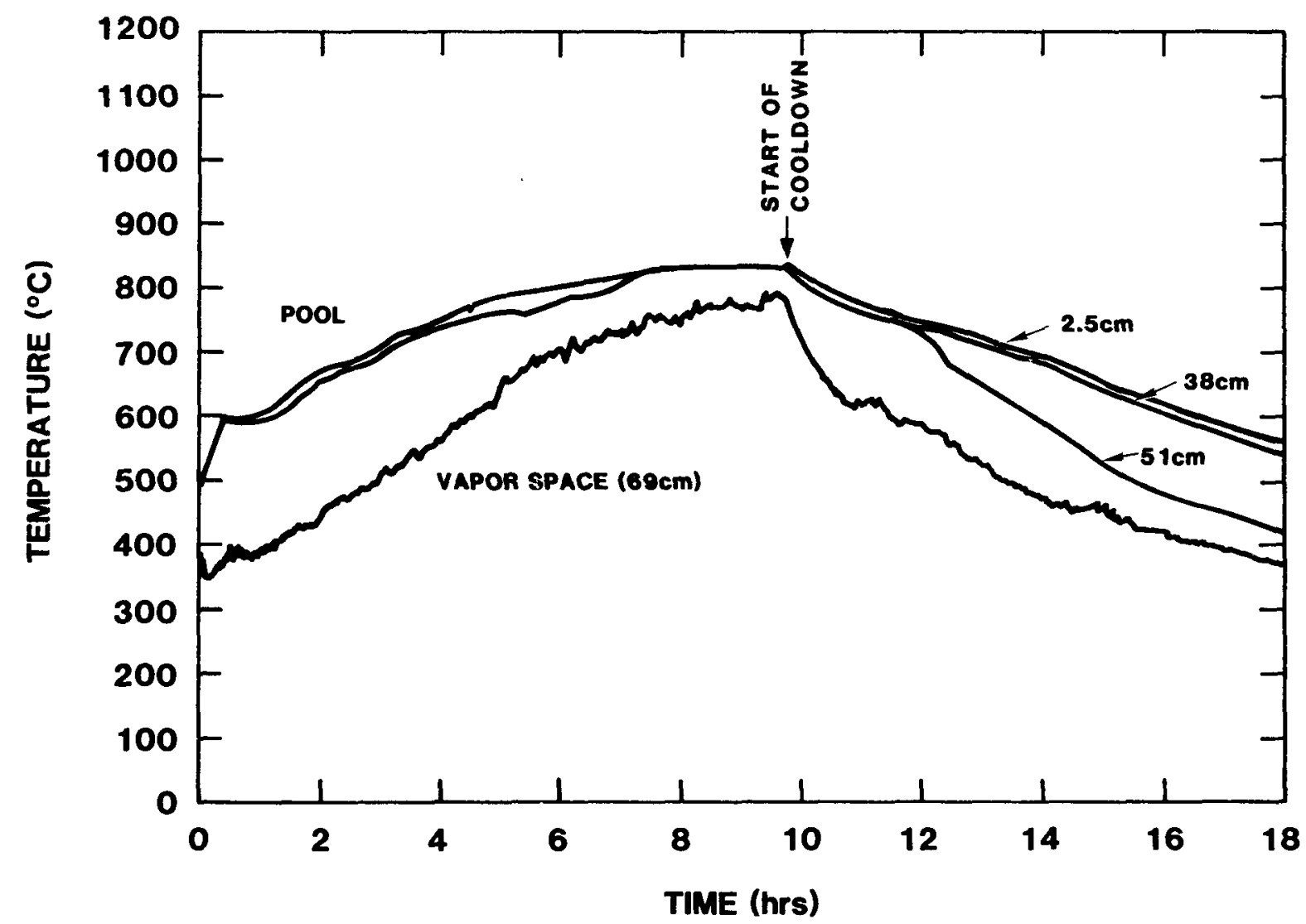

Figure 8. Calcite Test, Pool and Vapor space Thermocouple Data for Test $T$ ime and 8 Hours of Cooldown Period. 


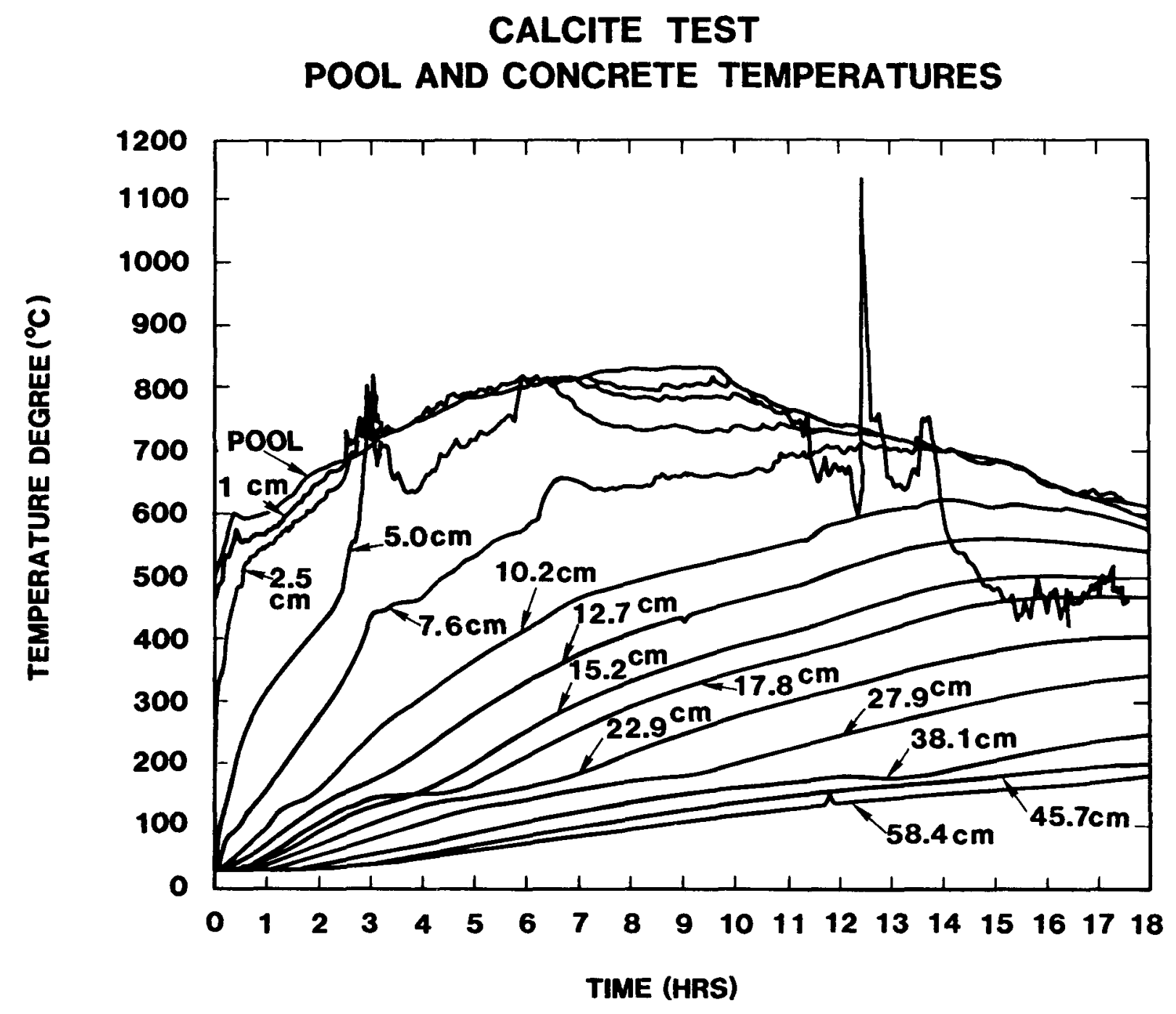

Figure 9. Calcite Test, Concrete Thermocouple Data for Test Time and 8 Hours of Cooldown Period. 
There were two obvious periods of energetic interactions during the test (Figure 7). The first and most vigorous exothermic reaction started at 2.6 hours. The second period of exothermic reaction started at approximately six hours and affected the 5 and $7.6 \mathrm{~cm}$ thermocouples. The second period of reaction was not as vigorous as the first period. Pool and concrete temperatures for the initial eight hours of the cooldown period are included in the temperature profiles of Figures 8 and 9. Although chemical reactions no doubt continued during the cooldown period, it is evident that no further vigorous exothermic reactions occurred during cooldown while the pool temperature was in excess of $600^{\circ} \mathrm{C}$.

The passing of the reaction zone noted by the thermocouples located at the centerline of the concrete can be used to determine a penetration rate. This is done by comparing the times when given thermocouples exhibit an extremely rapid increase in temperature, generally above the pool temperature. The data for the top three thermocouples shown in Figure 7 show that the reaction front moved from the $1.3 \mathrm{~cm}$ thermocouple to the $5.0 \mathrm{~cm}$ thermocouple, a distance of 3.7 $\mathrm{cm}$, in 22 minutes. The average penetration rate for this period of the vigorous reaction was therefore $1.7 \mathrm{~mm} / \mathrm{minute}$. The rapid penetration apparently subsided for the following three hours and the second temperature excursion, noted on the 5 and $7.6 \mathrm{~cm}$ thermocouples was not nearly as vigorous as the first temperature excursions. The reaction zone did not reach the $7.6 \mathrm{~cm}$ thermocouple during the test so no penetration rate can be calculated for the second period of reaction. 
Two additional thermocouples were placed in the concrete at a mid-radius position as shown in Figure 1 . The temperature profiles for these thermocouples (located 1.3 and $2.5 \mathrm{~cm}$ deep) are compared to the corresponding center thermocouples in Figure 10. The times at which energetic reactions occurred at the mid-radius position are noted on Figure 10. The first exothermic reaction was noted at the mid-radius position at five hours. A second energetic reaction period occurred at the mid-radius location beginning at nine hours. Both of these reactions were not as energetic as those noted by the center thermocouples.

The hydrogen flow rate data for the first 85 minutes of the test are shown in Figure 11. The hydrogen generation rate peaked at 20 minutes and decreased after this time. The hydrogen data are available for only the first 85 minutes of the test due to an overheating failure of the leak valve used in the differentially pumped mass spectrometer system. The peak hydrogen generation rate of $7 \mathrm{l} / \mathrm{min}$ during this time is 215 moles $/ \mathrm{m}^{2}-\mathrm{hr}$ which corresponds reasonably well with short time generation rates noted by other investigators on similar concretes. ${ }^{8}$ Unfortunately, no data were obtained during the exothermic reaction periods.

The test article was cooled in the test chamber for three days. The test fixturing was then dismantled and the test article removed. A small slot was cut in the steel shell of the test article to determine where the top of the reaction debris/unreacted sodium interface was located. The shell was then cut circumferentially at this location and the excess, unreacted sodium was removed from the test article. The remaining section which consisted of reaction debris and unreacted concrete was then cross-sectioned with a $50 \mathrm{~cm}$ 
CALCITE TEST

\section{CONCRETE TEMPERATURES}

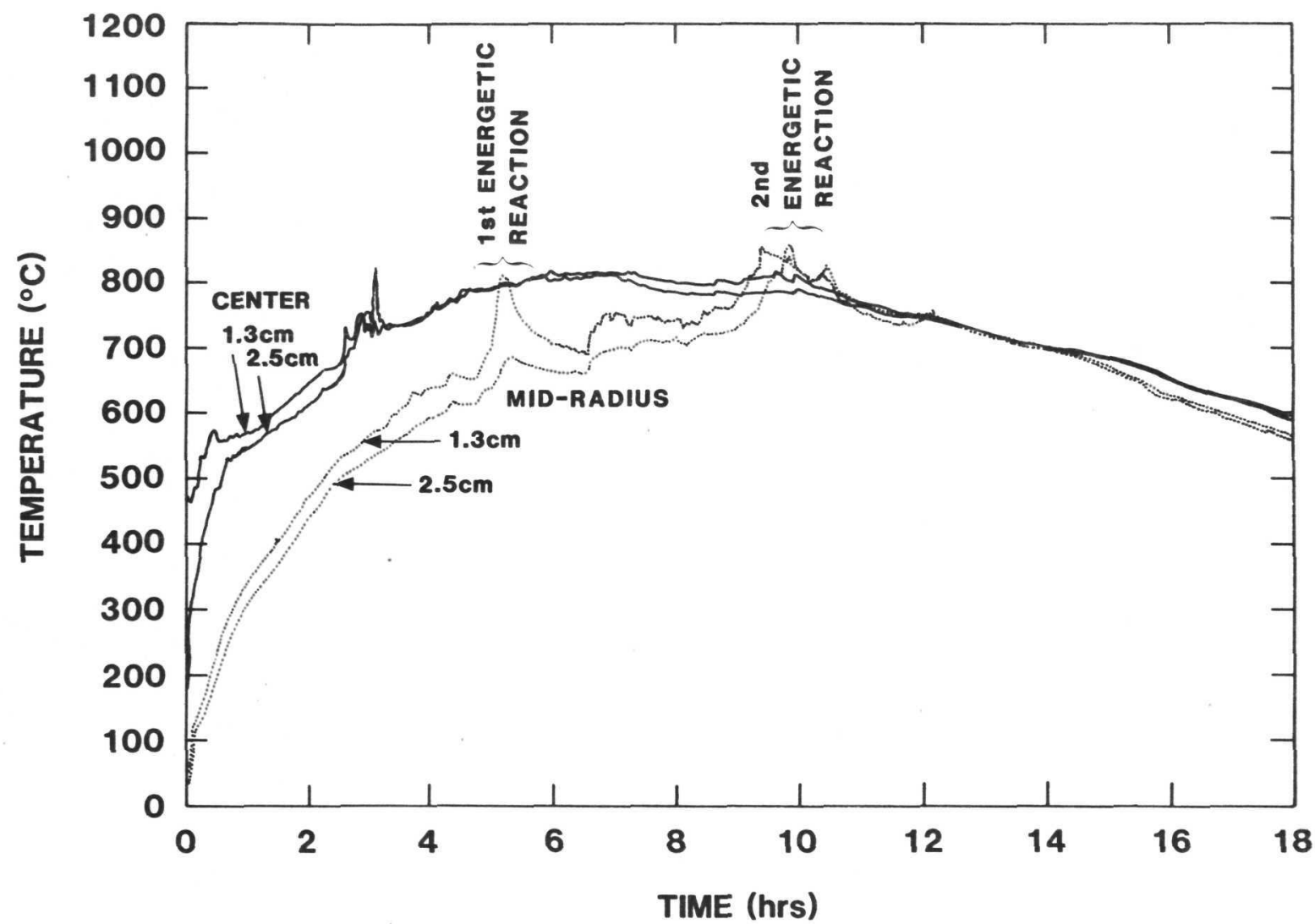

Figure 10. Calcite Test, Concrete Thermocouple Data for Centerline and Mid-radius Thermocouples Located at 1.3 and $2.5 \mathrm{~cm}$ Beneath Original Interface. 


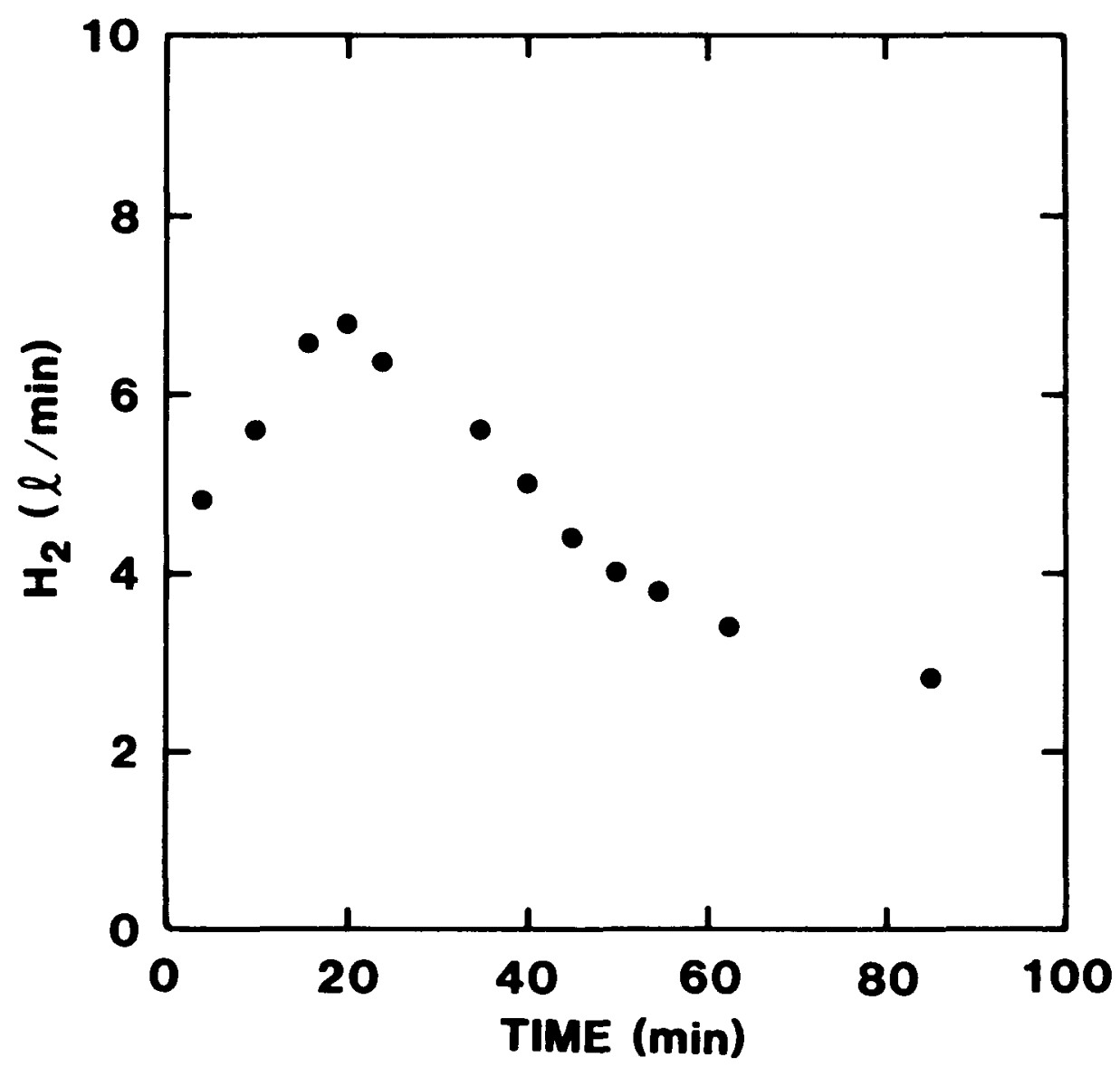

Figure 11. Calcite Test, Hydrogen Gas Generation. 
diameter SiC cuttoff wheel used dry. The cut was made along the axis of the cylinder directly through the centerline. The blade width was $0.6 \mathrm{~cm}$ but due to blade vibration and positioning difficulties, the width of the cut was about 1.2 $\mathrm{cm}$. This procedure resulted in two halves which had newly exposed interior surfaces that were located $1.2 \mathrm{~cm}$ apart in the original test article. A schematic of the test crosssection (cut surface) is shown in Figure 12. The reaction debris was $22 \mathrm{~cm}$ in thickness. The final penetration was measured at 14 points evenly spaced across each half of the cross-sectioned test article. The average penetration from the original concrete/sodium interface was $7.4 \pm 5.0 \mathrm{~cm}(95 \%$ confidence level). Two samples, noted as $A$ and $B$ in Figure 12, were taken for $x$-ray diffraction and chemical analysis. These samples were sealed in glass vials with an argon cover gas immediately after the test article was sectioned.

The sodium which was removed from the debris appeared to be relatively pure metallic sodium. The reaction debris was dull gray and was hard enough so that the samples for chemical analysis had to be removed by chiseling. When exposed to air, the reaction debris turned black and bubbles formed on its surface. Figure 13 is a photograph of the first half of the cross-sectioned test article from which the unreacted sodium and lower portion of the unreacted concrete have been removed for ease of handling. The upper portion of this photograph is the reaction debris which had already reacted with the air and the lower portion is unreacted concrete. As mentioned, the test article was cut with a carbide cutoff wheel from each side. The sawing operation could not completely separate the two sections because the saw bound up in the gummy reaction debris. The final parting operation was, therefore, done with chisels. The center 


\section{CAlcite test}

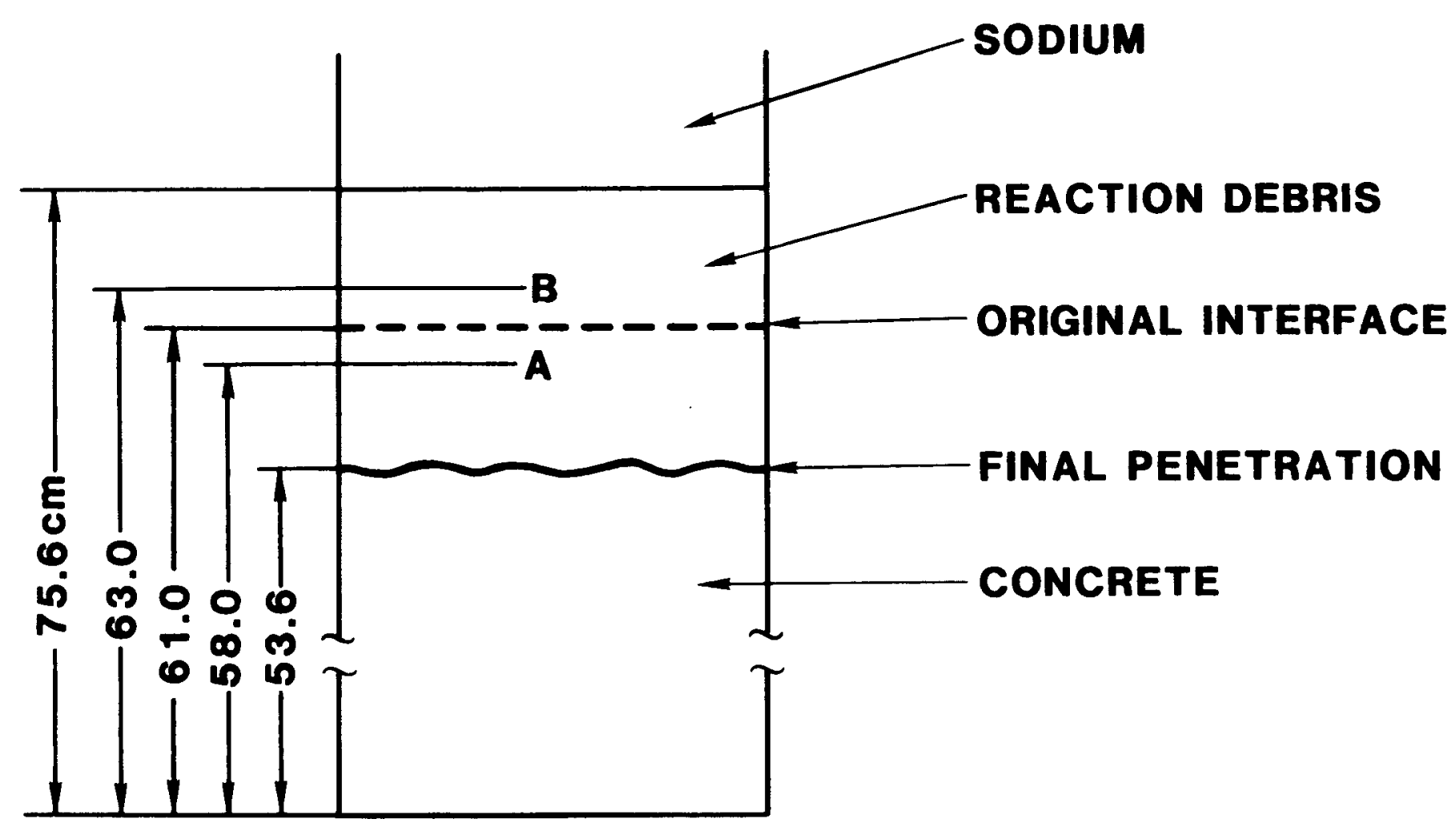

Figure 12. Schematic Cross Section of Calcite Test Article. 


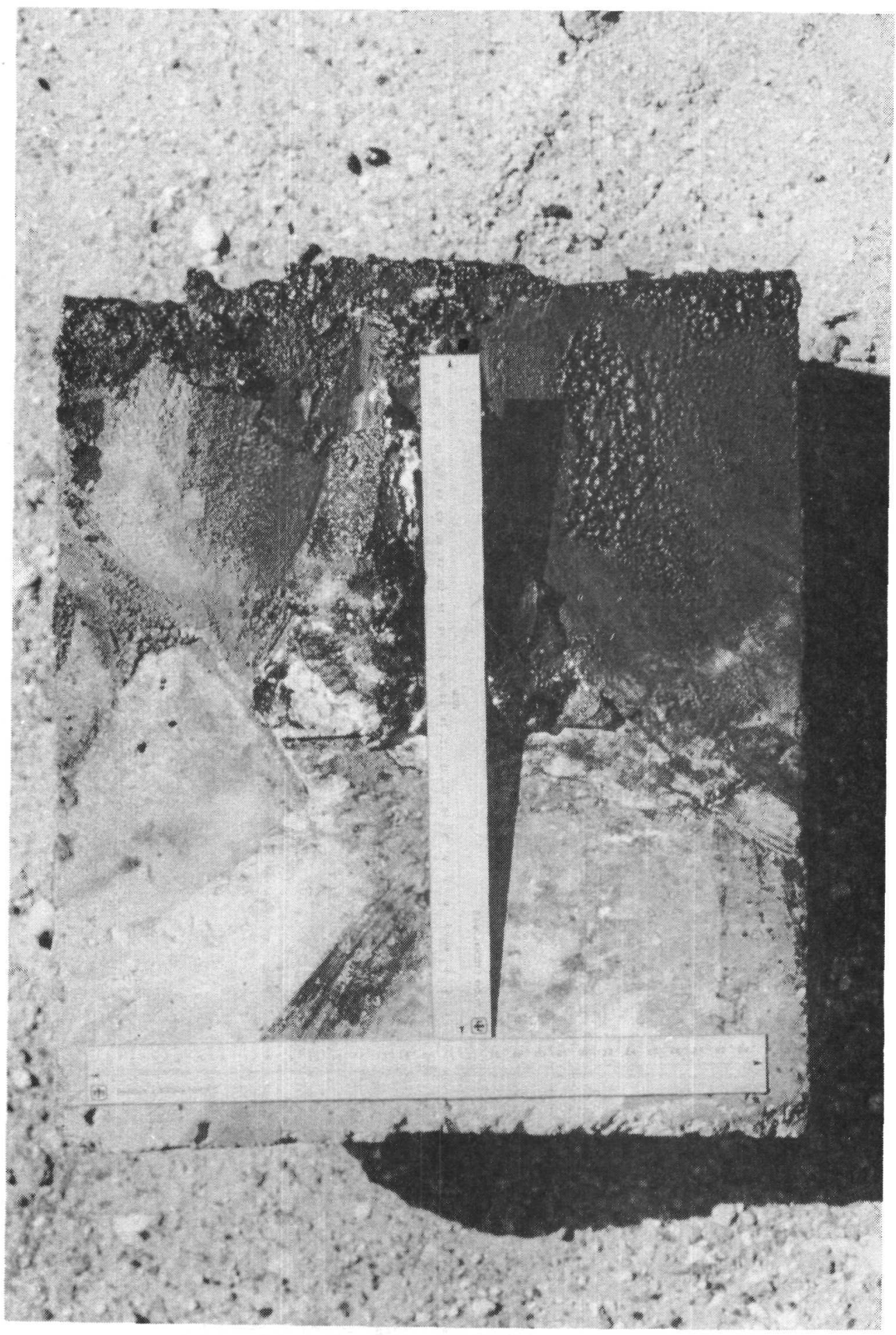

Figure 13. Cross-Sectioned Calcite Test Article (First Half) with Unreacted Sodium and Lower Portion of Concrete Removed. 
section of the debris on each half is somewhat uneven due to the final chiseling operation. A photograph of the second half of the test article is shown in Figure 14. A closeup photograph of the debris-concrete interface is shown in Figure 15. Even though the reaction front as a whole is quite non-planar, with a roughness approaching the penetration depth, the reaction front itself (e.g., the transition zone between unreacted concrete and debris) is on the order of millimeters in thickness.

The debris was very uniform in color and texture over its entirety except very close (within less than a centimeter) to the interface, that is, at the reaction front. The reader is cautioned, however, when interpreting these observations. It is extremely difficult to be certain that the appearance of the debris and/or reaction zone is as it was during the test and not an artifact of the cooldown period of the test. This is especially true in a situation such as the present test where the test time of 10 hours is relatively short in comparison to the cooldown period of three days. Reactions between the sodium or debris and the unreacted concrete no doubt continued to occur during the cooldown period.

The results from the chemical analyses of the two debris samples $A$ and $B$ are listed in Table 7 . There is a minor amount of free carbon in the debris. The majority of the carbon is present as a carbonate. The relative ratios of calcium and magnesium are typical of calcitic limestones where there is generally some magnesium. The major portion of the debris which does not appear in this chemical analysis is assumed to be $\mathrm{NaOH}$ which is possibly mixed with sodium and sodium hydride. $X-r a y$ diffraction analysis showed strong 


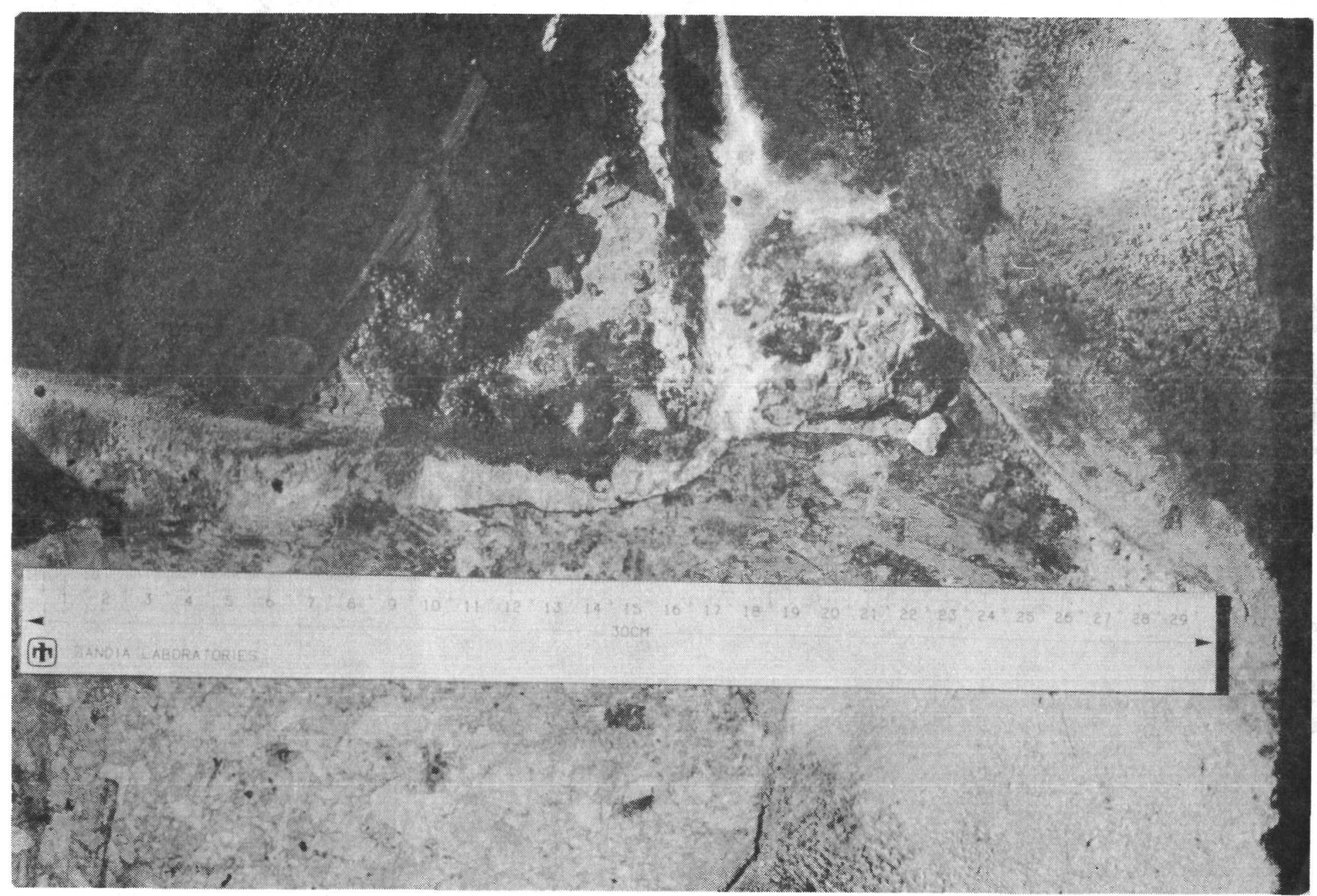

Figure 14. Sodium/Concrete Reaction zone in Calcite Test (Second Half). (Note Unevenness of Interface Between the Reaction Debris and Unreacted Concrete.) 


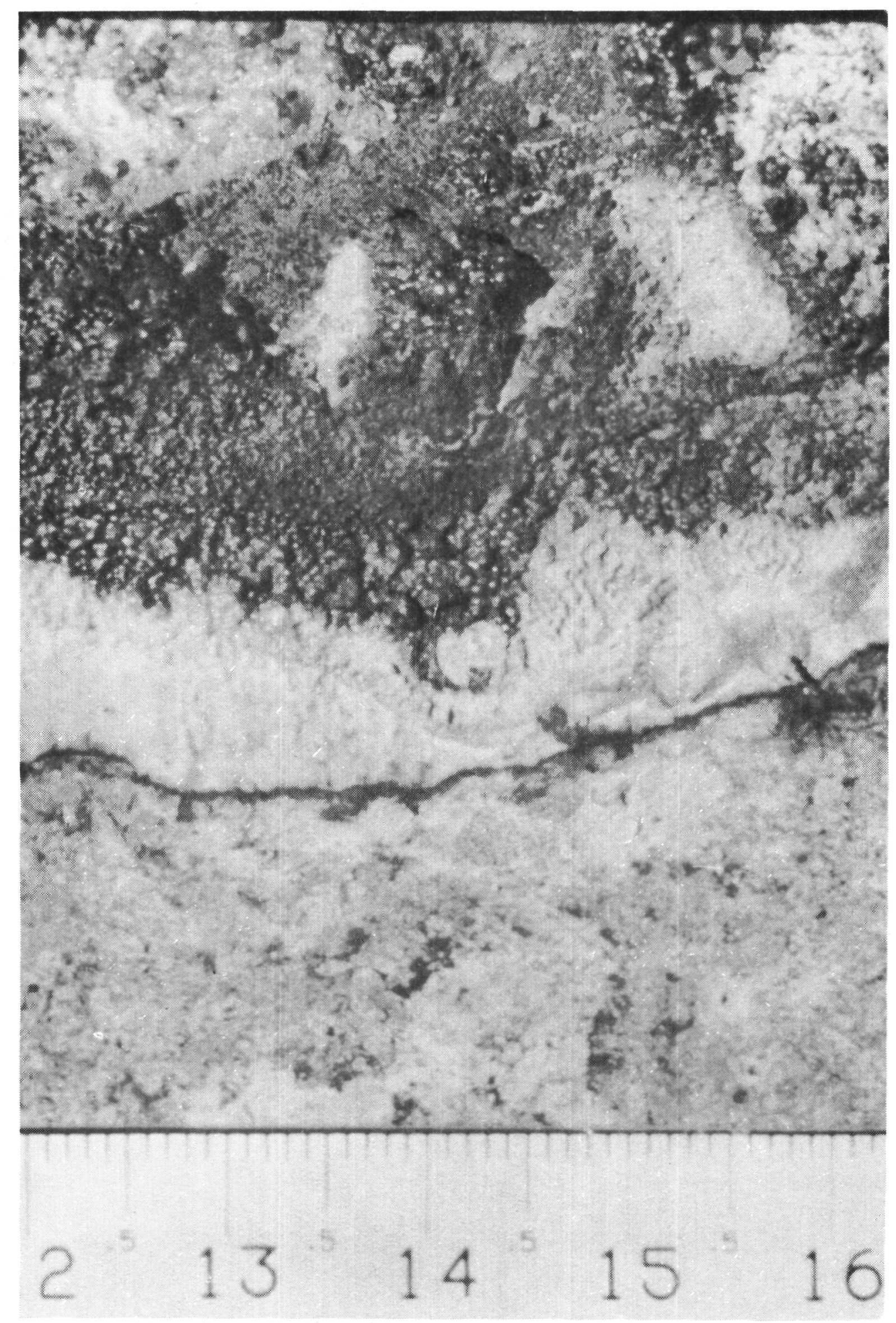

Figure 15. Closeup Photograph of Debris/Concrete Interface. (Note clear Demarcation Between Completely Reacted Debris and Unreacted Calcite Concrete.) 


\section{TABLE 7}

Chemical Analyses of Calcite and Dolomite Test Debris

$$
\text { Calcite Test }(w / 0)
$$

A

B

13.

$<0.1$

4.

1.1

$\mathrm{Na*}$

Insoluble $\pm \quad 0.4$
9.

0.5

13.5

3.

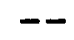

4.
A

10.

$<.1$

2 .

3.

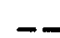

2.5
Dolomite Test $(w / 0)$

B

C

D

31

0.2

33.

8.

4.

37.

37.

1.3

2.5

17.

$* \quad \pm 1^{\mathrm{w}} / \mathrm{o}$

+ Non-carbonate $c$, actual results listed parenthetically $\pm .05^{w} / 0$

\pm insoluble residue following dilute $\mathrm{HCl}$ leach 
TABLE 8

X-Ray Diffraction Pattern of Calcite Test Debris

Lattice Spacings ( $(\AA)$ and Normalized $I / I_{0}$ Values*

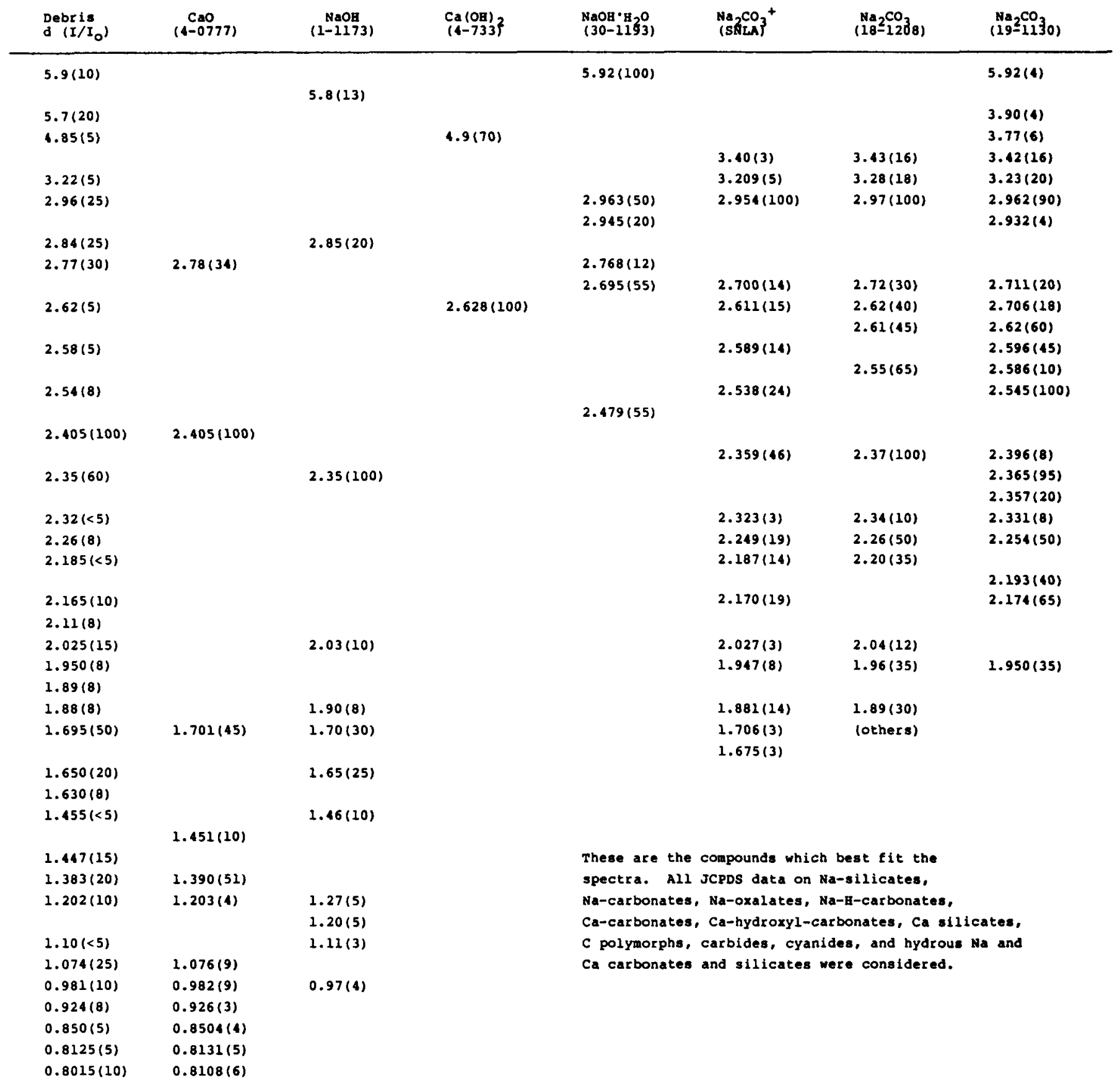

- I and $I / I_{0}$ values from Joint Committee on Powder Diffraction standards, PDF numbers shown in parentheses.

+ AR grade $\mathrm{Na}_{2} \mathrm{CO}_{3}$ fused at $950^{\circ} \mathrm{C}$, air cooled and powdered. 
lines for $\mathrm{NaOH}$, weak 1 ines for $\mathrm{CaO}$ and $\mathrm{Na}_{2} \mathrm{CO}_{3}$ and possible lines for $\mathrm{NaOH} \cdot \mathrm{H}_{2} \mathrm{O}$ (Table 8 ). The $\mathrm{x}$-ray diffraction patterns showed no evidence of crystalline $\mathrm{Na}_{2} \mathrm{O}$. The combined results of the chemical and $x-r$ ay diffraction analyses of the debris show that the majority of the carbon is present as a carbonate and that this carbonate is $\mathrm{Na}_{2} \mathrm{CO}_{3}$. The main products of the interaction, therefore, appear to be $\mathrm{NaOH}$, $\mathrm{Na}_{2} \mathrm{CO}_{3} \mathrm{CaO}$, and $\mathrm{MgO}$.

At the time of cross-sectioning, the reaction debris was a rigid solid. Since the debris was a mixture of $\mathrm{NaOH}$ and various oxides, at test temperatures, it no doubt was a fluid. To further characterize the physical properties of the debris, the high temperature viscosity of a debris sample was measured. As outlined in the appendix, the viscosity was a function of temperature and shear rate. The viscosity was fairly constant at about 2300 centipoise in the temperature range of 550 to $595^{\circ} \mathrm{C}$.

The test was terminated after 10 hours because of safety concerns which resulted from the sodium fire on top of the test article. The fire was caused by sodium or sodium vapor leaking from the test article near the sodium transfer line. When the test fixturing was dismantled the vent system was found to be blocked by an aerosol plug. The plug had formed at the inlet to the $5 \mathrm{~cm}$ pipe used as the vent line on the test article. Figure 16 shows the plug. The aerosol material was metallic gray. $X-r a y$ diffraction analysis identified it as sodium metal. Downstream from the aerosol plug, the aerosol which settled in the vent line was dull gray and very porous. Scanning electron microscope (SEM) photographs of the material collected $66 \mathrm{~cm}$ downstream from 
the plug are shown in Figure 17. The primary particle size is approximately one micron.

\section{Dolomite Test}

The dolomite test was similar in most respects to the calcite test. A minor modification, which consisted of adding one more $5 \mathrm{~cm}$ vent line in parallel to the existing line (as described in the procedures section) was made to the test article vent system in order to avoid plugging.

The sodium charge, preheated to $750^{\circ} \mathrm{C}$, was transferred to the test article when the surface temperature of the concrete reached $95^{\circ} \mathrm{C}$. The desired and actual pool heatup curves are shown in Figure 5. The time-temperature histories recorded by the thermocouples in the sodium pool, vapor space, and concrete are shown in Figures 18 and 19. The temperatures in the pool and vapor space during the heatup and isothermal portions of the test are similar to that for the calcite test. The fluctuations noted in the pool and vapor space thermocouples at 16 hours were caused by corrosive failure of thermocouples. Similar wild fluctuations were noted for the pool thermocouple in Figure 9. In this type of service, thermocouples tend to remake new junctions at random locations along their length. Temperatures become erratic during this process and after the new junction is made the new temperature may not be indicative of the true temperature near the tip of the thermocouple or even at the new junction.

The concrete temperatures show only one period of vigorous exothermic reaction during the test (Figure 19). The reaction was first noted by the $1.3 \mathrm{~cm}$ thermocouple at 


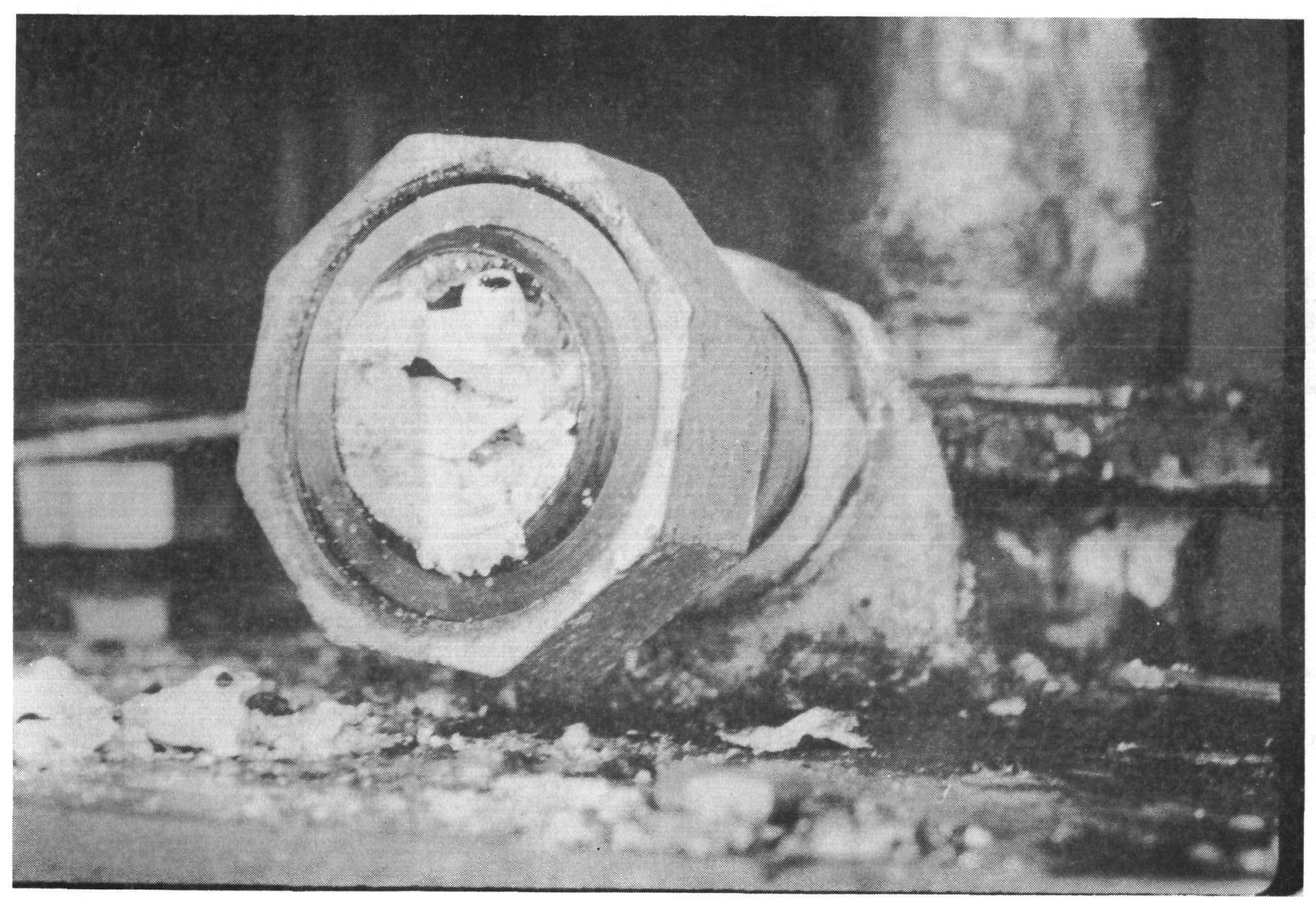

Figure 16. Aerosol Plug in Vent Line of Calcite Test Article. 

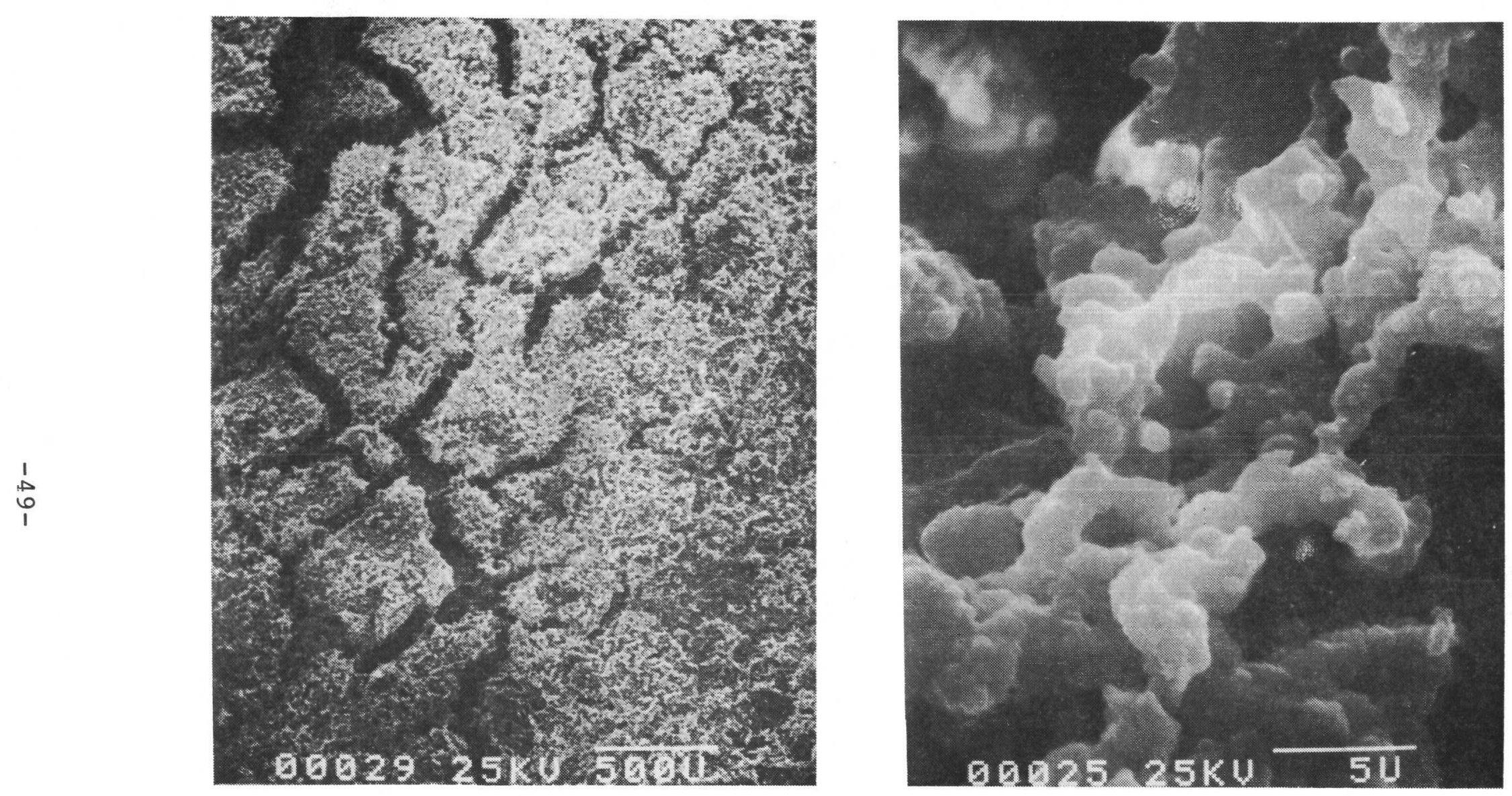

Figure 17. Scanning Electron Micrographs of Aerosol from Calcite Test, a) $35 \mathrm{x}$, b) $4000 \mathrm{x}$. 


\section{DOLONITE TEST \\ POOL AND VAPOR SPACE TEMPERATURES}

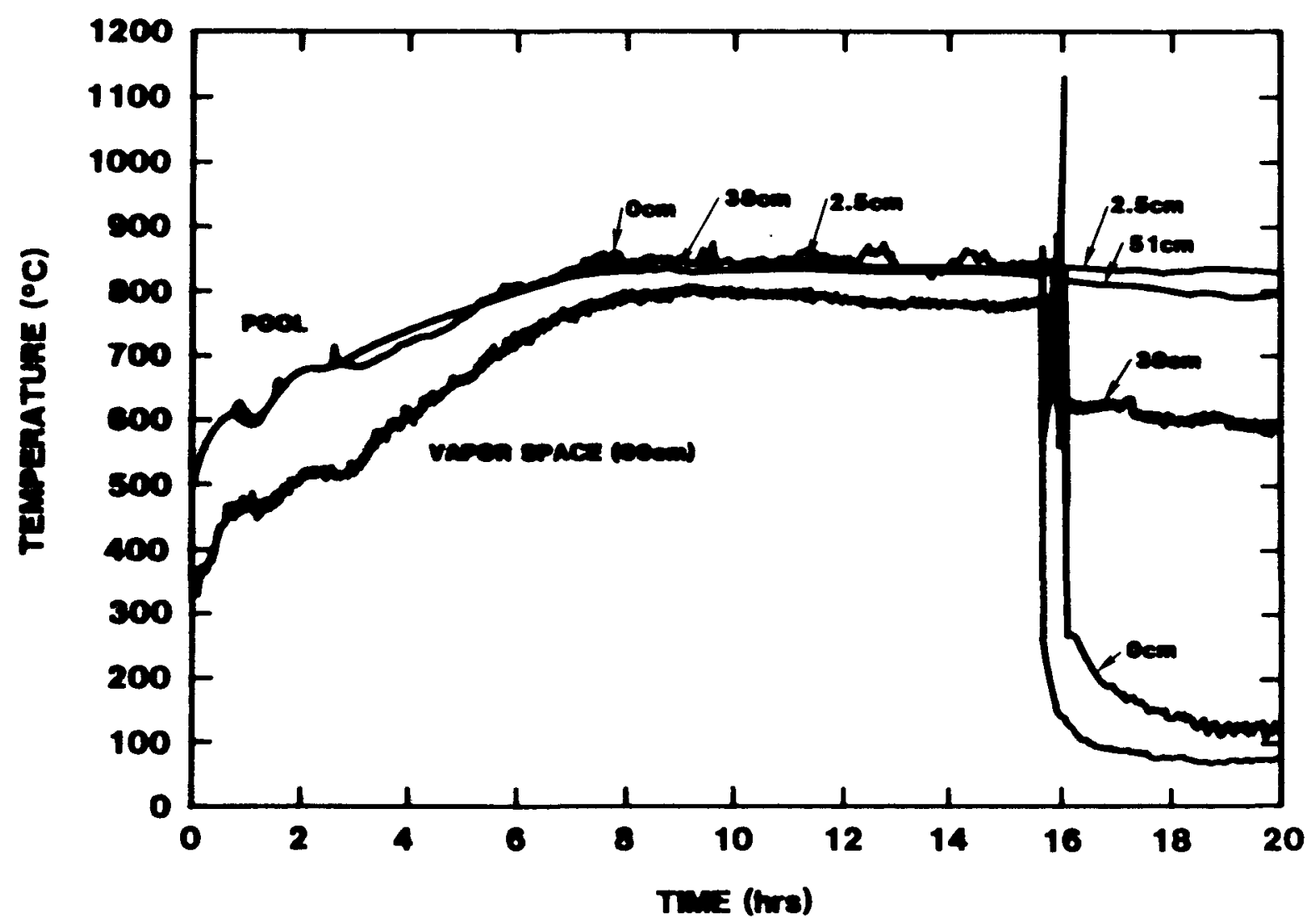

Figure 18. Dolonite Test, Pool and Vapor Space Thermocouple Data. 


\section{DOLOMITE TEST \\ POOL AND CONCRETE TEMPERATURES}

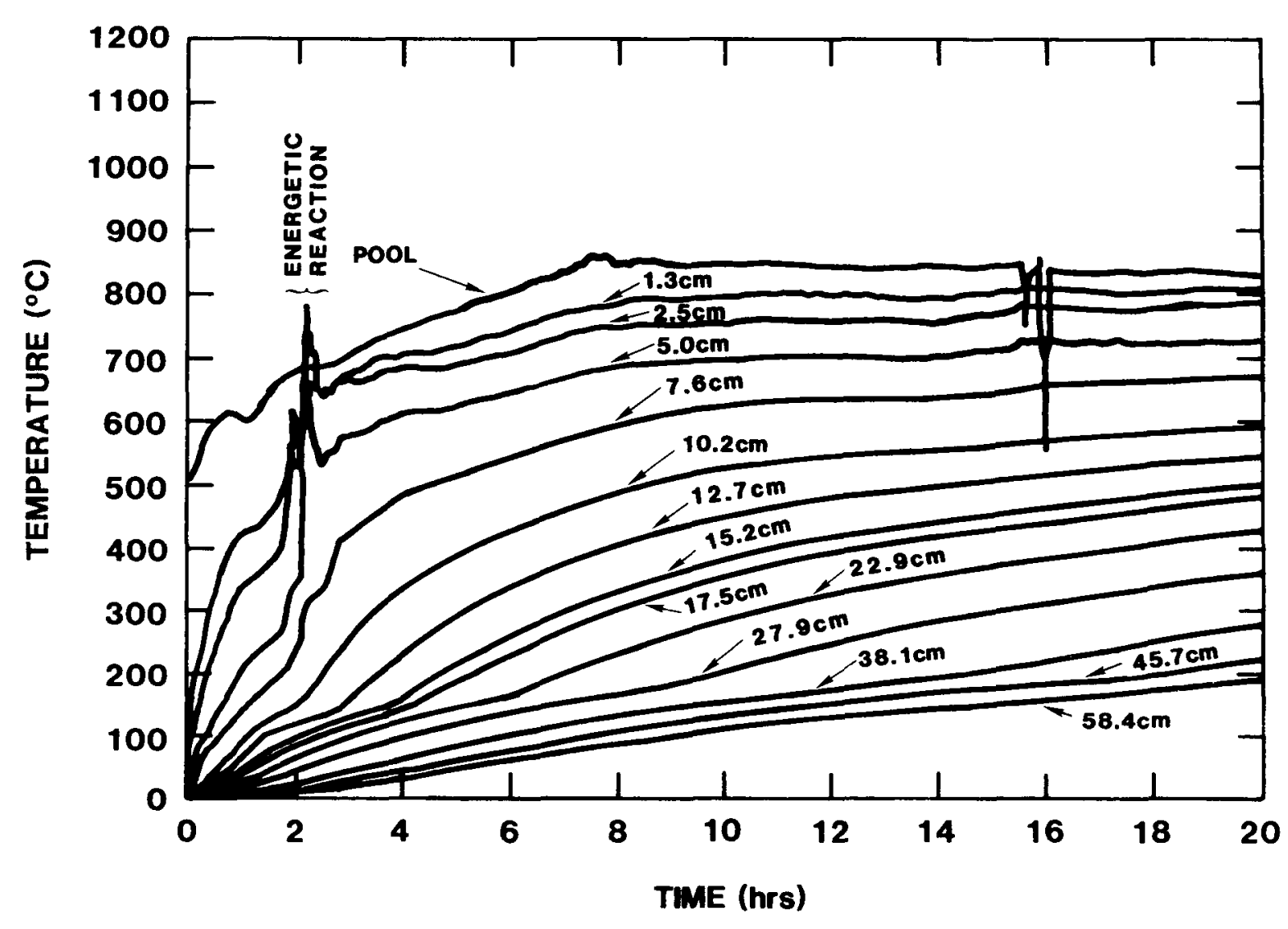

Figure 19. Dolomite Test, Concrete Thermocouple Data. 
DOLOMITE TEST

CONCRETE TEMPERATURES

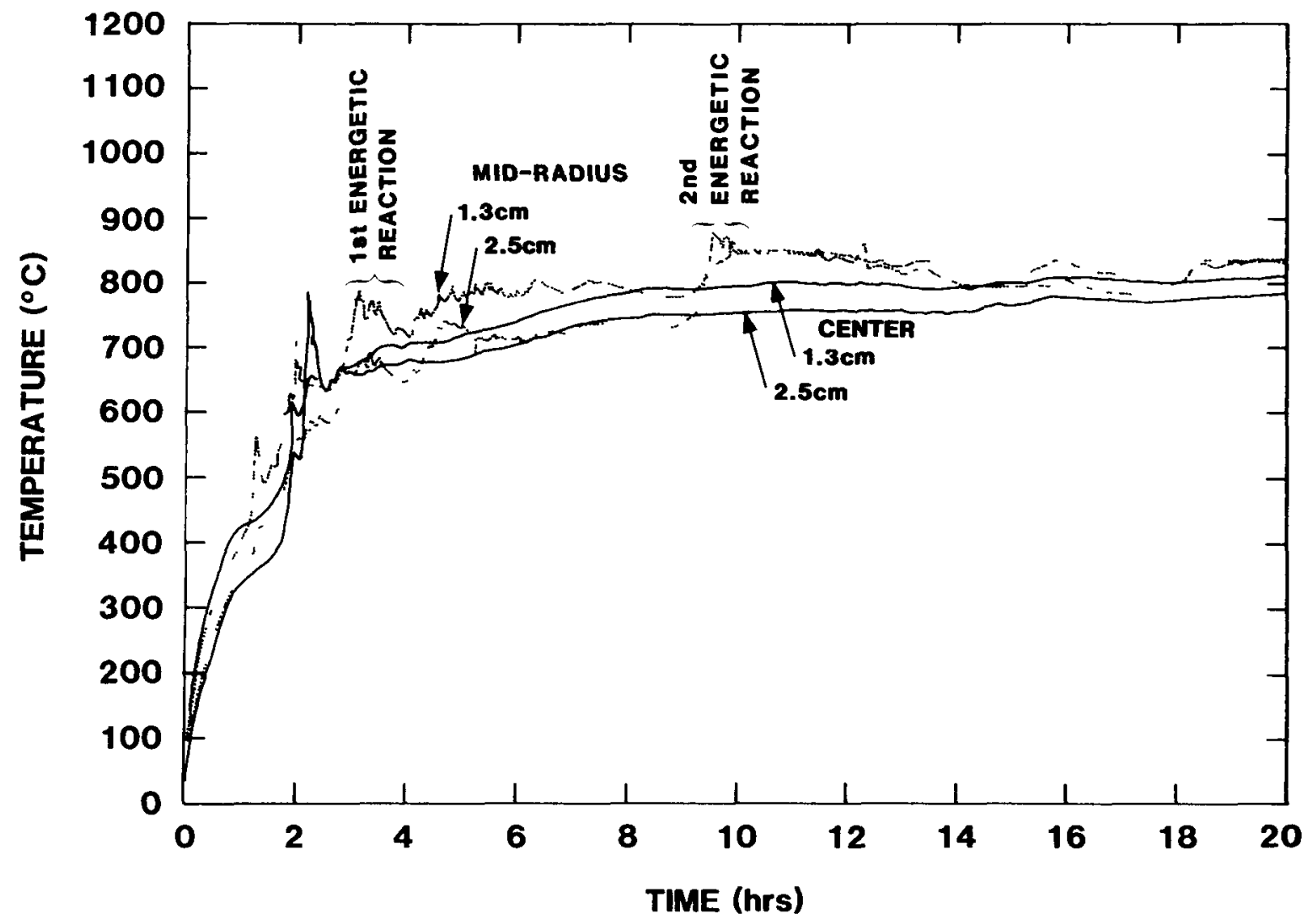

Figure 20. Dolomite Test, Thermocouple Data for Centerline

and Mid-radius Thermocouples Located at 1.3 and $2.5 \mathrm{~cm}$

Beneath original Interface. 
1.9 hours. The total duration of the reaction was 35 minutes. The peak temperature in the concrete during this reaction was $790^{\circ} \mathrm{C}$ when the pool temperature was $690^{\circ} \mathrm{C}$. The thermocouples recorded the movement of the reaction front from 1.3 to $5.0 \mathrm{~cm}$ in 27 minutes. This corresponds to a penetration rate during this period of $1.4 \mathrm{~mm} / \mathrm{min}$. The longterm temperature response of the thermocouples located near the surface in the dolomite test is not similar to the response shown for the calcite test. It is not clear from the temperature data of the uppermost thermocouples when, or if, the thermocouples in the dolomite concrete entered the advancing pool which was at a very uniform temperature (Note, for example, the $\Delta \mathrm{T}$ maintained between these thermocouples in Figure 19. This $\Delta \mathrm{T}$ is not seen in Figure 7). The temperature excursions noted by the thermocouples at approximately two hours in the dolomite test indicate that the reaction front had penetrated at least to a depth of 5 $\mathrm{cm}$. The $7.6 \mathrm{~cm}$ thermocouple responded to the exothermic reactions which occurred during the time period between two and three hours, but apparently did not experience the exothermic reaction itself. Thermocouple responses, therefore, indicate that the penetration during the test was between 5 and $7.6 \mathrm{~cm}$.

The temperatures recorded by the 1.3 and $2.5 \mathrm{~cm}$ thermocouples located at the mid-radius position are compared with the temperatures recorded by the corresponding center thermocouples in Figure 20. The data are quite similar. Some evidence of exothermic reaction was noted by the mid-radius thermocouples at about three and nine hours as noted in Figure 20. The relative temperature differences with respect to the pool temperature are much smaller than 
DOLOMITE TEST

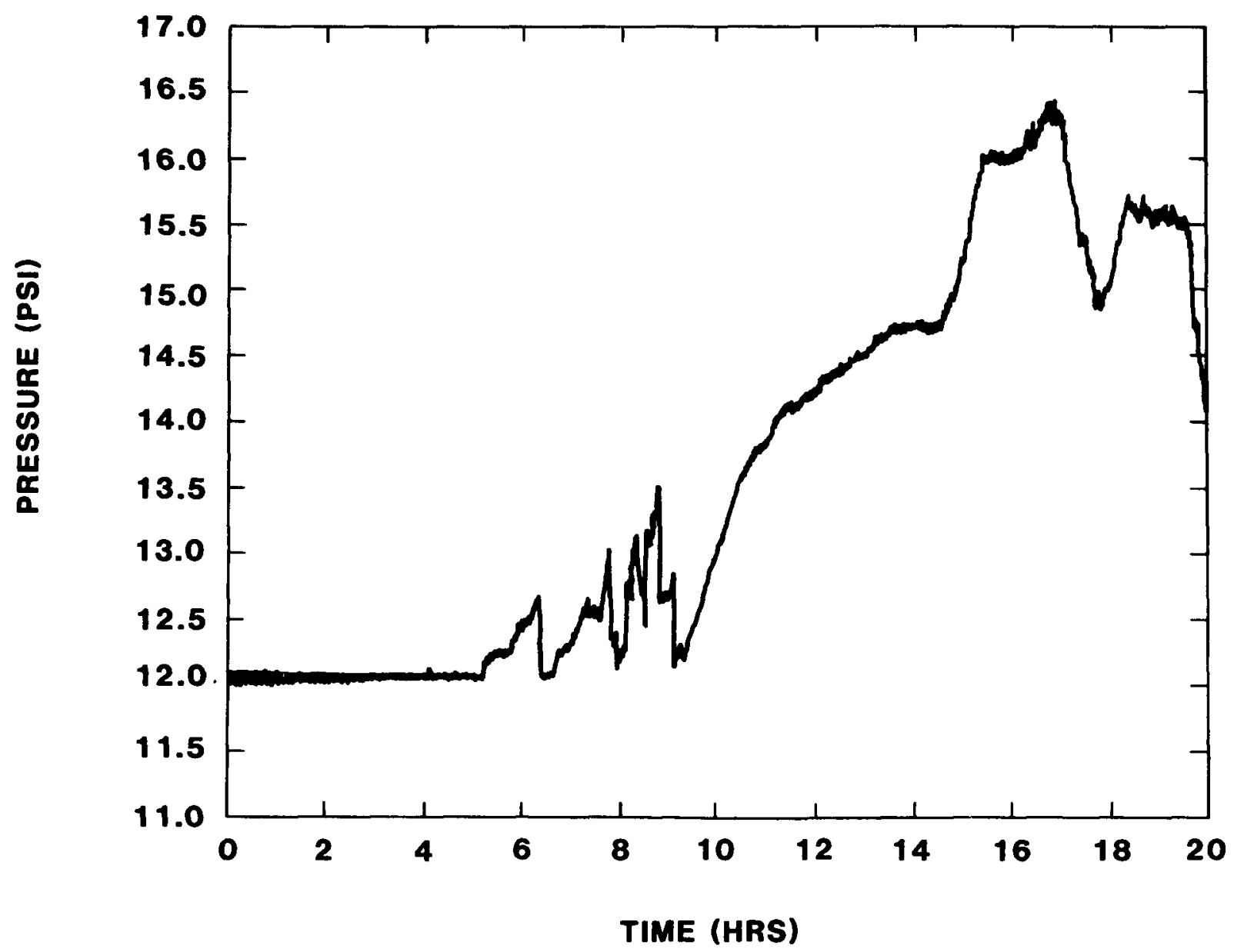

Figure 21. Dolomite Test, Internal Pressure. 


\section{DOLOMITE TEST}

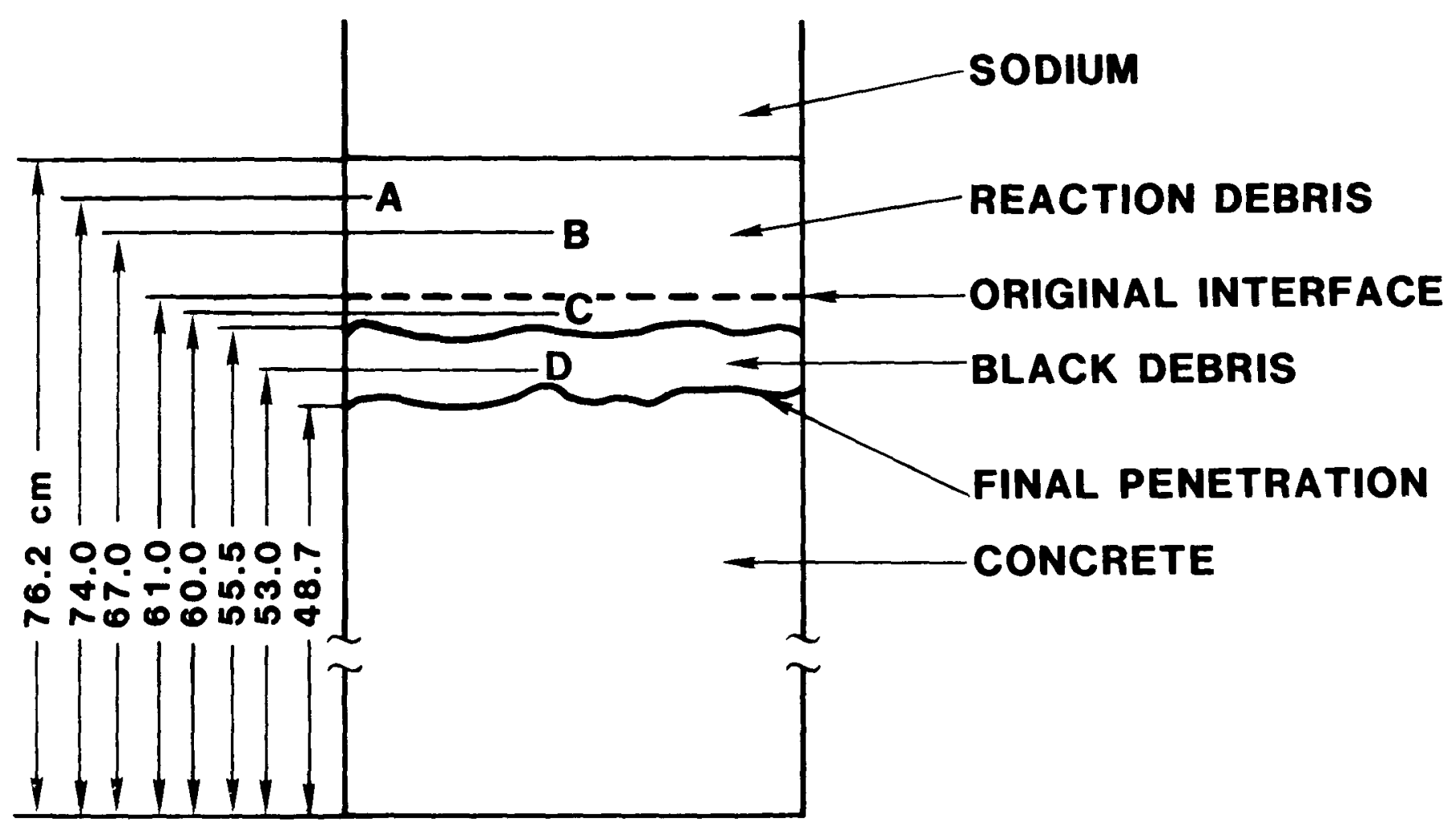

Figure 22. Schematic Cross Section of Dolomite Test Article. 
for the period of vigorous reaction noted by the center thermocouples at 1.9 hours.

No hydrogen gas generation data were recorded for this test. Although additional precautions had been taken in insulating and locating the leak valve for the mass spectrometer system, the gas data were erratic from the first few minutes of the test. It was later determined that this was due to an overheating failure of the leak valve and possible overheating of the spectrometer RF sensing head.

The internal pressure of the test article was monitored because of the difficulties encountered with pressurization of the calcite test. Figure 21 shows the pressure (reported in psia for clarity) for the test. Minor amounts of erratic pressurization occurred between five and nine hours. Apparently the two vent lines which were used in this test started plugging at this time but the plugs were not massive enough to maintain pressure in the test article. When the pressure rose a small amount, the plugs were blown free and the vent lines again became operational. By nine hours, however, the aerosol plugs that were forming in the vent lines were massive enough to maintain a significant pressurization of the test article. The maximum pressure recorded in the test article during the test was 16.3 psia (1.1 bars). The drop in the test article pressure at later times was probably due to leaks which formed at the various metal o-rings and seals.

The test article was cooled in the test chamber for three days. The test fixturing was then dismantled and the test article removed. The procedure used for sectioning the dolomite test article was the same as that for the calcite 
test. A schematic of the cross section of the dolomite test article is shown in Figure 22. The unreacted sodium which was removed from the debris appeared to be relatively pure metallic sodium. There were two layers of debris between the unreacted concrete and sodium. The reaction debris, as labeled in Figure 22, was dull gray in appearance and reacted with air similar to the calcite test debris. The reaction with air, however, was much slower than the reaction of the calcite test debris. This was possibly caused by a change in relative humidity on the day the dolomite test was cut. The gray debris layer was $20.7 \mathrm{~cm}$ thick (see Table 10 and Figure 22). It was hard and samples which were taken from it for chemical analysis (labeled A, B, and C in Figure 22) had to be chiseled free. Below this layer of debris was a partially blackened layer which consisted of black reaction debris and clasts of partially reacted and unreacted dolomite aggregate. The black debris layer was $6.8 \mathrm{~cm}$ thick. Sample D (Figure 22) was taken from this layer for analysis. Figures 23 and $24 a-c$ show the gray reaction debris and black debris layers. Figure 25 is a high magnification photograph of the left hand portion of the cross section shown in Figures 23 and $24 a$. It shows completely reacted clasts of large and small aggregate in the black debris layer near the gray debris but only partially reacted clasts near the unreacted concrete.

The final penetration was measured at 14 equally spaced points on each half of the cross-sectioned test article. Because of the presence of the two debris layers, two penetrations were measured. The penetration, as measured from the pretest concrete-sodium interface, to the bottom of the gray debris layer was $5.5 \pm 2.9 \mathrm{~cm}(958$ confidence level). The penetration to the bottom of the black debris e.g., the unreacated concrete was $12.3 \pm 2.9 \mathrm{~cm}$. 


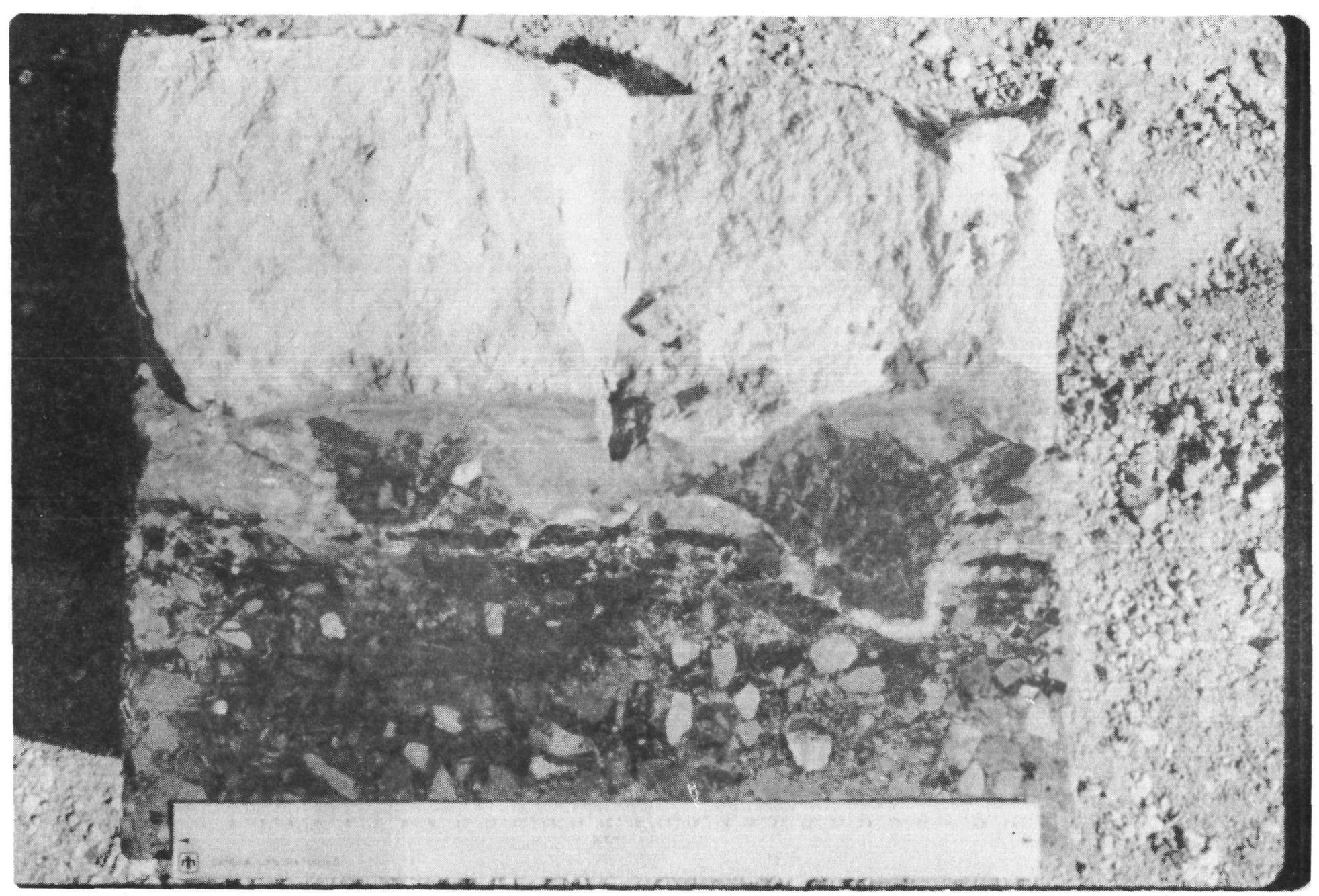

Figure 23. Cross-Sectioned Dolomite Test Article, Excess Unreacted Sodium, and Bottom Portion of Concrete Test Article Have Been Removed. 


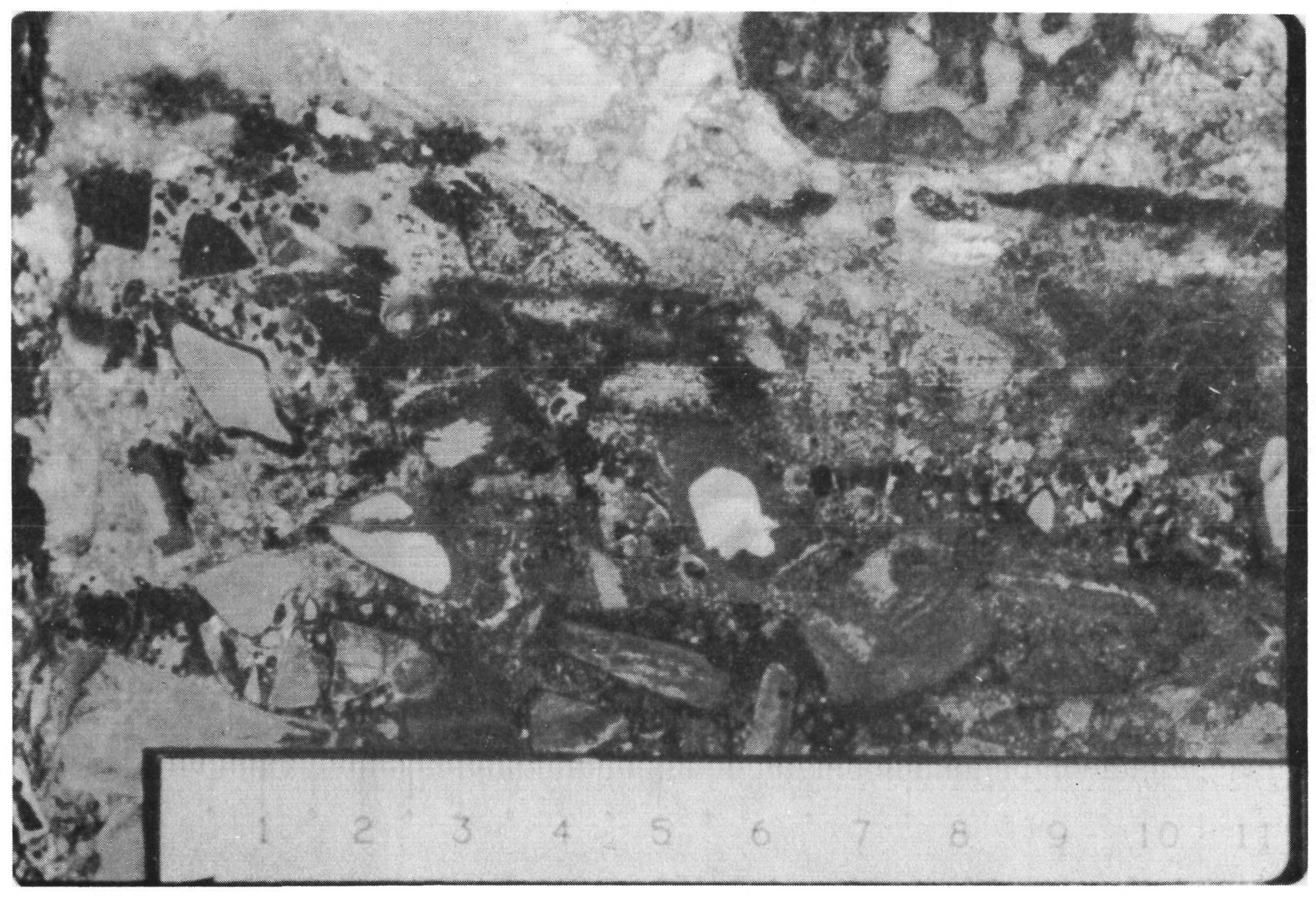

Figure 24. Higher Magnification View of Reaction zone in Dolomite Test, a)-c) Sequential Photographs Taken Left to Right on Figure 23. 


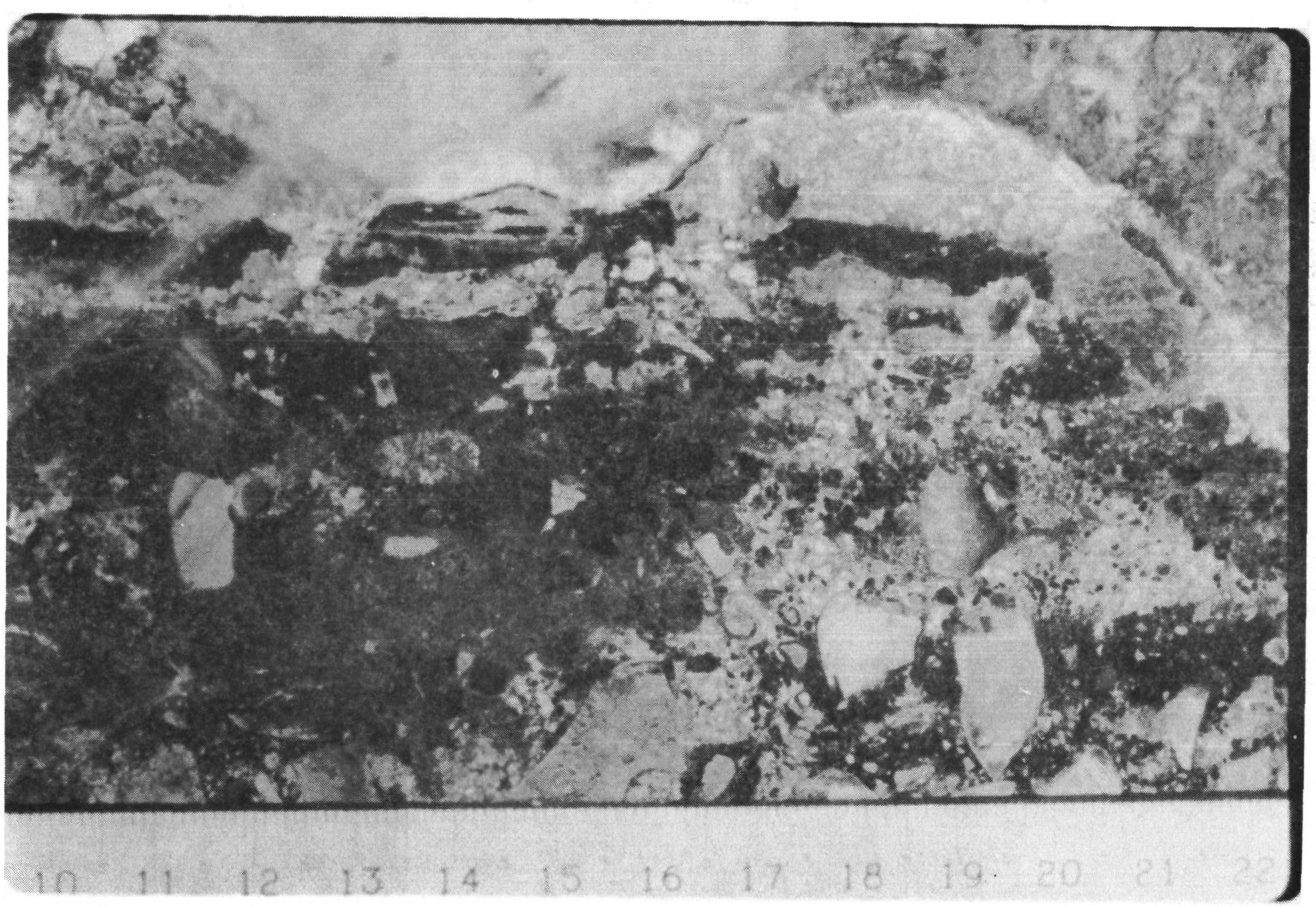

Figure 24b. 


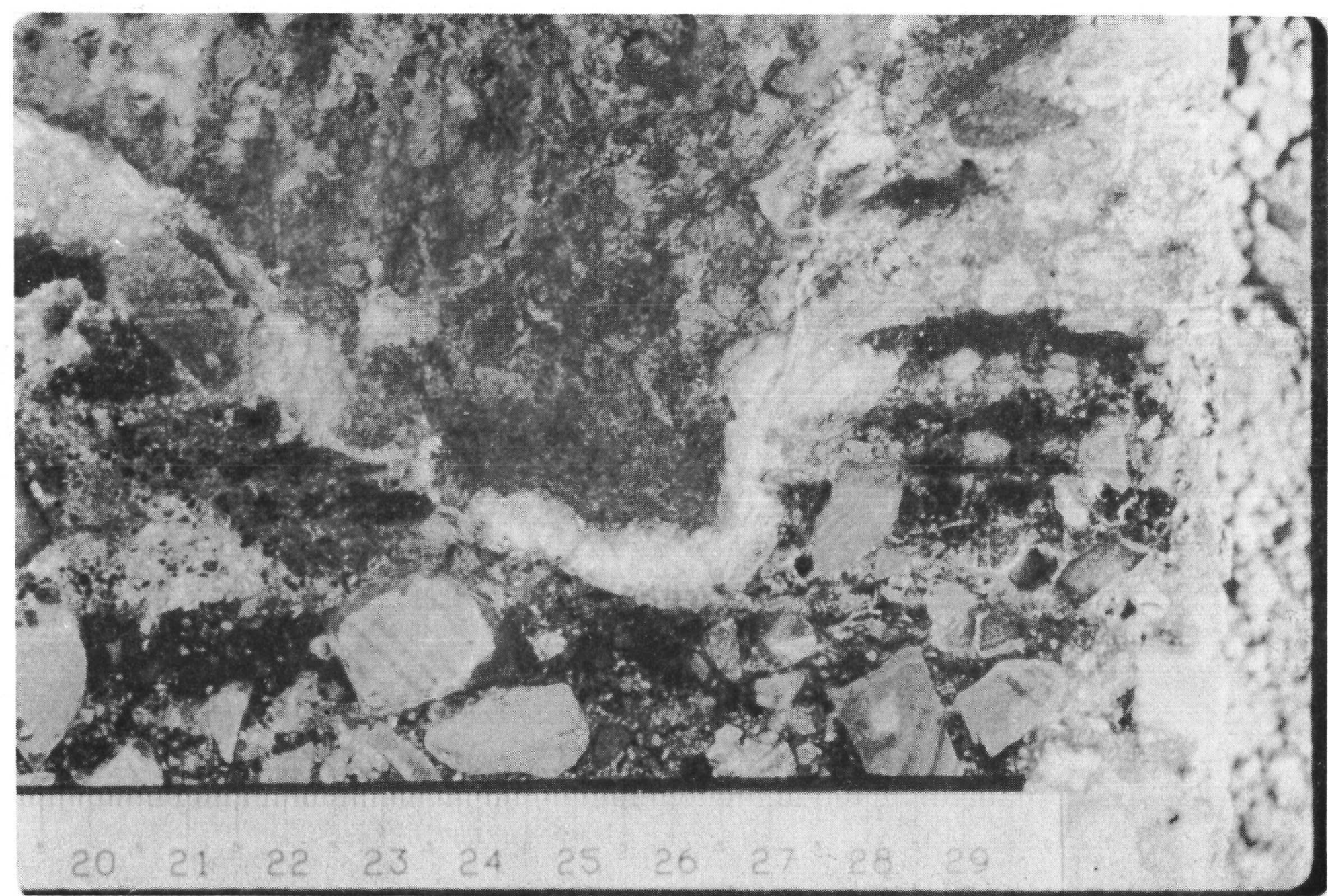

Figure 24c. 


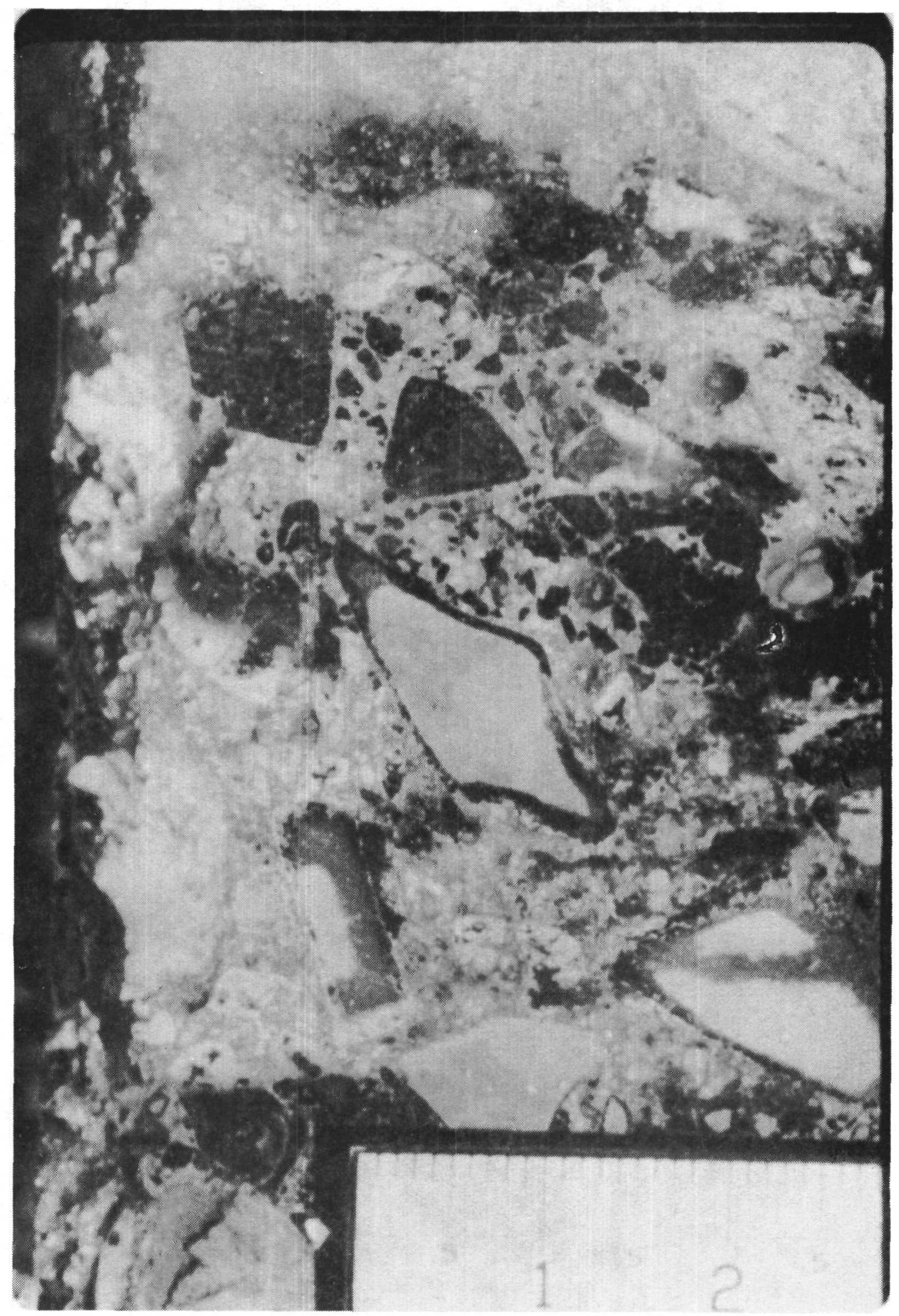

Figure 25. Closeup Photograph of Black Debris Layer Dolomite Test 
Samples from both layers of the debris (noted as A, B, $\therefore$, and $D$ in Figure 22) obtained for chemical and $x-r a y$ diffraction analyses samples were sealed in glass vials with an argon cover gas immediately after the test article was sectioned.

The $\mathrm{CO}_{2}, \mathrm{C}, \mathrm{Ca}, \mathrm{Mg}$, and $\mathrm{Na}$ compositions of the reaction debris samples are listed in Table 7. Very little free carbon is present in the debris. Most of the carbon is present as $\mathrm{CO}_{2}$, indicating the presence of a carbonate. Sample $D$, taken from the black debris layer, contained very little Na and was mostly unreacted dolomite. The major crystalline phases in the gray debris identified by $x-r a y$ diffraction analysis were $\mathrm{NaOH}$ and $\mathrm{Na}_{2} \mathrm{CO}_{3}$ (Table 9). No diffraction lines were found for $\mathrm{Na}_{2} \mathrm{O}, \mathrm{CaO}$, or $\mathrm{MgO}$ although the $\mathrm{NaOH}$ lines would mask the major $\mathrm{CaO}$ lines. The combined results of the chemical analyses and $x$-ray diffraction analysis indicate that the major phases in the gray debris are $\mathrm{NaOH}, \mathrm{Na}_{2} \mathrm{CO}_{3}, \mathrm{CaO}$, and $\mathrm{MgO}$. The black layer consists of partially reacted concrete with a minor amount of $\mathrm{NaOH}$ or $\mathrm{Na}_{2} \mathrm{CO}_{3}$.

When the vent system was dismantled, large plugs were found blocking both $5 \mathrm{~cm}$ vent lines. A schematic diagram of the vent system is shown in Figure 26. In the main vent line (the same vent line used for the calcite test) a solid plug was found which started at $10 \mathrm{~cm}$ and extended to $66 \mathrm{~cm}$ away from the test article. In addition, a small semi-solid plug had formed at the inlet to the auxiliary vent line. Photographs of the aerosol deposits, taken at positions $A$ through $E$ as noted on Figure 26, are shown in Figures $27 a$ through e respectively. Little condensed aerosol was found inside the test article. X-ray diffraction analysis of the 


\section{TABLE 9}

X-Ray Diffraction Patterns of Dolomite Test Debris, Lattice spacings $\left(\stackrel{\circ}{)}\right.$ and Normalized $I / I_{0}$ Values*

\begin{tabular}{|c|c|c|}
\hline $\begin{array}{l}\text { Debris } \\
\text { d }\left(I / I_{0}\right)\end{array}$ & $\begin{array}{c}\mathrm{NaOH} \\
(1-1173)\end{array}$ & $\mathrm{Na}_{2}^{\mathrm{SNLA}_{3}}{ }^{+}$ \\
\hline $5.7(40)$ & $5.8(13)$ & \\
\hline $3.41(<5)$ & & $3.40(3)$ \\
\hline $3.22(5)$ & & $3.209(5)$ \\
\hline $2.96(15)$ & & $2.954(100)$ \\
\hline $2.84(60)$ & $2.85(20)$ & \\
\hline $2.70(5-10)$ & & $2.700(14)$ \\
\hline $2.61(10-15)$ & & $2.611(15)$ \\
\hline $2.53(10-15)$ & & \\
\hline $2.35(100)$ & $2.35(100)$ & $2.359(46)$ \\
\hline $2.25(5-10)$ & & $2.249(19)$ \\
\hline & & $2.187(14)$ \\
\hline $2.175(15)$ & & $2.170(19)$ \\
\hline $2.13(<5)$ & & \\
\hline $2.025(20)$ & $2.03(10)$ & $2.027(3)$ \\
\hline $1.95(5-10)$ & & $1.947(8)$ \\
\hline $1.89(15-20)$ & $1.90(8)$ & $1.881(14)$ \\
\hline $1.695-1.700(40)$ & $1.70(30)$ & $1.706(3)$ \\
\hline $1.65(50)$ & $1.65(25)$ & $1.675(3)$ \\
\hline $1.625(5)$ & & \\
\hline $1.535(<5)$ & & \\
\hline $1.515(<5)$ & & \\
\hline $1.48(<5)$ & & \\
\hline $1.456(25)$ & $1.46(10)$ & \\
\hline $1.385(<5)$ & & \\
\hline $1.345(5)$ & $1.35(2)$ & \\
\hline $1.265(15)$ & $1.27(5)$ & \\
\hline $\begin{array}{l}\text { * I and I/I values from } \\
\text { Diffraction standards, }\end{array}$ & \multicolumn{2}{|c|}{$\begin{array}{l}\text { Joint Committee on Powder } \\
\text { PDF numbers shown in parentheses. }\end{array}$} \\
\hline
\end{tabular}




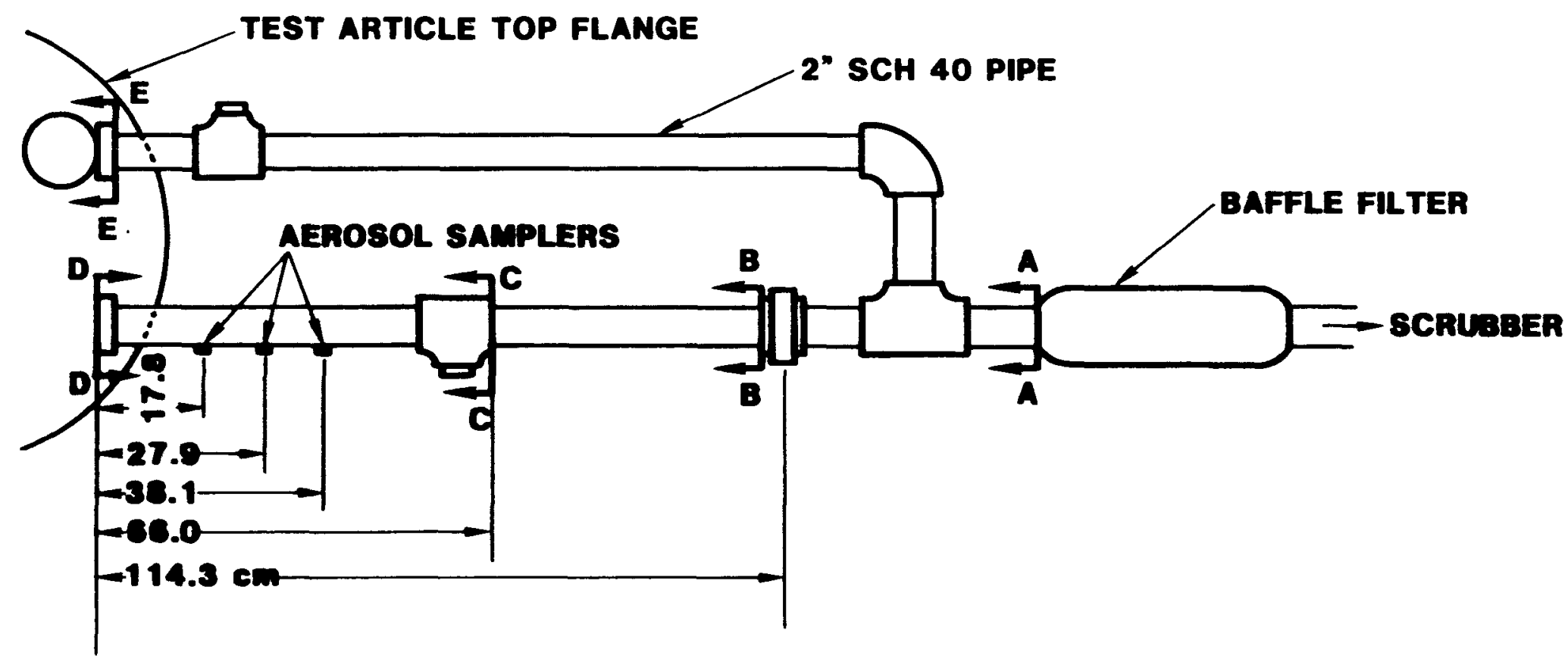

Figure 26. Modified Vent System for Dolomite Test. Lettered Sections Correspond to Photographs in Figure 27. 

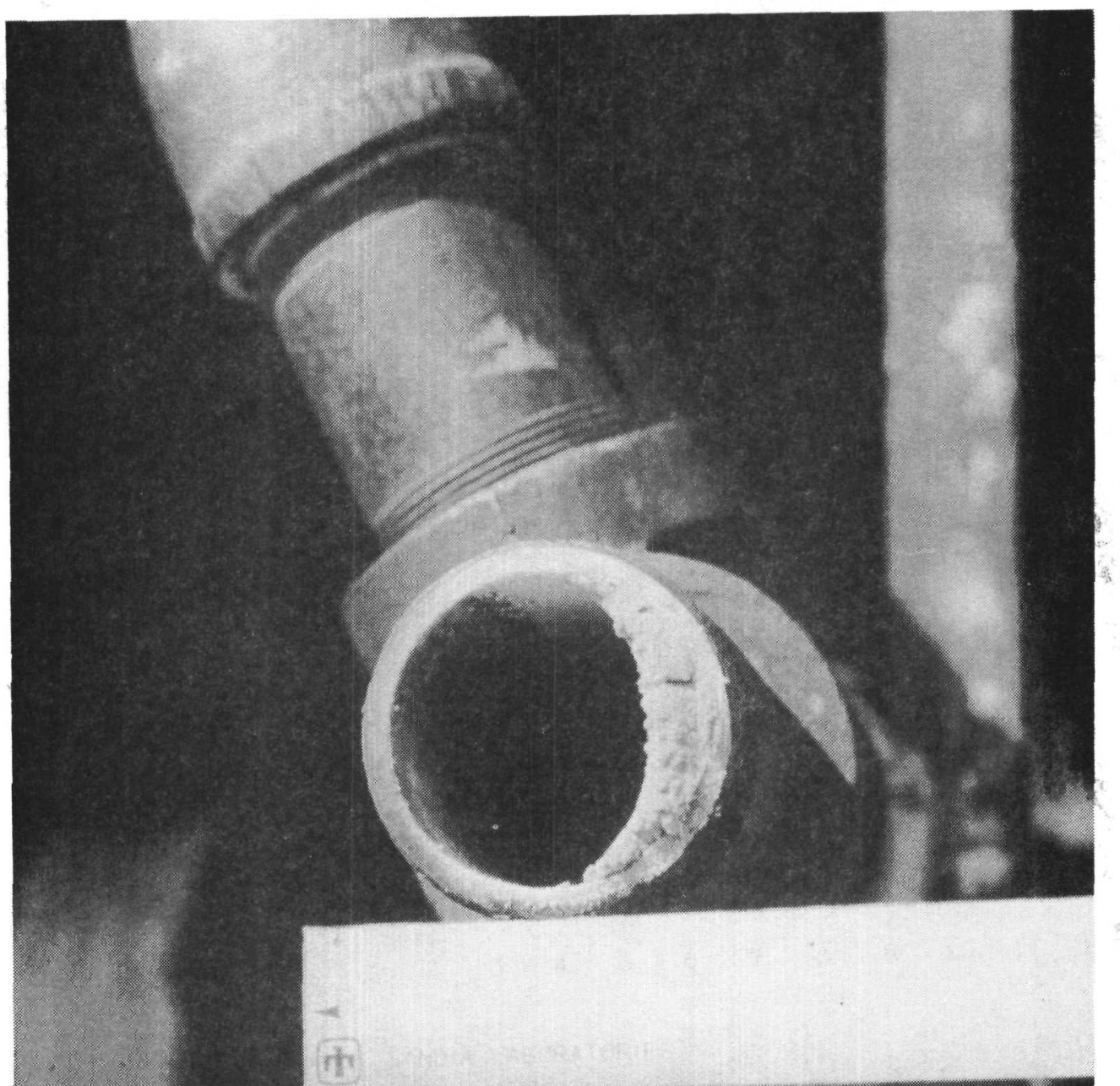

Figure 27. Aerosol Deposited in Main Vent Line (a-d) and Secondary Vent Line (e) a) section AA, b) Section BB, c) Section CC, d) Section DD, e) Section EE, as noted in Figure 26. 


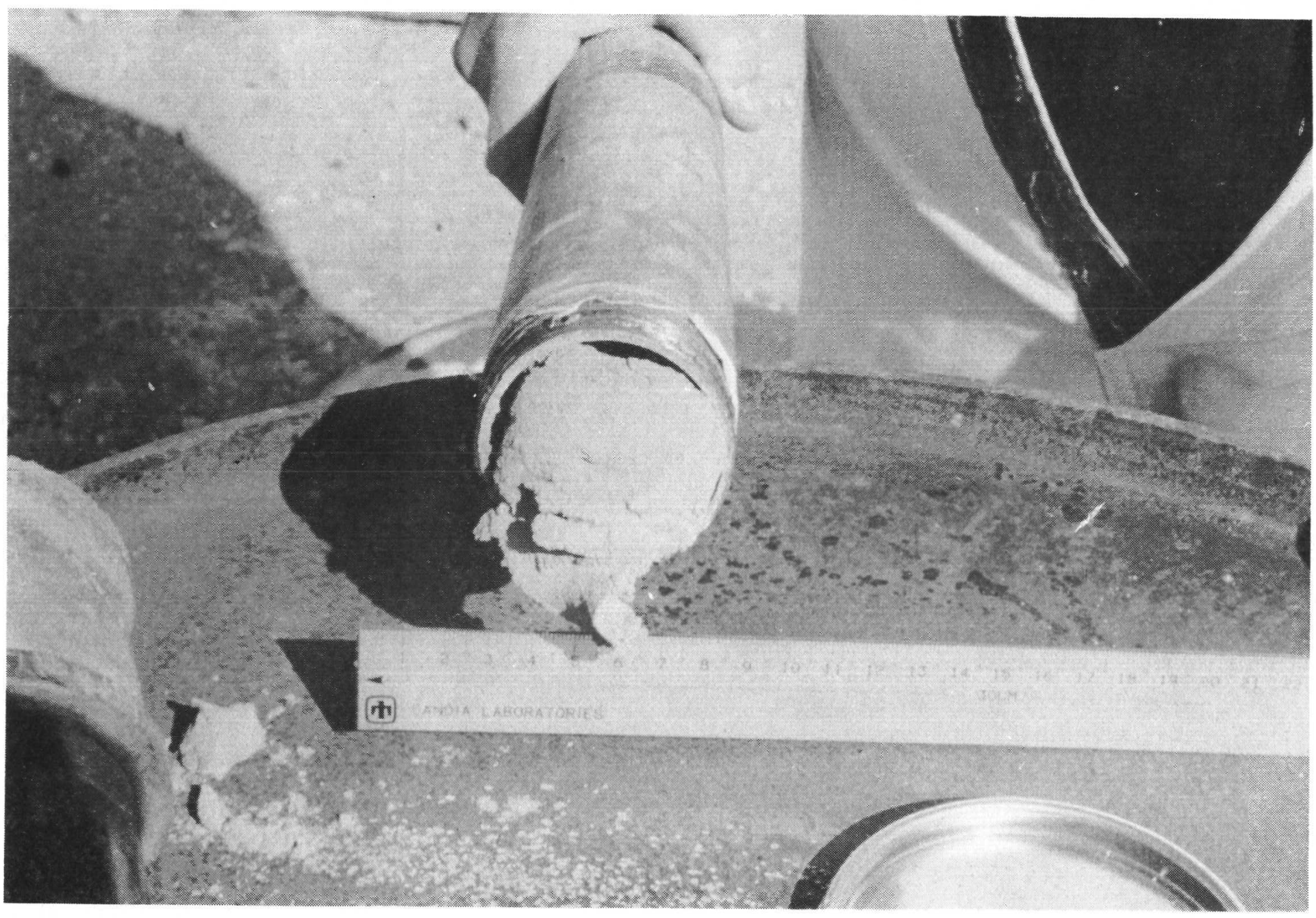

Figure 27b. 


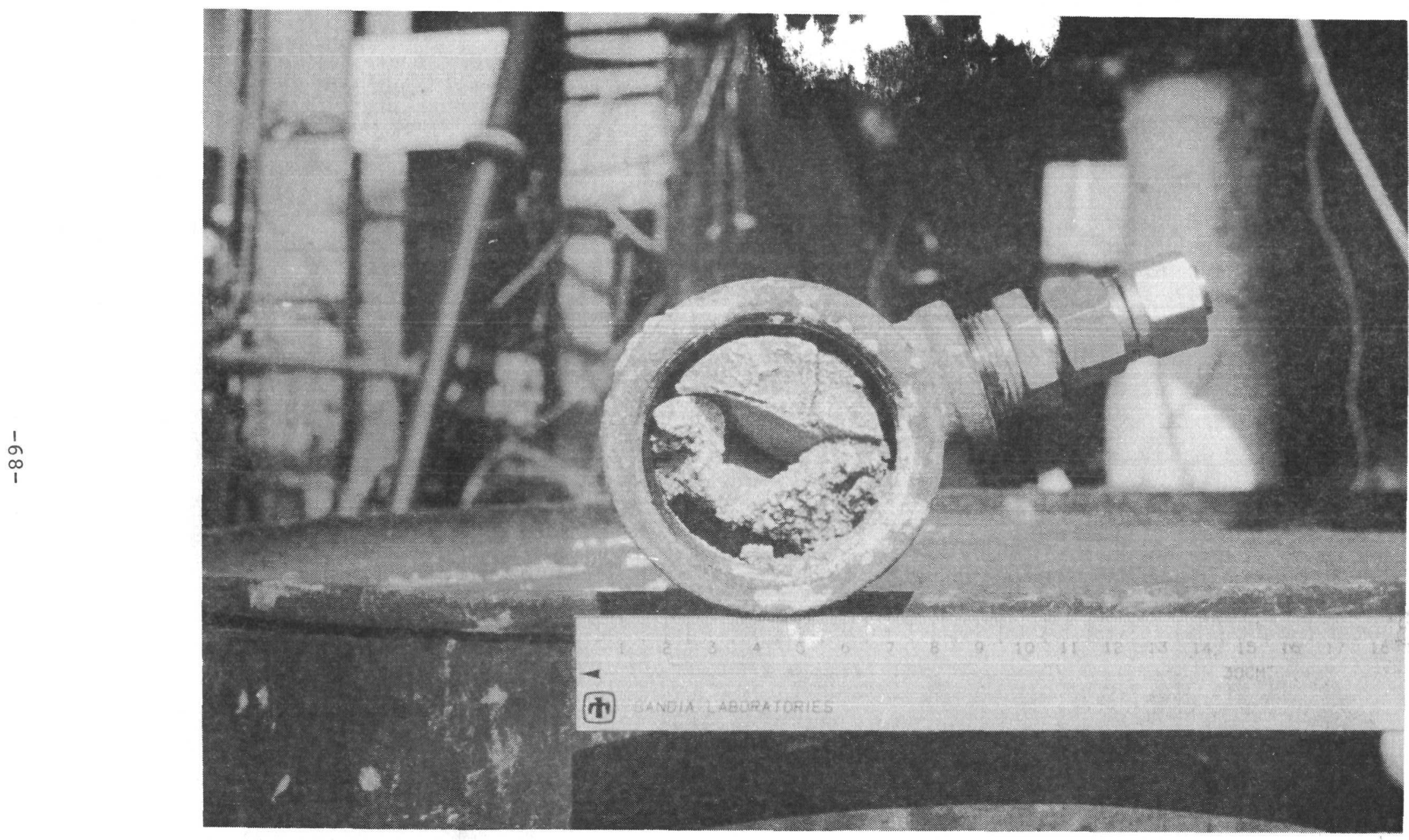

Figure 27c. 


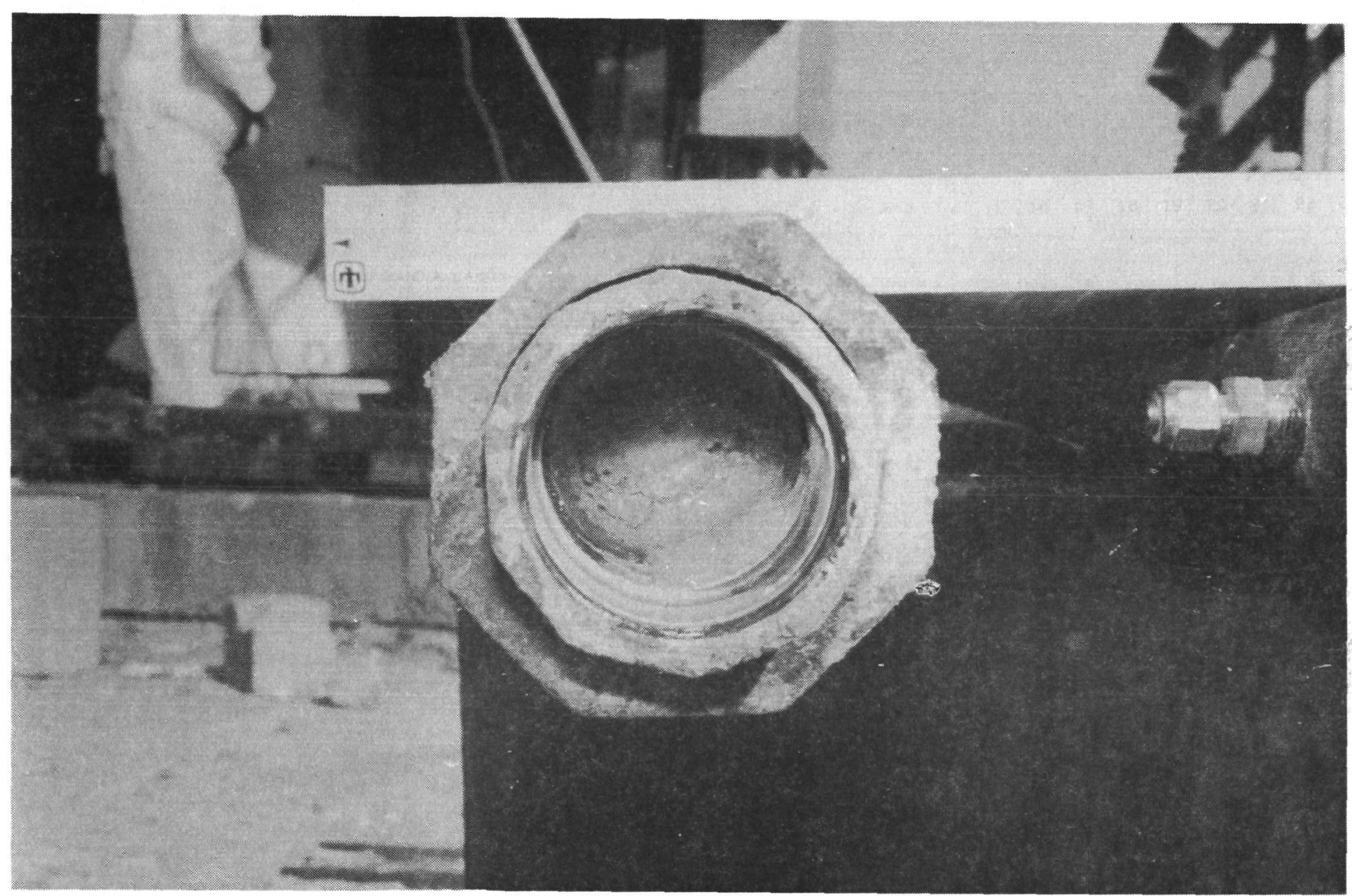

Figure 27d. 


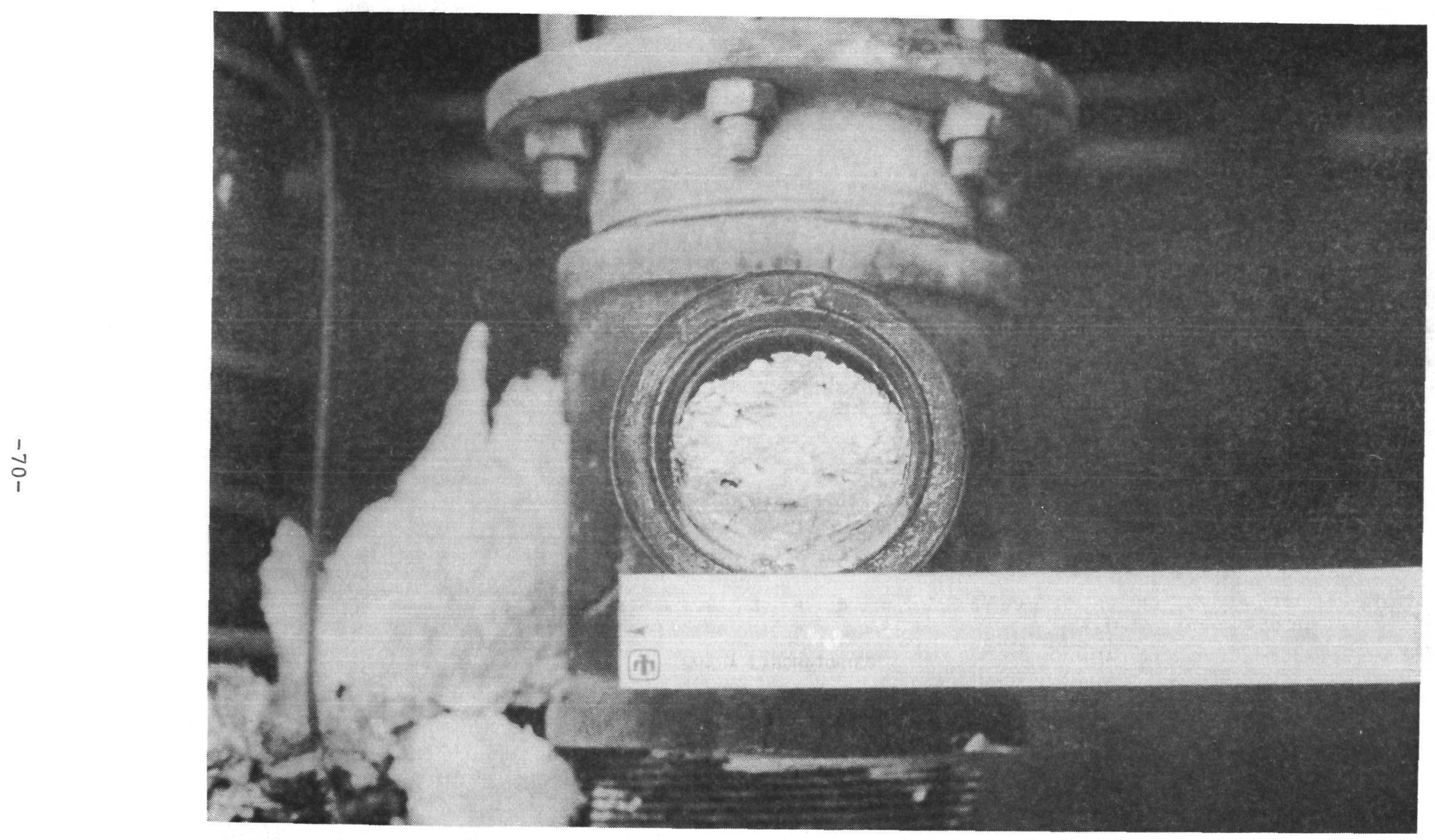

Figure 27e. 
aerosol at position $A$ identified metallic sodium and a possible minor amount (less than 158 ) of sodium hydride.

The three aerosol samples were each taken for 6 second periods at $0.5,1.5$, and 2.5 hours after the start of the test. Unfortunately, when the sampling devices were recovered and weighed, the amount of material on each filter was found to be $f a r$ in excess of anything that had been expected. Aerosol mass loadings in the gas evolved during the test determined by filter weight gains to be in excess of $400 \mathrm{~g} / \mathrm{m}^{3}$. Subsequent testing of the aerosol sampling devices demonstrated that a positive pressure of 0.2 bars ( 4 psi) at the inlet to the sampler system caused leaks at teflon gaskets used downstream from the filters. Such downstream leaks would cause a continued deposition of aerosol on the filters after their scheduled period of sampling. For this reason, the quantitative information from the aerosol samplers is considered inaccurate. SEM photographs of the material collected on the middle sampler, located $27.9 \mathrm{~cm}$ downstream (Figure 26), are shown in Figure 28. The material is well agglomerated but the primary particle size is approximately one micron which is the same primary particle size noted for the aerosol particulate in the calcite test (Figure 17). 

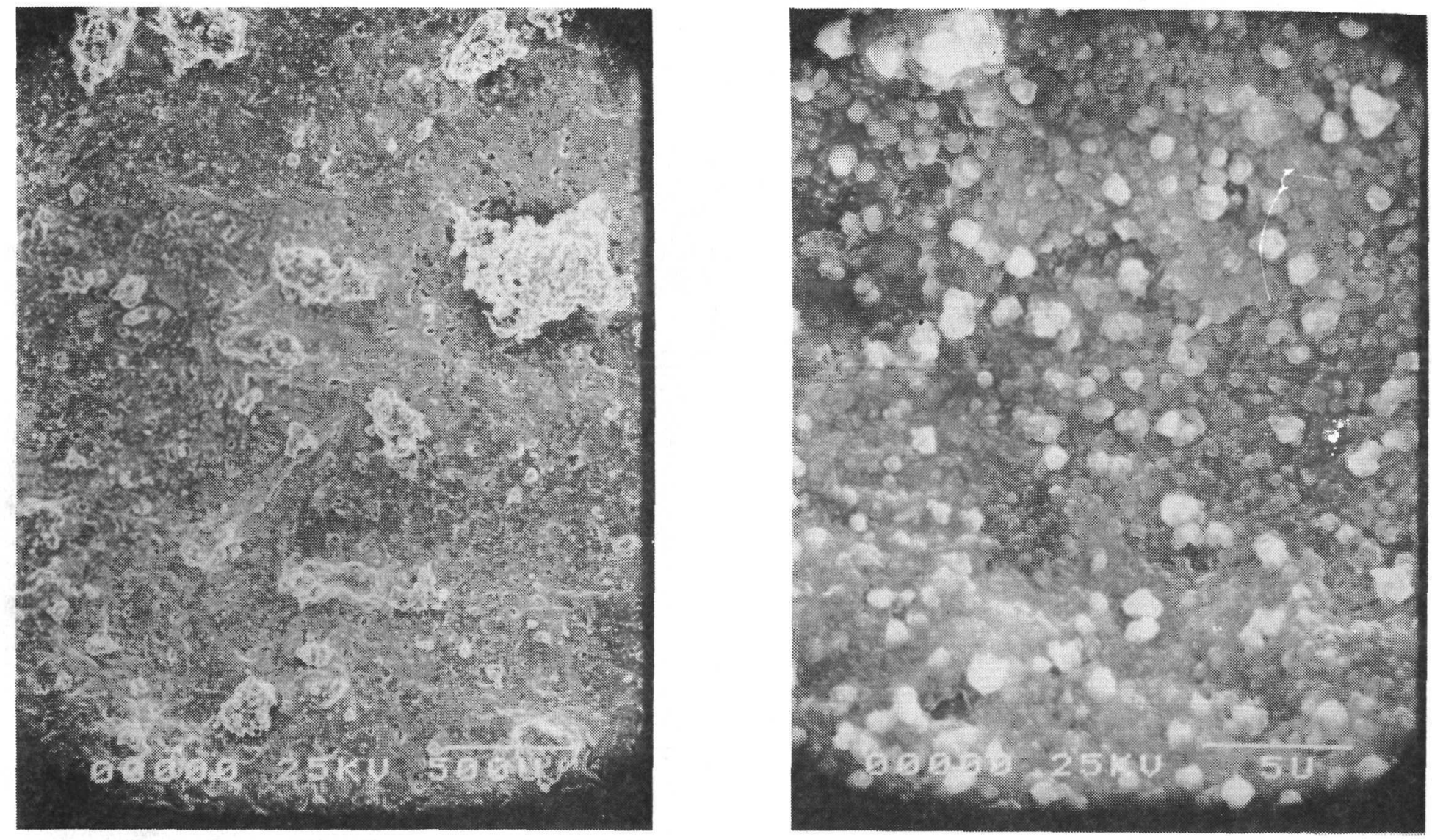

Figure 28. Scanning Electron Micrographs of Aerosol Sample Taken from Sampler 2 (see Figure 4) in Dolomite Test, a) $35 \mathrm{x}$, b) $4000 \mathrm{x}$. 


\section{DISCUSSION}

The major results of both tests are summarized and compared in Table 10. There were no outstanding differences in behavior noted between the concretes during the test. The temperature excursions were comparable in both extent and timing. The maximum penetration rates noted by the centerline thermocouples were approximately equal. The final penetrations are somewhat difficult to compare because of the difference in test lengths (10 hours for the calcite test vs 20 hours for the dolomite test) and the difference in appearance of the reaction zones. The difference in test lengths is probably not as important in this respect as the presence of the black debris in the dolomite test because most of the penetration in both tests apparently occurred between two and four hours. This time period for the rapid penetration is inferred from the thermocouple data of Figures 7 and 19. Penetration no doubt continued after this time, but at a much slower rate than that measured during the energetic phase. If the total penetration in the dolomite test, as measured to the reaction debris/black debris interface is compared with the calcite test penetration, the numbers are comparable: $5.5 \pm 2.9 \mathrm{vs} 7.4 \pm 5.0 \mathrm{~cm}$. Because of the extreme roughness of the interfaces, even the penetration as measured to the black debris/unreacted concrete interface, $12.3 \pm 2.9 \mathrm{~cm}$, in the dolomite test must be considered statistically (at a 958 confidence level) the same as the penetration in the calcite test.

The relative magnitude and duration of the temperature excursions at the reaction zone in the dolomite test appear to be less than those for the calcite test (Figures 7 and 


\section{TABLE 10}

Summary of Calcite and Dolomite Test Results

$\begin{array}{lcc} & \text { Calcite } & \text { Dolomite } \\ \text { Test Date } & 08 / 19 / 82 & 10 / 13 / 82 \\ \text { Test Temperature }\left({ }^{\circ} \mathrm{C}\right) & 830 & 830 \\ \text { Sodium Used (kg) } & 45.5 & 45.5 \\ \text { Test Length (hr) } & 10 & 20 \\ \text { Sodium Preheat Temperature }\left({ }^{\circ} \mathrm{C}\right) & 750 & 750 \\ \text { Minimum Quench Temperature }\left({ }^{\circ} \mathrm{C}\right) & 510 & 510 \\ \text { Maximum Concrete Temperature }\left({ }^{\circ} \mathrm{C}\right) & 830 & 2.2 \\ \text { which occurred at (hr) } & 2.6 & 5.5 \pm 2.9 \\ \text { Penetration (cm)* } & 7.4 \pm 5.0 & 12.9 * \\ & & 1.4 \\ \text { Maximum Penetration Rate by } & & \\ \text { thermocouple indications (mm/min) } & & \end{array}$


19). Due to the large variability seen by previous invescigators in delay times, magnitude, and duration of such reactions, $3,5,7$ however, the response of both concretes is considered the same. There are several examples of variability in the present tests. Note that there is a significantly larger difference in the temperature profiles of the center and mid-radius thermocouples for the calcite test than for the mid-radius thermocouples in the calcite test and both sets of thermocouples in the dolomite test. The mid-radius thermocouples for the calcite test increased in temperature much slower than the corresponding center thermocouples for the first few hours of the test. We interpret this to indicate that spalling or cracking of the concrete occurred at the center of the test article but did not occur at the mid-radius location. The center and mid-radius thermocouples in the dolomite test increased in temperature in a slow uniform manner, similar to the mid-radius thermocouples of the calcite test. We interpret this to mean that spalling and/or cracking did not occur in the dolomite test at the thermocouple locations. Furthermore, the post-test cross sections of both test articles did have extremely uneven sodium-concrete interfaces as the uncertainty in the final penetration shows. Also, the center thermocouples showed evidence of exothermic reactions occurring at three and six hours while the mid-radius thermocouples showed evidence of reactions at six and nine hours. From this, we assume that the reaction front between the sodium and concrete is not very uniform over the lateral distances involved in the tests. Such behavior is unpredictable but no doubt, is a significant factor in increasing the variability of results. The differences in delay times noted by the center and mid-radius thermocouples, in fact, suggest that vigorous attack may be localized in small regions over 
the surface of the concrete. This may be caused by inhomogeneities in the concrete which allow rapid penetration in one region but not in another until a later time, sidewall effects, differences in constraint in certain regions, or even local stress concentrations in the concrete caused by a long row of closely spaced thermocouples. Such condiderations show the value of complete post-test examinations, including cross-sectioning, to assure that thermocouple results are not misinterpreted.

The overall runtime results are comparable for both tests. The post-test sectioning, however, illustrated that there was a difference in the appearance of the reaction zones. In the calcite test, the transition between unreacted concrete and the usual gray debris layer occurred over the span of only a few millimeters (Figure 15). There was no evidence of thermal decomposition of the calcite aggregate less than one centimeter from the interface even though temperatures in this region were above $600^{\circ} \mathrm{C}$ for a large portion of the test (Figure 7). This is not surprising since, as Table 1 shows, appreciable $\mathrm{CO}_{2}$ release from $\mathrm{CaCO}_{3}$ should not occur below $800^{\circ} \mathrm{C}$ and thermal decomposition should not be expected in this region. In the dolomite test, a diffuse blackened debris layer, $6.8 \mathrm{~cm}$ thick, was found between the usual gray debris and unreacted concrete. This layer contained partially decomposed or chemically attacked dolomite aggregate (Figure 25). Temperatures in this region ranged from $550^{\circ} \mathrm{C}$ to $670^{\circ} \mathrm{C}$ for a large portion of the test after the energetic phase had ceased (Figure 19). Thermodynamic arguments predict a $\mathrm{P}_{\mathrm{CO}_{2}}$ of 20 to 200 atmospheres in this region at equilibrium (Table 2). The experimental evidence suggests that these pressures are not realized. Chemical analyses of material taken from the debris (sample D 
in Table 7) verified it to be mostly partially decomposed dolomite concrete. Stoichiometric dolomite, $\mathrm{CaMg}\left(\mathrm{CO}_{3}\right)_{2}$ ' reduced to the oxides is $30.48 \mathrm{CaO}, 21.98 \mathrm{Mgo}$, and $47.78 \mathrm{CO}_{2}$ by weight. Sample D, reduced to the oxides, is roughly 468 $\mathrm{CaO}, 13 \% \mathrm{MgO}$, and $318 \mathrm{CO}_{2}$. If the $\mathrm{Na}$ is assumed to be present as $\mathrm{NaOH}$, sample D contains roughly $6 \% \mathrm{NaOH}$. (Due to the heterogeneous nature of the debris samples and the difficulty in their handling and preparation, all chemical analysis results must be considered as approximate. They are used here as guideposts only.) The $\mathrm{MgO} / \mathrm{CO}_{2}$ ratio of $\mathrm{D}$ is 0.42 which is, within our analytical error estimates, the same as that for stoichiometric dolomite, 0.46. The Ca/Mg ratio is higher than that for dolomite, however. There are two possible causes for this. The cement phase has a high $\mathrm{Ca} / \mathrm{Mg}$ ratio and contains no $\mathrm{CO}_{2}$ so the presence of cement would cause an increased $\mathrm{Ca} / \mathrm{Mg}$ ratio but no change in the $\mathrm{MgO} / \mathrm{CO}_{2}$ ratio. A second possibility is that the aggregate is not stoichiometric dolomite but actually contains some calcite. The second possibility, however, would substantially change the $\mathrm{Mgo} / \mathrm{CO}_{2}$ ratio. Therefore, we feel the presence of the cement phase is the cause for the high Ca/Mg ratio. This interpretation is consistent with visual observation of partially decomposed dolomite aggregate clasts in the black debris layer.

The gray debris produced in both tests was quite similar in chemical composition. For the calcite test debris, the crystalline compounds $\mathrm{NaOH}, \mathrm{CaO}$, and $\mathrm{Na}_{2} \mathrm{CO}_{3}$ were identified. For the dolomite test debris, only the compounds $\mathrm{NaOH}$ and $\mathrm{Na}_{2} \mathrm{CO}_{3}$ were identified. $\mathrm{CaO}$ and $\mathrm{MgO}$ were not detected. Depending upon sample composition and crystallite size, compounds present in quantities $<58$ would probably not be detected by the Debye-scherrer $x-r a y$ technique used. If 
crystalline Mgo were present, only a minor amount was in the debris or the crystallite size was $<<$ micron.

The chemical analyses 1 isted in Table 7 show only minor amounts of free carbon. The bulk of the carbon is combined as a carbonate (e.g., $\mathrm{CO}_{2}$ in the table). Since no $\mathrm{CaCO}_{3}$ or CaMg $\left(\mathrm{CO}_{3}\right)_{2}$ was found by the $\mathrm{x}$-ray diffraction, the carbonate is assumed to be $\mathrm{Na}_{2} \mathrm{CO}_{3}$. Simple free energy calculations ${ }^{23}$ show that $\mathrm{G}_{1000 \mathrm{~K}}$ for the reactions

$$
\begin{aligned}
& \mathrm{CaO}+2 \mathrm{NaOH} \longrightarrow \mathrm{Ca}(\mathrm{OH})_{2}+\mathrm{Na}_{2} \mathrm{O} \\
& \mathrm{MgO}+2 \mathrm{NaOH} \longrightarrow \mathrm{Mg}(\mathrm{OH})_{2}+\mathrm{Na}_{2} \mathrm{O}
\end{aligned}
$$

is $+27.9 \mathrm{kcal}$ and $+36.9 \mathrm{kcal}$ respectively. CaO and Mgo are stable in the presence of $\mathrm{NaOH}$ and the respective hydroxides would not be expected to form at test temperatures. The Ca and $\mathrm{Mg}$ in the debris are, therefore, assumed to be present as $\mathrm{CaO}$ and Mgo. This interpretation agrees with the $x-r a y$ diffraction results. The 0.4 - 4.08 insoluble residue which remains from the chemical analyses is assumed to be composed largely of silicate and aluminate reaction products. These would be primarily complex silicates, as well as some unreacted calcium silicates and calcium aluminates from the cement phase. The complex silicates are considered to be the primary cause for the large number of unindexable lines in the diffraction patterns 1 isted in Tables 8 and 9.

The combined analyses of the reaction debris of both tests show that the primary constituents of the debris are $\mathrm{NaOH}, \mathrm{Na}_{2} \mathrm{CO}_{3}, \mathrm{CaO}$, and $\mathrm{MgO}$. There is probably some metallic $\mathrm{Na}$ in the debris but the amount is rather small since it is 
not visible optically. A significant result of these findings is the small amount of free carbon in the debris. This is important because it is an indicator of which chemical reactions are predominant. There are numerous chemical reactions which can occur between $\mathrm{Na}$ and aggregate in the concrete. ${ }^{8}$ Three of the most important exothermic reactions for calcite aggregate are:

$$
\begin{aligned}
& 4 \mathrm{Na}+3 \mathrm{CaCO}_{3} \longrightarrow 2 \mathrm{Na}_{2} \mathrm{CO}_{3}+3 \mathrm{CaO}+\mathrm{C} \\
& 4 \mathrm{Na}+\mathrm{CaCO}_{3} \longrightarrow 2 \mathrm{Na}_{2} \mathrm{O}+\mathrm{CaO}+\mathrm{C} \\
& 2 \mathrm{Na}+\mathrm{H}_{2} \mathrm{O}+\mathrm{CaCO}_{3} \longrightarrow \mathrm{Na}_{2} \mathrm{CO}_{3}+\mathrm{CaO}+\mathrm{H}_{2}
\end{aligned}
$$

(Note that (12) is an overall reaction and $\mathrm{NaOH}$ is probably involved in the intermediate steps of the actual reaction mechanism) Similar reactions exist for reactions with dolomite. The basic differences among these reactions are whether $\mathrm{H}_{2} \mathrm{O}$ is needed for the reaction, whether $\mathrm{C}$ is produced, and/or whether $\mathrm{Na}_{2} \mathrm{CO}_{3}$ or $\mathrm{Na}_{2} \mathrm{O}$ is an end product. As long as $\mathrm{H}_{2} \mathrm{O}$ is present in the concrete, $\mathrm{H}_{2}$ will be produced, but whether it is necessary for an exothermic reaction with the aggregate is open to speculation. Equations (10) and (11) both produce $C$. Per mole of $\mathrm{CaCO}_{3}$ consumed, (10) produces one-third as much $C$ as (11). The ratio of $\mathrm{C} / \mathrm{CO}_{2}$ (by weight) in the products for (10) is 0.136 (12) produces no $\mathrm{C}$ and (11) produces no $\mathrm{Na}_{2} \mathrm{CO}_{3}$. The gray debris contained a large amount of $\mathrm{Na}_{2} \mathrm{CO}_{3}$ and had an average $\mathrm{C} / \mathrm{CO}_{2}$ ratio of .018 . Since the $\mathrm{C}$ contents were near the detectability limits on the samples analyzed, this probably represents an upper bound on $C$. These findings favor (12) as the overall major chemical reaction occurring in the system and (10) as a minor reaction. 
It is quite possible that various reactions occur at different times during the interaction. For example, (10) may occur initially before much $\mathrm{NaOH}$ has formed. At later times, the intimate contact between $\mathrm{Na}$ and the aggregate is prevented by an $\mathrm{NaOH}$ layer which forms at the reaction zone. (12) then becomes dominant. Unfortunately, the only way to ascertain the precise mechanism of attack is sequential real-time sampling of the debris during the test. The only statement which can be made at the present time about the sample analysis is that (12) is the major overall reaction in these tests.

The above treatment of the chemical system is, of course, simplistic. Sequential, one-line reactions are not adequate to describe complex real systems. Unfortunately, a more complete treatment which considers all solid, liquid and gas species simultaneously is beyond the scope of this report. Since some amount of all species will generally be found to be present in such a complex system, all three reactions occur to some extent but (12) predominates.

The aerosols resulting from sodium vaporization in both tests caused plugging of the vent lines. Pressurization of the calcite test article had apparently begun at nine hours when the sodium fires were first observed. Assuming that complete plugging of the vent line started at this time, the method of Vaughan 21 was used to calculate the average aerosol mass loading during this time period. Although this method strictly applies to solid aerosols, it can be used to estimate the aerosol loadings in the present test. These calculations are highly dependent upon the assumed gas flow rate. For a combined argon and hydrogen flow rate of four liters/minute the mass loading is $370 \mathrm{~g} / \mathrm{m}^{3}$ and for a combined argon and hydrogen flow rate of seven liters/minute the mass 
loading is $210 \mathrm{~g} / \mathrm{m}^{3}$ during the first nine hours of the test. These mass loadings are approximately an order of magnitude larger than typical aerosol loadings resulting from sodium fires. 22

Vent line plugging in the dolomite test started at about the same time so the calculated mass loadings are roughly the same. $\mathrm{X}$-ray diffraction and SEM analysis indicate that there is little or no contribution to the aerosol loading by the sodium-concrete reaction products. 


\section{CONCLUSIONS}

The difference in response to attack molten sodium for calcite and dolomite concretes which are suggested by thermodynamic considerations are not verified by experiment. Both concretes exhibit similar behavior with respect to the magnitude and timing of energetic reactions. Penetration rates during the energetic reactions are similar for both concretes and the rapid penetration lasts less than an hour. The maximum penetration rate observed in the calcite test was $1.7 \mathrm{~mm} / \mathrm{min}$ and the maximum penetration rate in the dolomite test was $1.4 \mathrm{~mm} / \mathrm{min}$. The total penetration in the calcite and dolomite tests were, respectively, $7.4 \pm 5.0 \mathrm{~cm}$ and 12.3 $\pm 2.9 \mathrm{~cm}$ (or $5.5 \pm 2.9 \mathrm{~cm}$ for the dolomite test as explained in the results section). There are indications that the reaction intensity may vary considerably over a period of time. There is evidence that rapid penetration may occur in localized areas of the concrete at different times during the interaction.

The $\mathrm{Na} /$ concrete reaction zones were different for the two concretes. The calcite concrete had a well demarcated boundary between completely reacted and unreacted concrete. The dolomite concrete had a thick, diffuse layer of partially decomposed concrete and reaction debris separating the completely reacted and unreacted concrete. This layer is apparently a result of the lower temperatures required for the thermal decomposition of dolomite as compared to calcite.

The major chemical species in the reaction debris are $\mathrm{NaOH}, \mathrm{Na}_{2} \mathrm{CO}_{3}, \mathrm{CaO}$, and $\mathrm{MgO}$. Minor species are free $\mathrm{C}$ and possibly metallic Na. The low $C$ content of the debris suggests that the oxygen potential is high enough to prevent 
the total reduction of the reacting species to $\mathrm{C}$ and $\mathrm{Na}_{2} \mathrm{O}$. Since $\mathrm{Na}_{2} \mathrm{CO}_{3}$ is a major end product and the $\mathrm{C}$ content is near the reliable detectability limits, the most important overall chemical reaction for both concretes appears to be the reaction of $\mathrm{Na}$ and $\mathrm{H}_{2} \mathrm{O}$ with limestone to form $\mathrm{Na}_{2} \mathrm{CO}_{3}, \mathrm{H}_{2}$, and the respective oxides $\mathrm{CaO}$ and $\mathrm{MgO}$. A minor reaction appears to be the reaction of $\mathrm{Na}$ with 1 imestone to form $\mathrm{Na}_{2} \mathrm{CO}_{3}$, free $\mathrm{C}$ and the respective oxides $\mathrm{CaO}$ and $\mathrm{MgO}$.

The above conclusions are based on only two intermediate-scale tests. Caution should be exercised when using these results since the effects of scale and the high degree of variability found in the experimental results can be important and possibly misleading when comparing these with other test results. 


\section{ACKNOWLEDGEMENTS}

The authors would like to thank L. A. Kent for his assistance in test setup and performance and F. M. Hosking and A. A. Netz for the high temperature viscosity measurements. 


\section{References:}

1. M. G. Chasanov and G. E. Staahl, Sr., "High Temperature Sodium - Concrete Interactions," J. Nucl.Matls. 66 $(1977)$, p. 217-220.

2. R. U. Acton, R. A. Sallach, J. E. Smaardyk, and L. A. Kent, Molten Sodium Interactions with Basalt Concrete and Siliceous Firebrick, NUREG/CR-0934, SAND79-0938, 1979.

3. E. Randich, R. U. Acton, and J. E. Smaardyk, Large Scale Exploratory Tests of Sodium/Limestone Concrete

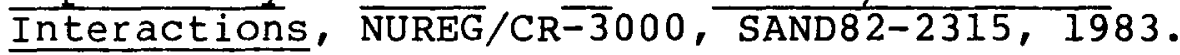

4. E. Randich, R. U. Acton, Large Scale Exploratory Tests of Sodium/Magnetite Concrete NUREG/C $\overline{R-3189, ~ S A N D 83-0356, ~} 19 \overline{983 .}$

5. J. A. Hassberger and L. D. Muhlestein, IntermediateScale Sodium-Concrete Reaction Tests with Basalt and Limestone Concrete, HEDL-TME79-55, 1979 .

6. M. W. McCormick, et al., Large-Scale Sodium-Basalt Concrete Reaction Test LSC-1, HEDL-TME80-57, 1980 .

7. R. P. Colburn and L. D. Muhlestein, Separate Effects Sodium-Concrete Reaction Tests, SET-1 Through SET-10, HEDL-TME81-41, $198 \overline{1}$.

8. L. D. Muhlestein and A. K. Postma, Sodium Concrete Reaction Executive Summary Report: Application to Limestone concrete, HEDL-TME82-15, 1982 .

9. C. Casselman, "Consequences of Interacation Between Sodium and Concrete," Nucl. Eng. Design 68 (1981) 207-212.

10. M. G. Barker and P. G. Gadd, "A Chemical study of the Sodium-Concrete Reaction," Proc. LMFBR Safety Topical Mtg., Lyon, Ecully, France, July, 19.82, II $\overline{\mathrm{I}}$ 91-10

11. A. J. Suo-Anttila, "SLAM - a Sodium-Limestone Concrete Ablation Model," NUREG/CR-3379, SAND83-7114, 1983.

12. J. R. Carver, J. D. McCormack, L. D. Muhlestein, and R.

P. Colburn, Sodium-Limestone Concrete Reactions with Calcite and Dolomite Aggregate Concrete, HEDL-TME 83-20, 1983 . 
13. R. A. Robie, B. S. Hemingway, and J. R. Fisher, "Thermodynamic Properties of Minerals and Related Substances at $298.15 \mathrm{~K}$ and 1 Bar $\left(10^{5}\right.$ Pascals) Pressure and at Higher Temperatures," Geological Survey Bulletin 1452 , U.S. Government Printing Office, 1978 .

14. I. Barin and O. Knacke, Thermochemical Properties of Inorganic Substances, Springer, New York, 1973 .

15. K. H. Stern and E. L. Weise, High-Temperature Properties and Decomposition of Inorganic salts Part 2. Carbonates, NSRDS-NBS $\frac{3}{3}$, National Bureau of standards, 1969.

16. T. L. Webb and J. E. Kruger, "Carbonates," Differential Thermal Analysis, Vol. 1, R. C. Mackenzie, Ed.; Academic Press, 1970.

17. R. I. Harker and O. F. Tuttle, Am. J. Sci. $\underline{253} 209$, 1955 .

18. H. Hashimoto, E. Komaki, F. Hayashi, and T. Vematsu, "Partial Decomposition of Dolomite in $\mathrm{CO}_{2}, "$ J. Solid State Chem. 33 (1980) 181-188.

19. J. Paulik, F. Paulik, and K. Wieczorek-Ciurowa, "Influence of Foreign Materials upon the Thermal Decomposition of Dolomite, Calcite and Magnesite, Part II. Influence of the Presence of Water," Thermo. Acta, 38 (1980) 165-172.

20. CRBRP-3, Vol. 2, "Assessment of Thermal Margin Beyond the Design Base," March, 1980.

21. E. U. Vaughan, Simple Model for Plugging of Ducts by Aerosol Deposits, TANSAO 28 $\overline{1-804} \overline{(1978)}$ vol. $2 \overline{8,507 .}$

22. S. Kitani et al., "Behavior of Sodium Oxide Aerosol in a Closed Chamber," J. Nucl. Sci. Tech 10 (9), 1973, p. 566-573.

23. D. R. Stull and H. Prophet (eds.), JANAF Thermochemical Tables (1974, 1975, and 1978 Supplements), U. S. Government Printing Office, Washington, DC, 2nd Edn., 1971. 


\section{APPENDIX}

Viscosity measurements on a sample of the reaction debris from the calcite test were made over a temperature range of approximately $470^{\circ} \mathrm{C}$ to $600^{\circ} \mathrm{C}$. A Brookfield digital viscometer, model LVTD with a concentric type 316 stainless steel cylinder spindle $(\mathrm{LV}-3)$, was used to measure the viscosity. The spindle had dimensions of $12.5 \mathrm{~mm}$ diameter by $1.5 \mathrm{~mm}$ in height. This type of viscometer has a synchronous motor which drives the spindle at a constant preset speed through a calibrated beryllium copper spring. The deflection of the spring caused by the viscous drag which opposes the rotation of the spindle in the test fluid is a measure of torque. The torque is converted into an electrical signal and read on the digital display of the viscometer. The signal is also recorded on a strip chart recorder. To obtain viscosity values from the readings, a calibrated multiplying factor is used for a given spindle type and a rotational speed combination. Table A-l lists the multiplying factors which were obtained for the LV-3 spindle used in this study. A silicone fluid viscosity standard having a viscosity of 4,775 centipoise was used to calibrate the system.

The viscosity measurements were made in a glove box with a cover gas of argon. Figure $A-1$ is a schematic diagram of the apparatus. Approximately $60 \mathrm{~g}$ of the debris were melted in a type 304 stainless steel crucible which had dimensions of $3.8 \mathrm{~cm}$ ID by $6.4 \mathrm{~cm}$ deep. Surrounding clamshell chromealuminum-iron alloy resistive heating elements were used to heat the crucible. Deviations in the output of the viscometer due to heat radiation from the heater and crucible assembly were minimized by insulating the viscometer housing. 
Melt temperatures were monitored with a chromel-alumel (type K) thermocouple.

The heated sample softened significantly at approximately 350 to $375^{\circ} \mathrm{C}$. Viscosity measurements were continuously recorded from 470 to $595^{\circ} \mathrm{C}$. For most of the tests, a rotational speed of $12 \mathrm{rpm}$ was used. Table A-2 lists the results at $5^{\circ} \mathrm{C}$ intervals during the heatup period. Figure A-2 shows the effect of temperature on the debris viscosity. The viscosity decreased from $5310 \mathrm{cp}$ at $470^{\circ} \mathrm{C}$ to $1900 \mathrm{cp}$ at $595^{\circ} \mathrm{C}$.

Chemical analysis of the debris had indicated that, at temperature, the material would be a liquid-solid mixture consisting of sodium hydroxide liquid with entrained calcium oxide, magnesium oxide and sodium carbonate solids. Liquid sodium hydroxide has a viscosity of approximately two to five centipoise in the temperature regime of this study. The solids in the heated debris, therefore, strongly influence the debris viscosity. This type of material would be expected to have a viscosity which would be shear rate dependent. To determine whether this was the case, the sample was held at $595^{\circ} \mathrm{C}$ and the spindle speed was varied from $6 \mathrm{rpm}$ to $30 \mathrm{rpm}$. The viscosity was $3510 \mathrm{cp}$ at the $6 \mathrm{rpm}$ speed and decreased to $1040 \mathrm{cp}$ at the $30 \mathrm{rpm}$ speed. Thus the viscosity of the sample does appear to be shear rate dependent. 


\section{Table $A-1$}

\section{Calibrated* Multiplying Factor for the Brookfield LV-3 Spindle (12.5 $\mathrm{mm}$ dia. $x 1.5 \mathrm{~mm})$}

\begin{tabular}{|c|c|c|}
\hline $\begin{array}{l}\text { Rotational } \\
\text { Speed (rpm) }\end{array}$ & $\begin{array}{l}\text { Viscometer } \\
\text { Display (D) }\end{array}$ & $\begin{array}{l}\text { Multiplying } \\
\text { Factor }(4775 \pm \text { D) }\end{array}$ \\
\hline 0.3 & 1.2 & 3900 \\
\hline 0.6 & 2.5 & 1900 \\
\hline 1.5 & 6.3 & 760 \\
\hline 3.0 & 12.2 & 390 \\
\hline 6.0 & 24.5 & 195 \\
\hline 12.0 & 49.0 & 97.5 \\
\hline 30.0 & 99.0 & 48.2 \\
\hline
\end{tabular}

* $3.8 \mathrm{~cm}$ dia., 304 stainless steel fluid container; 4775 centipoise silicone fluid standard. 
Table A-2

Calcite Test Reaction Debris Viscosity

\begin{tabular}{|c|c|c|c|}
\hline Temperature $\left({ }^{\circ} \mathrm{C}\right)$ & $\begin{array}{l}\text { Rotational } \\
\text { Speed (r pm) }\end{array}$ & $\begin{array}{l}\text { Viscometer } \\
\text { Output (D) }\end{array}$ & $\begin{array}{l}\text { Viscosity } \\
\text { (Centipoise) } \\
\end{array}$ \\
\hline 470 & 12 & 54.45 & 5310 \\
\hline 475 & 12 & 40.00 & 3900 \\
\hline 480 & 12 & 36.00 & 3510 \\
\hline 485 & 12 & 32.00 & 3120 \\
\hline 490 & 12 & 30.05 & 2930 \\
\hline 495 & 12 & 28.70 & 2800 \\
\hline 500 & 12 & 27.60 & 2690 \\
\hline 505 & 12 & 25.65 & 2500 \\
\hline 510 & 12 & 24.60 & 2400 \\
\hline 515 & 12 & 23.10 & 2250 \\
\hline 520 & 12 & 21.80 & 2125 \\
\hline 525 & 12 & 22.10 & 2150 \\
\hline 530 & 12 & 22.35 & 2180 \\
\hline 535 & 12 & 22.55 & 2200 \\
\hline 540 & 12 & 22.80 & 2225 \\
\hline 545 & 12 & 23.10 & 2250 \\
\hline 550 & 12 & 24.60 & 2400 \\
\hline 555 & 12 & 25.40 & 2475 \\
\hline 560 & 12 & 25.10 & 2450 \\
\hline 565 & 12 & 25.10 & 2450 \\
\hline 570 & 12 & 25.40 & 2475 \\
\hline 575 & 12 & 25.10 & 2450 \\
\hline 580 & 12 & 24.90 & 2425 \\
\hline 585 & 12 & 23.10 & 2250 \\
\hline 590 & 12 & 21.20 & 2070 \\
\hline 595 & 12 & 19.50 & 1900 \\
\hline 595 & 6 & 18.00 & 3510 \\
\hline 595 & 30 & 21.60 & 1040 \\
\hline
\end{tabular}




\section{GLOVE BOX}

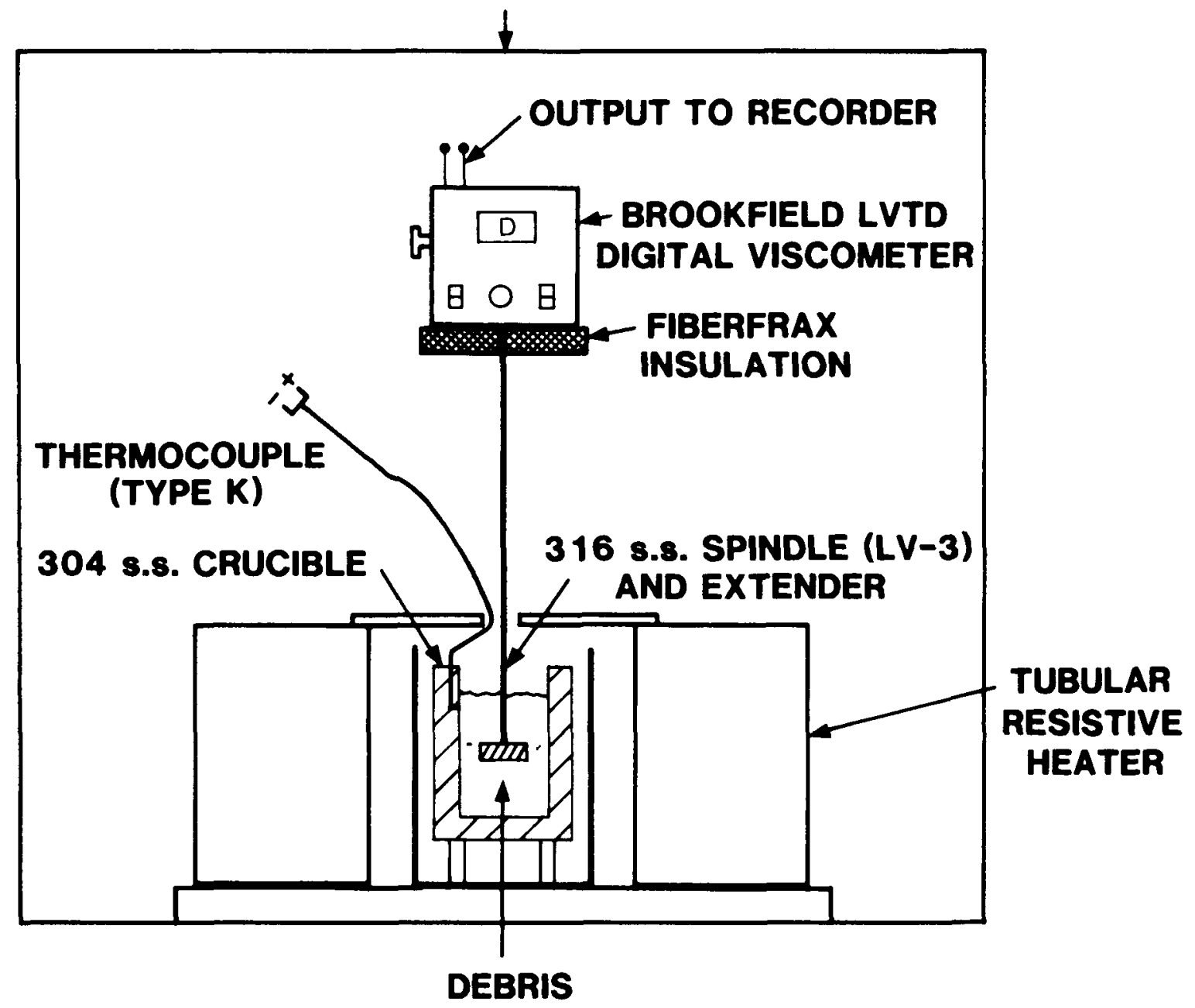

Figure A-1. Schematic Diagram of High Temperature Viscosity Apparatus. 


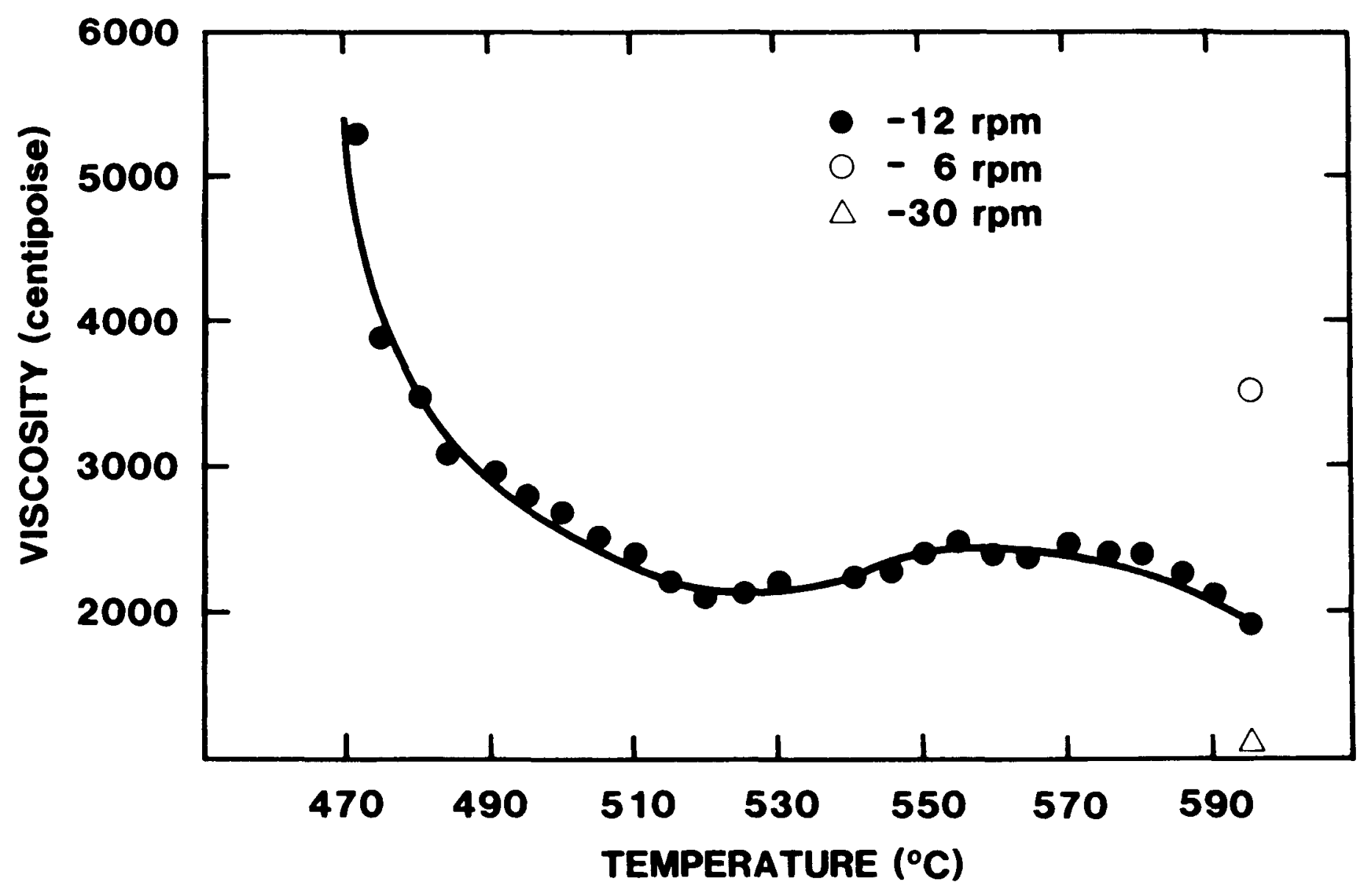

Figure A-2. Viscosity of Calcite Test Debris. 


\section{DISTRIBUTION}

U. S. NRC Distribution Contractor (CDSI) 7300 pearl street

Bethesda, MD 20014

250 copies for $\mathrm{R} 7$

U. S. Nuclear Regulatory Commission (13)

Office of Nuclear Regulatory Research

Washington, DC 20555

Attn: O. E. Bassett

B. S. Burson

R. T. Curtis

C. N. Kelber

$\mathrm{J}$. Larkins

M. Silberberg

L. S. Tong

R. W. Wright

T. Walker (5)

U. S. Nuclear Regulatory Commission (6) Office of Nuclear Regulatory Regulation Washington, DC 20555

Attn: N. Anderson

$\mathrm{J}$. K. Long

J. F. Meyer

A. R. Marchese

T. P. Speis

W. Morris

U. S. Department of Energy (2)

Albuquerque Operations office P. O. Box 5400

Albuquerque, NM 87185

Attn: J. R. Roeder, Director Operational Safety Division

D. K. Nowlin, Director Special Programs Division For:

C. B. Quinn

D. Plymale

U. S. Department of Energy

Office of Nuclear Safety Coordination Washington, DC 20545

Attn: R. W. Barber 
General Electric Corporation

310 De Guigne Drive

Sunnyvale, CA 94086

Attn: J. W. McDonald, Mgr.

Containment \& Radiological Evaluation

M. I. Temme, Mgr.,

Safety Criteria \& Assessments

K. H. Chen, M/C S-54

W. Tarbell

Ktech Corp.

901 Pennsylvania NE

Albuquerque, NM 87110

I. Catton

UCLA

Nuclear Energy Laboratory

$405 \mathrm{Hilgard}$ Avenue

Los Angeles, CA 90024

Brookhaven National Laboratory (3)

Upton, NY 11973

Attn: D. Hsieh

T. Pratt

Los Alamos National Laboratory (3)

P. O. Box 1663

Los Alamos, NM 87545

Attn: T. Butler

D. Jensen

A. Neuls

L. Baker, Jr.

ANL

9700 S. Cass Ave.

Argonne, IL 60439

Burns Roe Industrial Services Corp.

650 Winters Ave.

P. O. Box 667

Paramus, NJ 07652

Attn: A. T. Dajani

R. E. Palm

Prof. Charles E. Semler, Director

Refractories Research Center

The Ohio State University

17 watts Hall

2041 College Road

Columbus, OH 43210 
Westinghouse HEDL (3)

P. O. 1970

MS $\mathrm{W}-221 \mathrm{~T}$ (HE)

Richland, WA 99352

Attn: L. Muhlstein

D. H. Nguyen

J. Carver

Cathy Anderson

Nuclear Safety Oversight Commission

1133 15th St., NW

Room 307

Washington, DC 20005

Battelle Columbus Laboratory

$505 \mathrm{King}$ Avenue

Columbus, OH 43201

Attn: J. Gieseke

Wang Lau

TVA

400 Commerce, W9C157-CK

Knoxville, TN 37902

Nuclear Engineering Department (2)

University of Wisconsin

Madison, WI 53706

Attn: M. L. Corradini

S. Abdu1-Kalik

D. Swanson

P. O. Box 214

Hawthorne, CA 90250

M. Fontana

Director, IDCOR Program

Technology for Energy, Inc.

P. O. Box 22996

10770 Dutchtown Rd.

Knoxville, TN 37922

E. Arbtin

EG\&G, Idaho Inc.

P. O. Box 1625

Idaho Falls, ID 83401

Westinghouse Corp. (2)

Advance Reactor Division

Box 158

Madison, PA 15663

Attn: L. Strawbridge

T. W. Ball 


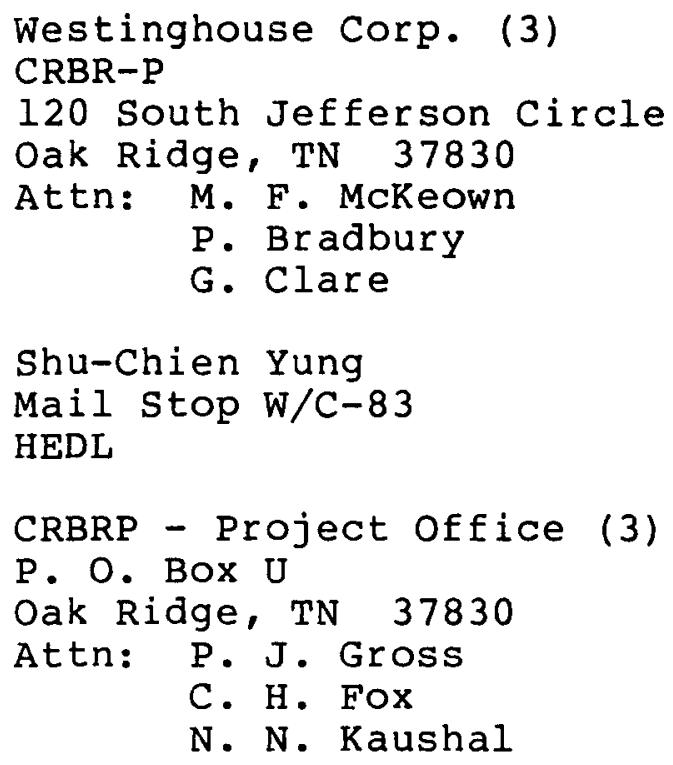

Hiroshi Hiroi

PNC/O-arai Engineering Center 4002 Narita, O-arai machi

Higashi-Ibaraki, Ibaraki 311-13 JAPAN
1543 T. M. Gerlach
1543 H. W. Stockman
1543 H. R. Westrich
7500 W. A. Gardner
7537 N. R. Keltner
7537 R. U. Acton (5)
6400 A. W. Snyder
6410 D. J. MCCloskey
6411 A. S. Benjamin
6412 J. W. Hickman
6413 N. R. Ortiz
6414 G. B. Varnado
6420 J. V. Walker
6421 T. R. Schmidt
6422 D. A. Powers (4)
6422 J. E. Brockmann
6422 E. Randich (5)
6423 P. S. Pickard
6424 K. D. Bergeron
6425 W. J. Camp
6425 A. Suo-Anttila
6426 G. L. Cano 

6440 D. A. Dahlgren
6441 M. Berman
6442 W. A. Von Riesemann
6443 D. D. Carlson
6444 S. L. Thompson
6445 L. O. Cropp
6446 B. E. Bader
$6450 \mathrm{~J}$. A. Reuscher
8214 M. A. Pound
3141 L. J. Erickson (5)
3151 W. L. Garner (3) 


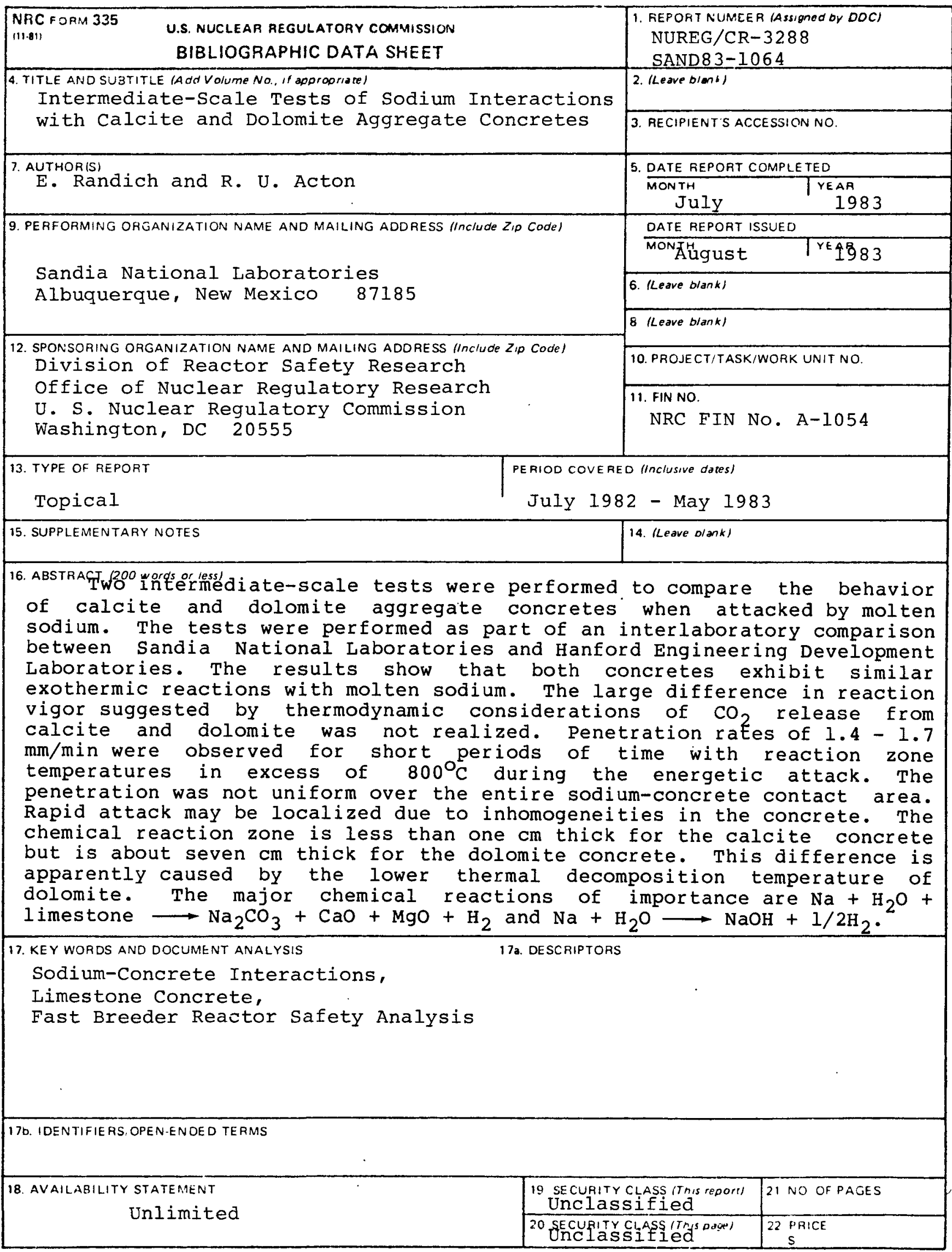

